\title{
An Examination of the Stability of Canadian Employment Tenures
}

\author{
by \\ Luke Ignaczak
}

A thesis submitted to the Faculty of Graduate and Postdoctoral Affairs in partial fulfillment of the requirements for the degree of

\author{
Doctor of Philosophy \\ in \\ Economics
}

\author{
Carleton University \\ Ottawa, Ontario
}

(C) 2014

Luke Ignaczak 


\begin{abstract}
Popular perception holds that employment stability declined towards the end of the twentieth century. However, most studies conclude that the proportion of long term jobs has remained remarkably stable over the last few decades. This study focuses on this discrepancy by tracking self-reported changes in Canadian employment durations over an extended period. This is done in order to reconcile popular perception with recent studies and nest the existing literature in a broader historical context. The study makes use of finite mixture decompositions on successive cohorts of employees starting from the 1950s to identify worker types within cohort-based distributions. Then, using tests of stochastic dominance, it is shown that the distribution of employment has indeed changed. Furthermore, detailed examination by employment spell and birth cohort is used to identify contributing factors to the identified declines in stability. It is surmised that structural changes in the economy and broader society played a large role in the seeming reduction in employment stability. While for men these shifts were clear, for women the evidence was more mixed.
\end{abstract}




\section{Foreword}

The topic of this thesis is the stability of employment across working lives. This work is broken down into two parts composed of the contents of Chapter 2 on the one hand and of Chapters 3 and 4 on the other. Chapter 2 is a largely non-parametric examination of employment tenures by the decade when those tenures began. The item of interest is the employment spell rather than the individuals holding those spells. The heterogeneity of individuals is used to describe the properties of the spell itself. Chapters 3 and 4, focus on individuals and examine the characteristics of individuals which contribute to the length of time they spend in employment. The direction and aims of the project have evolved from what was originally envisioned.

The original manuscript - Chapter 2 in this document - was started nearly six years ago as part of an econometrics class assignment. The techniques applied were refined and the data set used evolved over the course of the project and a complete chapter was first presented in 2010. Rather than continuing on with the dissertation, it was decided that the paper would be submitted for publication before continuing on with further exploration of the data. The paper was published in 2011 under the title A Retrospective Analysis of Employment Duration: Evidence from the Second Half of the Twentieth Century. What is contained in this document is a variant of that paper, in that it is written as a chapter rather than a stand alone paper and has some minor differences from its final form. The third chapter makes reference to the published work rather than to what is presented herein as Chapter 2 since it was completed well after the publication of the first part of the dissertation. 
Chapter 3, which focuses on first employment spells, was largely completed in 2012 and was, as the previous chapter, revised as a stand alone document for publication. It was published in 2014 under the title A Birth Cohort Analysis of First Employment Spells. The results presented in this document differ from that version as the data set has been pared down to line up with the data used for Chapter 4. That chapter focuses on the characteristics of individuals engaged in employment spells beyond the first.

The final major component of the thesis evolved over late 2013 and early 2014 from a completely stand-alone project into an extension of Chapter 3. Because Chapter 2 used all employment tenures while Chapter 3 focused only on first spells it was felt that the analysis would be incomplete without addressing the characteristics of individuals in spells beyond the first. This is done for all available employment spells in Chapter 4.

With these three stand-alone yet inherently linked components the thesis sets out to answer the question of whether the stability of Canadian employment has changed over the second half of the twentieth century, and, if it has, to what extent it has become more or less stable? 


\section{Dedication}

This work is dedicated to my wife Taisa, who graciously supported me in this endeavor and to my children, Una, Eryk and Rhea who had to share their daddy with the University during their early years. 


\section{Acknowledgments}

I owe my gratitude to a number of people and organizations who have helped make this work possible.

First and foremost I'd like to thank my adviser, Professor Marcel Voia for giving me invaluable guidance over the past past six years. Not only has he helped in shaping the ideas that are contained in this document but he has encouraged me to explore new and fascinating ways to approach empirical research. It has been a great pleasure working with him.

I would also like to thank Professor Pierre Brochu, Professor Christopher Worswick, Professor Jennifer Stewart and Professor Miana Plesca for agreeing to serve on my thesis committee and for sparing their invaluable time reviewing the manuscript. I would also like to thank Professor Lynda Khalaf who participated as part of my thesis committee in previous years.

In addition I would like to thank my past and current managers, Mario Lapointe and Frank Lee at Human Resources and Skills Development Canada and at the Department of Finance respectively for their support and understanding over these last few years.

I would also like to acknowledge the generous financial support of Carleton University and of the Department of Economics. I would also like to acknowledge the generosity of the Social Sciences and Humanities Research Council in funding access to the Carleton, Ottawa, Outaouais Research Data Centre. And, of course, I would like to thank the staff of the Research Data Centre for their support and 
assistance during the lengthy process of acquiring the quantitative results for this work.

Finally, I would like to thank all the colleagues, discussants and participants at the various venues in which I had a chance to discuss portions and earlier incarnations of this work.

My deepest thanks to you all. 


\section{Table of Contents}

List of Tables $\quad$ ix

List of Figures $\quad$ xii

1 Introduction and Summary 1

1.1 Introduction . . . . . . . . . . . . . . . . . . . . 1

2 A Nonparametric Test of Employment Stability 6

2.1 Introduction . . . . . . . . . . . . . . . . . 6

2.2 Theory and Evidence . . . . . . . . . . . . . . . . . 8

2.3 Methodology .......................... 14

2.3.1 Distribution Analysis . . . . . . . . . . . . . . . 15

2.3.1.1 Nonparametric Density Estimation . . . . . . . . . 15

2.3.1.2 Testing for internal heterogeneity . . . . . . . . . 16

2.3.2 Stochastic Dominance Testing . . . . . . . . . . . . . 18

2.4 Data . . . . . . . . . . . . . . . . . 20

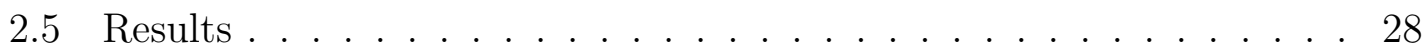

2.5.1 Aggregate Data Analysis . . . . . . . . . . . . . . . . 30

2.5.2 Distribution Analysis . . . . . . . . . . . . . . . . . . 34

2.5.2.1 Identifying Worker Types . . . . . . . . . . . 35

2.5.3 Testing Employment Duration . . . . . . . . . . . . . . 46

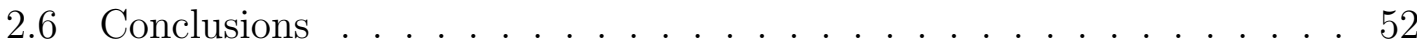

3 First Employment Spells by Birth Cohort 55

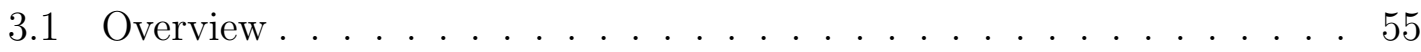

3.2 Data . . . . . . . . . . . . . . . . . . . 57

3.2.1 The Canadian General Social Survey . . . . . . . . . . . . 58

3.2.2 Benchmarking Employment Tenures with Job Tenures . . . . 62

3.3 Empirical Methodology . . . . . . . . . . . . . . . . . . 70

3.4 Results . . . . . . . . . . . . . . . . . . . 72

3.4.1 Proportional Hazard Model Results . . . . . . . . . . . . . . . 72

3.4.2 Competing Risks Regression Results . . . . . . . . . . . . . . 91

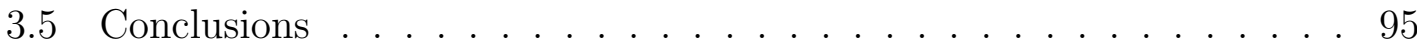


4 Employment Spells beyond the First 97

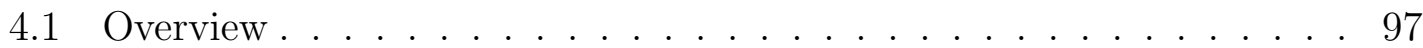

4.2 Data . . . . . . . . . . . . . . . . . . . 101

4.3 Method and Results . . . . . . . . . . . . . . . . . 107

4.3.1 Overall Assessment . . . . . . . . . . . . . . . 111

4.3.2 The Second Spell . . . . . . . . . . . . . . . . . . . . . 118

4.3.3 The Third Spell . . . . . . . . . . . . . . . . . . . . . . . 124

4.3 .4 The Fourth Spell . . . . . . . . . . . . . . . . . . . . . 129

4.3.5 The Fifth Spell . . . . . . . . . . . . . . . . . . 134

4.4 Conclusions . . . . . . . . . . . . . . . . . . . . . . . 140

5 Conclusions 142

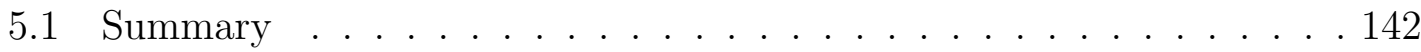

5.2 Conclusion . . . . . . . . . . . . . . . . . . . . . 146

5.3 Future Work . . . . . . . . . . . . . . . . . . 147

A Annex 149

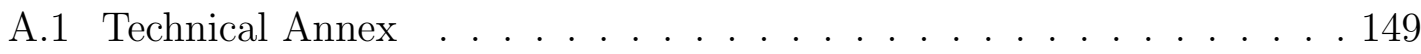

A.1.1 Heterogeneity Testing . . . . . . . . . . . . . . . . . 149

A.1.2 Stochastic Dominance Testing . . . . . . . . . . . . . . . . 151

A.1.2.1 Testing $H_{0}^{(1)}$ vs $H_{1}^{(1)}$. . . . . . . . . . . . . . . . 151

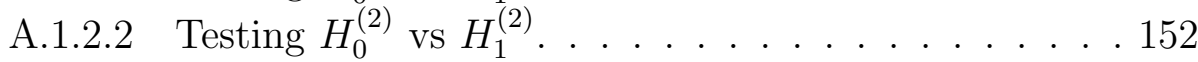

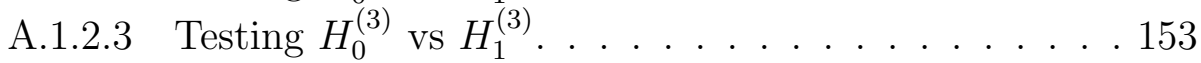

A.1.3 Parametric Bootstrap . . . . . . . . . . . . . 153

B Variable Description 156

$\begin{array}{ll}\text { Bibliography } & 157\end{array}$ 


\section{List of Tables}

2.1 Mean survey weights by employment cohort . . . . . . . . . . . . 24

2.2 Test (for the null) of Equality: mean survey weights of employment cohorts by gender . . . . . . . . . . . . . . . . 24

2.3 Z-tests (for the null) of equality between cohort proportions of nonrespondents by gender . . . . . . . . . . . . . . 25

2.4 Z-tests (for the null) of equality of proportions for respondents that answered "don't know" by gender . . . . . . . . . . . . . . . . 25

2.5 Z-tests (for the null) of equality of men and women's proportions of non-respondents and "don't know" responses . . . . . . . . . . . . 26

2.6 Mean Employment Durations by Cohort . . . . . . . . . . . . . . . . 31

2.7 Decompositions for complete employment spells of 32 years or less by cohort ..................... 36

2.8 Shares for ongoing employment spells of 33 years or more by cohort . 38

2.9 Decompositions for complete employment spells of 22 years or less by cohort . . . . . . . . . . . . . . . . . . 40

2.10 Shares for ongoing employment spells of 23 years or more by cohort . 41

2.11 Decompositions for complete employment spells of 12 years or less by cohort . . . . . . . . . . . . . . . . . . 42

2.12 Shares for ongoing employment spells of 13 years or more by cohort . 43

2.13 Stochastic Dominance Tests for Employment Duration by Cohort: Men 48

2.14 Mean test results for $H_{0}: \Delta \bar{Y}_{\text {Cohort }} \leq 0$ weighted employment durations by cohort for men . . . . . . . . . . . . . . . . . . . . . 49

2.15 Stochastic Dominance Test Results for Employment Durations by Cohort: Women . . . . . . . . . . . . . . . . 51

2.16 Mean test results for $H_{0}: \Delta \bar{Y}_{\text {Cohort }} \leq 0$ weighted employment durations by cohort for women . . . . . . . . . . . . . . 52

3.1 Summary Statistics of First Employment Spells, 2001 and 2006 GSS data . . . . . . . . . . . . . . . . . 59

3.2 Correlation between LFS and GSS attrition and retention rates . . . 69

3.3 Population Regression: GSS and LFS variables . . . . . . . . . . . . 70

3.4 Cox Semiparametric Estimates of Employment Spells: Men . . . . . . 76 
3.5 Cox Semiparametric Estimates of Employment Spells: Women . . . . 78

3.6 Probability Values for the Schoenfeld Residual Test of Proportionality 82

3.7 Cox Semiparametric Estimates of Employment Spells with TimeVarying Covariates: Men . . . . . . . . . . . . . . . . . 84

3.8 Cox Semiparametric Estimates of Employment Spells with TimeVarying Covariates: Women . . . . . . . . . . . . . . . . 86

3.9 Cox-Snell Residual Shares . . . . . . . . . . . . . . . . . . . . . . 89

3.10 Competing Risks Regression (Work Related Separation vs. Other Reasons): Men .................... . . 92

3.11 Competing Risks Regression (Maternity/Parental Related Separation vs. Other Reasons): Women . . . . . . . . . . . . . . . . . 93

4.1 Completed Spell Frequency by Birth Cohort and Spell Number, Women104

4.2 Completed Spell Frequency by Birth Cohort and Spell Number, Men 104

4.3 Completed Spell Frequency by Birth Cohort, Women . . . . . . . . . 105

4.4 Completed Spell Frequency by Birth Cohort, Men . . . . . . . . . . . 105

4.5 Ongoing Spell Frequency by Birth Cohort and Spell Number, Women 105

4.6 Ongoing Spell Frequency by Birth Cohort and Spell Number, Men . . 105

4.7 Ongoing Spell Frequency by Birth Cohort, Women . . . . . . . . . . 106

4.8 Ongoing Spell Frequency by Birth Cohort, Men . . . . . . . . . . . . 106

4.9 Summary Means for Five Employment Spells . . . . . . . . . . . . . . 108

4.10 Cox Proportional Hazard Results: Both Genders by Spell Number . 113

4.11 Cox Proportional Hazard Results: Men by Spell Number . . . . . . . 115

4.12 Cox Proportional Hazard Results: Women by Spell Number . . . . . 116

4.13 Cox Proportional Hazard Results: Second Spells for Both Genders by Birth Cohort . . . . . . . . . . . . . . . . . . . . . . 120

4.14 Cox Proportional Hazard Results: Second Spells for Men by Birth Cohort . . . . . . . . . . . . . . . . . . 121

4.15 Cox Proportional Hazard Results: Second Spells for Women by Birth Cohort . . . . . . . . . . . . . . . . . . . . 122

4.16 Cox Proportional Hazard Results: Third Spells for Both Genders by Birth Cohort . . . . . . . . . . . . . . . . . . . 125

4.17 Cox Proportional Hazard Results: Third Spells for Men by Birth Cohort . . . . . . . . . . . . . . . . . . . . 127

4.18 Cox Proportional Hazard Results: Third Spells for Women by Birth Cohort . . . . . . . . . . . . . . . . . . . . . . 128

4.19 Cox Proportional Hazard Results: Fourth Spells for Both Genders by Birth Cohort . . . . . . . . . . . . . . . . . . . 131

4.20 Cox Proportional Hazard Results: Fourth Spells for Men by Birth Cohort . . . . . . . . . . . . . . . . . . . 132

4.21 Cox Proportional Hazard Results: Fourth Spells for Women by Birth Cohort . . . . . . . . . . . . . . . . . . . 133

4.22 Cox Proportional Hazard Results: Fifth Spells for Both Genders by Birth Cohort . . . . . . . . . . . . . . . . . 136

4.23 Cox Proportional Hazard Results: Fifth Spells for Men by Birth Cohort137 
4.24 Cox Proportional Hazard Results: Fifth Spells for Women by Birth Cohort . . . . . . . . . . . . . . . . . . . . 139 


\section{List of Figures}

2.1 Empirical CDF - men by cohort . . . . . . . . . . . . . . . . . . . . . 28

2.2 Unweighted cohort-specific means and NSR by gender . . . . . . . . . 32

2.3 Weighted cohort-specific means and NSR by gender . . . . . . . . . . 33

2.4 Adaptive Kernel Density Plot (Total 1960-69 Cohort) . . . . . . . . . 34

2.5 Type-specific means by cohort and gender . . . . . . . . . . . . . . . 45

2.6 Type-specific SNR by cohort and gender . . . . . . . . . . . . . . . 46

2.7 Empirical CDF - women by cohort . . . . . . . . . . . . . . . 50

3.1 Employment and Retention Rates . . . . . . . . . . . . . . 67

3.2 Comparative Retention Rates . . . . . . . . . . . . . . . . . . . . 68

3.3 Smoothed Hazards . . . . . . . . . . . . . . . . . . . . . . . 73

3.4 Total Baseline Hazard . . . . . . . . . . . . . . . . . . . . . . . 79

3.5 Baseline Hazard Plots by Cohort: Men . . . . . . . . . . . . . . . . . 80

3.6 Baseline Hazard Plots by Cohort: Women . . . . . . . . . . . . . . . 80

3.7 Cox-Snell Residual Plots: Men . . . . . . . . . . . . . . . . . . . 87

3.8 Cox-Snell Residual Plots: Women . . . . . . . . . . . . . . . . . . . . 88

4.1 Smoothed Empirical Hazards for Spells Beyond the First . . . . . . . 110

4.2 Baseline Hazards by Spell Number and Gender . . . . . . . . . . . . 117

4.3 Baseline Hazards: Second Spells by Gender and Birth Cohort . . . . 123

4.4 Baseline Hazards: Third Spells by Gender and Birth Cohort . . . . . 129

4.5 Baseline Hazards: Fourth Spells by Gender and Birth Cohort . . . . . 134

4.6 Baseline Hazards: Fifth Spells by Gender and Birth Cohort . . . . . . 138 


\section{Chapter 1: Introduction and Summary}

\subsection{Introduction}

Towards the end of the twentieth century across the developed world there was a perception that the labour market had fundamentally changed. These widely-held perceptions were re-enforced through anecdotes and repeated in the news. Broadly speaking, it was felt that the labour market was not as stable as it had been during most of the post-war period. The main issues revolved around feelings of worker insecurity in their jobs and the truism that having and holding a lifetime job was no longer a possibility.

The second half of the twentieth century was a time of unprecedented social improvement. The first half of this period saw a dramatic rise in the security of workers through improvements to the ability for workers to collectively organize as well as active legislation to improve the position of labour. Moreover, the welfare state evolved greatly giving workers and citizens far greater security. These gains for workers, were reversed to some degree over the final quarter of the century. These declines in labour power and to some extent the generosity of the welfare state came in tandem with the rising insecurity being felt by workers.

At the same time as labour was on the ascent, changes in the role of women 
in society caused another dramatic shift which continues to be played out today. Women, long having been pigeonholed into domestic and non-market roles, began to move into the labour market. This generational shift into labour market participation has reshaped labour markets and social relations around the globe.

The narrative of job instability tended to focus more on men, and more specifically, on working class men than on women. Part of the narrative also reflected a deep unease with globalization and the shift from goods to service production over the latter portion of the twentieth century. A final element in the story was the demographic impact of the baby-boom generation. Born over the decades following the second world war, this generation - the largest in history - would provide a massive infusion of young labour into this period.

While it is arguably the case that a more dynamic economy will need a high degree of job churn, the evidence points to longer-term, stable jobs being of higher quality and remuneration than short-tenured position. Moreover, individuals with prolonged bouts of unemployment - and often the result of job displacement - are more likely to face financial hardship, family breakups, higher suicide rates as well as lower levels of personal satisfaction. Clearly, at least for some individuals, the decline in employment stability is not beneficial. On the other hand, switching jobs voluntarily is often associated with higher pay and a better job match. As such, it is difficult to conclusively state whether stability should trump mobility or vice-versa, despite that a balance must be struck.

Having contextualized the period under study thus, we can turn to the central questions of this work. Can it be said that over the latter half of the twentieth 
century the stability of employment has declined? And, if a decline in the ability to find continuous employment had indeed occurred what factors contribute to this? A number of authors have written on this topic and the verdict is still largely out, pending more refined data. In Canada, most authors tend to find that jobs have been stable since reliable data has been released. In this study, a series contributions are made to this debate.

The first contribution is the ability to look farther back in time using a novel dataset that asks retrospective questions on work histories. This data allows for inquiry into employment spells which began as early as the 1930s. This is quite significant, as Canadian studies - and most studies globally - tend to extend back only to the 1970 s. $^{1}$ While the dataset does impose a number of limitations, it does permit analysis for a period of time largely unexamined by the literature on the topic. The second major contribution is a novel parametric bootstrap test using complete and incomplete employment durations on data with right censoring. Finally, the key results themselves - that employment durations declined between the 1960s and $70 \mathrm{~s}$ - are a contribution simply because it was, as stated above, an under-examined period of history (with regards to the stability literature).

The following chapter, Chapter 2, deals with the question of whether employment spells themselves have declined. In the chapter, decadal tenure distributions of employment spells, representing the initial working conditions of individuals who

\footnotetext{
${ }^{1}$ While the U.S. CPS supplements provide information on mobility for January of 1951,1963 , 1966, and 1968 the questions posed in these data sets differ from those posed after 1981 and hence, with the notable exception of Hall [1], are not frequently used in the literature.
} 
began working in that year, are decomposed to determine whether shifts between heterogeneous worker types could be used to explain the apparent declines in tenure over the second half of the twentieth century. A parametric bootstrap test, composed of the estimated distributions of combined worker types, is used to formally test declines in tenures for succeeding cohorts of workers. For men, this assertion is borne out, while for women the results are more mixed. The analysis focuses solely on answering whether or not these shifts can be said to occur but does not empirically test for causal factors.

In Chapter 3 the first employment spell of individuals is examined to see what characteristics of individual workers contribute to a shorter or longer employment spell. Use is made of birth-cohort effects to proxy for socio-economic factors beyond those available in the dataset used. It is shown that macroeconomic factors affect the hazard more strongly for succeeding birth cohorts of men, this is also consistent with recessionary periods generating decreasing employment stability across cohorts. For women, cohort effects are consistent with the increasing generosity of maternity leave provisions through the unemployment insurance system. This chapter also benchmarks the Canadian General Social Survey - the primary data source for this study - with the Canadian Labour Force Survey, the single best time series data on the labour market in Canada.

Chapter 4, then examines employment spells beyond the first to determine whether the prevalence of multiple spells can explain the decline in tenures observed in Chapter 2. Many of the same factors which affect first spells tend to affect latter spells. Cohort effects tend to play a weaker role in these spells implying that spells 
beyond the first are more uniform across the generations. One of the key results is the simple fact that men are far more likely to be engaged in the labor market on a continuous basis than are women - but the strength of this relationship does decline across succeeding cohorts of men.

Finally, chapter 5 provides a conclusion and overall assessment of these results and their implications for the thesis. 


\section{Chapter 2: A Nonparametric Test of Employment Stability}

\subsection{Introduction}

It is commonly perceived that employment stability has declined over the past few decades, that is, workers are more likely to have a larger number of shorter term jobs over the course of their career than had been the case in the past. Evidence is mixed on the issue of declining job tenure, by which most studies proxy job stability, in North America. Furthermore, there have been only a limited number of comprehensive studies on job tenure in the Canadian context and existing studies showed no long term secular declines in these employment relationships. The aim of this chapter is to fill a gap in the long term analysis of employment stability using evidence gleaned from the Canadian General Social Survey (GSS). However, while the concept of stability is the underlying focus, it will be examined through the use of employment duration. This concept is closely related to stability but captures both voluntary and involuntary separations, only the latter of which is commonly to be seen as potentially problematic.

The importance of better understanding historical patterns of employment durations is twofold. Firstly, for workers, consistent employment is important in the maintenance of an individual's human capital and is generally associated with 
higher-quality work and higher levels of satisfaction. As such, shorter-tenured employment is more often associated with lower-quality and more modestly remunerated positions. This has a number of policy implications - particularly with respect to labour market regulation - when combined with information on which factors affect employment tenures. Secondly, by using a long term perspective it is possible to reconcile the puzzling discrepancy between popular opinion and the academic literature. The discrepancy is addressed by pointing out that many of the major changes in tenure occurred between those who started employment before the 1970s and those who began working afterward. Aside from the GSS, there are no Canadian data sources which can track individual-level Canadian employment histories over the entire second half of the twentieth century. It is very likely that there are few other surveys anywhere which offer such a long term view of employment relationships. This is important because most studies only begin looking at tenure data in the 1970s ( [2], [3], [4]).

Evidence from distributions of completed and censored employment spells shows that employment durations have changed over time. Continuous finite mixture decompositions and stochastic dominance tests which account for both the heterogeneity and censoring in the distributions of interest are used below to show cohort-based changes in employment tenures using data from the 1950s onwards. To carry out the analysis, cohorts are formed based on employment commencement rather than on birth years. The results show decreasing employment tenures for men over the latter half of the twentieth century. It is likely that because of major social and economic changes over this period, the employment tenures of women do 
not show the same dramatic declines. This difference between the sexes is important because it identifies distinctive patterns of change along gender lines. This is the first analysis to identify broad, secular declines in employment tenures for Canada over the period under study.

Section 2.2 discusses the literature on job tenure and outlines a simple worker heterogeneity model which will be the point of reference for the ensuing analysis. Section 2.3 will detail the empirical methods used and the tests employed in the study. Section 2.4 focuses on the retrospective dataset and describes some of the problems that are encountered using it. Section 2.5 presents the results. Finally, section 2.6 concludes.

\subsection{Theory and Evidence}

The majority of studies on job tenures are focused on the United States. The seminal paper in this field was that of Hall [1] who, using the Current Population Survey (CPS) of 1968 and 1978, constructed synthetic cohorts, and found three characteristics which continue to define job durations in the U.S.. The first of these is that most jobs do not last a long time, but those that last for at least five years are likely to last up to twenty years. Secondly, a substantial proportion of workers

will, at some point in their careers be in a "lifetime job," this being defined as one which lasts 20 years or more. Finally, men are more likely than women, and whites are more likely than blacks to be in jobs of a longer duration.

A number of authors have written on the topic of U.S. job stability. The 
results are sometimes conflicting, but more often than not show a degree of overall stability in job tenures. It was Hall [1] who first showed using the CPS that a large proportion of workers would at some point be in a lifetime job. In addition, Diebold et al. [2] and Farber [3], also using CPS data found that - broadly speaking - job durations had not declined between the 1970s and early 1990s among the broader population. Both papers identified decreases in stability among the less educated, and the latter pointed out that declining stability among men had been offset by increases among women. Furthermore, Jaeger and Stevens [5], using the Panel Study of Income Dynamics (PSID) as well as the CPS, found little evidence of a trend in job tenure.

Conversely, using CPS data Swinnerton and Wial [6] showed that there had been a decline in durations over the 1980s. Rose [7] corroborated Swinnerton and Wial's results using the PSID and argued that job stability decreased between the 1970s and 1980s for men. On a related matter, it has been surmised that worker displacement may have seen significant increases between the 1970s and 1980s (Fallick [8]). Furthermore, evidence from the PSID shows that job losses stemming from plant closures rose between the 1960s and 1980s [9]. More recently, Farber [10] using a birth-cohort approach found an increase in short-tenure positions and declines in long-term employment relationships using the 1973-2006 CPS. In particular, Farber's results indicate that mean employment tenure for men has deteriorated by about 50\% after controlling for education between the 1914 and 1975 birth cohorts. For women the declines were smaller. A number of the above results indicate that declines may have occurred before the 1980s, when the concerns about this phe- 
nomenon became widespread.

In the Canadian context, researchers have primarily focused on the period following 1976, when the Labour Force Survey (LFS) data became readily available to research. In this literature it has been largely shown that there is no long term downward trend and that declines in job tenure are largely cyclical. Green and Riddell [11] found that, between 1979 and 1991, the distribution of job durations "hollowed out", such that both, short and long tenure jobs increased at the expense of mid-length jobs. Picot, Heisz, and Nakamura [12], using the LFS, the Longitudinal Worker File (LWF), Survey of Consumer Finances (SCF) and Survey of Labour and Income Dynamics (SLID) showed that job duration declined in the 1980s but rose correspondingly over the 1990s, leading to no long-term declines in Canadian job tenures. Heisz [4], using retention rates obtained from LFS data, examined each year over the 1976 to 2001 period and showed, over this period, that there was no period-long drop in Canadian job stability and an increase since the early 1990s. This is the first year-by-year examination of job stability of its kind; as such this was the first study to be able to distinguish between secular and cyclical changes. In addition, by comparing his findings to those of the CPS results of the U.S. ( [6], [13]) he pointed out that, contrary to the Canadian experience, job stability had declined slightly in the United States. Finally, Brochu [14], updating the Canadian evidence into the 2000s, found a secular increase in job tenure after the 1990s, with a notable increase in the retention rates for workers with less than one year of initial tenure. He found that the sources of the increase in stability were in large part explained by the rising age of the workforce, with further contributions made by the increasing 
participation of women and rising educational levels particularly with regard to the decline in the share of low educated workers.

In general, because of data availability, the literature generally focuses on analyzing either in-progress job lengths or retention rates. Using a cross-cut of the data to analyze in-progress job lengths allows for a clear picture of tenure at a particular point in time. However, this method leads to the problem of length bias wherein the number of short-term jobs tend to be under reported [15]. This method is also sensitive to job inflows for example, the entry of the baby-boomers into the labour force would create evidence of an increase in short term spells, solely due to demographic composition changes. As such, the literature shows a clear preference for analyzing retention rates in repeated cross section data.

The retention rate approach solves this problem by looking at the share of jobs which continue into the next period given their initial tenure. An example of a retention rate approach is to generate a time series of shares for jobs which will last 5 years into the future for the subset of workers who have been employed for 1 year in the initial period. A complication for some of the studies using this method is that the estimates rely on synthetic cohorts in repeated cross-section data. These data may be prone to errors generated by changes in the composition of the cohorts. Brochu (2011) shows that the synthetic cohort approach will be consistent only if the compositional changes due to immigration, emigration or death lead to breaks in tenure spells. In particular, this means that when members of a cohort immigrate or emigrate they do not retain their current job.

The retention rate approach is prone to the problems of telescoping and recall 
errors as years in the current job are generally recorded at the time of the survey. Optimally, it would be desirable to follow workers from the start to termination of employment but data for this purpose is generally lacking or of limited duration. The method described below will use retrospective data to generate distributions of fully observed employment spells.

The theoretical basis for the ensuing analysis will be a model of worker heterogeneity. The model is a modified version of the pure mover-stayer model of worker heterogeneity introduced by Blumen et al. [17] as described by Farber [15]. While that model deals with turnover probabilities, here the object of focus will be employment tenures.

Suppose the mean tenure of employment $(E(Y))$ can be represented by the mean tenures of $K$ types of heterogeneous workers denoted by $\mu_{k}, k=1, \ldots, K$. The mean tenure of all workers in the labour market can then be described by a weighted mean of the tenures of all worker types. This can be written as

$$
E(Y)=\sum_{k=1}^{K} p_{k} \mu_{k}
$$

where $p_{k}$ is the proportion of type $k$ workers and $\sum_{k=1}^{K} p_{k}=1$.

To isolate worker types within observable data, the above model is extended to allow for variability within the types. Assume instead of having a fixed mean tenure that the type of worker comes from a continuous distribution which has both a specific mean and variance. In this case the model becomes: 


$$
E(Y)=\int y f(y) d y
$$

with $f(y)=\sum_{k=1}^{K} p_{k} f_{k}\left(y ; \mu_{k}, \sigma_{k}\right), f\left(y ; \mu_{k}, \sigma_{k}\right)$ defining the distribution of an outcome $y$ (tenure of employment) of the $k^{\text {th }}$-type worker, with mean $\mu_{k}$ and standard deviation $\sigma_{k}$.

To make a meaningful comparison of employment tenures over time, given limited data, it may be necessary to aggregate tenures into larger groups. Let $C_{d_{t}}$ represent a cohort grouping of employment tenures, with $d_{t}$ the period of time that a new employment spell is associated with a given cohort. Then $Y^{\left(C_{d_{t}}\right)}$ is the measure of employment tenure for a cohort of workers who began working in period $d_{t}$. The unconditional cumulative distribution function $F^{\left(C_{d_{t}}\right)}(y)$ of each cohort will then take the form:

$$
F^{\left(C_{d_{t}}\right)}(y)=\int_{0}^{y} \sum_{k=1}^{K} p_{k} f\left(s ; \mu_{k}, \sigma_{k}\right) d s .
$$

Because there is evidence that a worker can be of many "types" over their life course (see the survey of Farber [15]) and job characteristics often determine a worker's tenure, the cohorts are defined by the commencement of the workers' employment spell. This allows worker types to change across spells but not within them. Characteristics of these employment cohorts and their ability to enable consistent comparisons between distributions are discussed in detail in the data section below.

Finally, to make a comparison between complete distributions it is necessary to incorporate some degree of censoring in each distribution if there are any ongoing 
spells. If tenures cannot be observed beyond some censoring point $c$ then a threshold value, smaller or equal to the censoring value $\left(y_{c}\right)$, must be established. Thus, a comparison between censored distributions of the form $P\left[Y^{\left(C_{d_{t}}\right)} \leq y \mid y \leq y_{c}\right]=$ $F^{\left(C_{d_{t}}\right)}\left(y \mid y \leq y_{c}\right)$ should be made.

Identifying heterogeneous worker types serves two purposes. First, typespecific heterogeneity is used to identify if all or any specific worker types play a role in the declining mean tenures observed in the data. Second, accounting for the heterogeneity of the distribution allows for an improvement in the size and power of the test statistics employed. The methods employed are discussed below.

\subsection{Methodology}

After an empirical check, the cohort-specific employment spells are divided between complete and incomplete employment durations, both of which are accounted for in the analysis. For the completed employment spells, a finite mixture decomposition is used to identify worker types while incomplete spells are accounted for by their share. Two methods are used in the analysis. The first method uses finite mixture decomposition by decadal cohort to analyze completed employment spells. This is done to identify employment trends by worker type and explore the forces driving aggregate (average) movements in employment tenure. The second method will use a series of tests of stochastic dominance, again by decadal cohort, to test for an aggregate decline in spell length using both completed and ongoing employment spells and accounting for censoring in the distributions. 
A non-parametric graphical representation is used to decide what type of parametric specification can be used in the mixture model. The fit of the estimated mixture distributions is verified using tests of equality of distributions. The arguments about non-parametric estimation follow Silverman [18], the subsequent heterogeneity analysis uses the method of McLachlan and Peel [19], while the stochastic dominance tests are an extension of Linton, Maasoumi and Whang [20] which account for censored distributions as in Hyunh, Ignaczak and Voia [21]. The proposed extension has the advantage of allowing testing only on the range over which restricted dominance can be inferred. Further, the finite mixture decomposition suggests the presence of nuisance parameters in the distributions, which requires a parametric bootstrap in the estimation of critical values for the test statistics.

\subsubsection{Distribution Analysis}

This section describes the methods used in the subsequent analysis. Kernel methods are used to visualize the shape of the employment duration distribution. This analysis helps in deciding what class of parametric distributions may fit the data. Further, parametric decomposition of completed employment durations is used to identify the worker types and to analyze their changes across cohorts.

\subsubsection{Nonparametric Density Estimation}

Before assuming what type of decomposition is suitable, the distribution of completed employment spells by cohort is first examined using a kernel density 
estimator. Varying bandwidths are required when long-tailed or multi-modal density functions are estimated using kernel methods. Hence, an adaptive kernel density estimator is used to avoid the potential problems of using a fixed bandwidth, such as undersmoothing in areas with only sparse observations and oversmoothing in others. Adaptive kernels were introduced and discussed by the following authors: Silverman [18], Bowman and Azzalini [22], or Pagan and Ullah [23]. Salgado- Ugarte et al. [24], Salgado-Ugarte et al. [25] and Salgado-Ugarte and Perez-Hernandez [26]. The method employed is described in the technical annex. The information from the kernel plots is examined to evaluate the likelihood that a mixture of distributions exists in the employment duration distribution. Furthermore, the kernel density estimate will show which class of distributions can be used to approximate the mixtures if they are found to be present.

\subsubsection{Testing for internal heterogeneity}

A finite mixture decomposition of the cohort-specific outcome duration distribution is used to identify the potential number of types of workers in each cohort. The results of these decompositions are then used to understand the changes in unobserved worker heterogeneity and the composition of worker types across cohorts.

There are three reasons for using continuous mixture decompositions. The first is that any skewed distribution of unknown shape can be approximated with a mixture of continuous distributions of known shapes. Secondly, the type of identified workers are not restricted to a single unique parameter with this method (which 
is the case if we restrict our decomposition to discrete mixtures). Additionally, the convergence to the parameters of the mixture is achieved faster when continuous mixtures are employed (as opposed to discrete mixtures) as the mixture of densities exploits the smoothness of a density to achieve better finite sample performance. Finally, the information from the mixture decomposition can then be used to simulate the necessary data for the computation of the critical values of the proposed test statistics.

For a random variable Y (our outcome variable of interest), the finite mixture model decomposes a probability density $f(y)$ into the sum of $K$ class probability density functions. In this case, if $f_{k}(y)$ is the $k^{\text {th }}$ class probability density function and $p_{k}$ denotes the proportion of the $k^{t h}$ class, we can define the finite mixture model with K components as $f(y)=\sum_{k=1}^{K} p_{k} f_{k}(y)$. The proportion $p_{k}$ can be interpreted as the prior probability of observing a sample from class $k$, with the property that is greater or equal to zero and that they sum to one $\left(p_{k} \geq 0\right.$ and $\left.\sum_{k=1}^{K} p_{k}=1\right)$.

The objective of the decomposition is to estimate the parameters of the class probability densities and the proportions $p_{k}$ of each class, while fixing an upper bound on the number of possible classes. The class of probability densities are assumed to have parametric components that can be estimated. The adaptive kernel density plots are examined to determine how many, if any, mixtures are present in the employment duration distributions. Using visual inspection it was determined that log-normal mixtures best fit the outcome variable of interest. Hence, after performing a test for the exogeneity of the censoring, the distribution can be divided in two parts; a truncated part that contains only complete employment spells that 
do not pass the censoring threshold and, a censored part that contains all the spells that passed the censoring threshold. The truncated part of the distribution is then estimated using a mixture of truncated log-normals to fit the uncensored data, ensuring no values exceed the censoring point. The following likelihood function is used:

$$
f\left(y, \theta \mid y<y_{c}\right)=\frac{\sum_{k=1}^{K} p_{k} \frac{1}{y \sigma_{k} \sqrt{2 \pi}} \exp \left(\frac{-\left(\log y-\mu_{k}\right)^{2}}{2 \sigma_{k}^{2}}\right)}{\int_{0}^{y_{c}} \sum_{k=1}^{K} p_{k} \frac{1}{y \sigma_{k} \sqrt{2 \pi}} \exp \left(\frac{-\left(\log y-\mu_{k}\right)^{2}}{2 \sigma_{k}^{2}}\right) d y} \times \mathbf{1}\left\{y<y_{c}\right\}
$$

The parameters of interest are: $\theta=\left\{K, p_{k}, \mu_{k}, \sigma_{k}\right\}$ with $k=1, \ldots, K$ and $\sum_{k=1}^{K} p_{k}=$ 1 , where $p_{k}$ is the proportion of a given type with $\sum_{k=1}^{K} p_{k}=1, \mu_{k}$ is the mean of given type and $\sigma_{k}$ is the standard deviation of a given type. All the parameters of interest with the exception of the number of types are estimated by the likelihood. The number of types are estimated using model selection based on the AIC criteria. The following AIC criteria is minimized:

$$
A I C_{k}=-2 \log l(\theta \mid y)+2 d_{k}
$$

where $d_{k}$ is equal to the dimension of the model and acts as a correction term without which one would choose the model that maximizes the unconditional log-likelihood.

\subsubsection{Stochastic Dominance Testing}

Tests of stochastic dominance and the equality of distributions are used to formally determine whether employment durations have declined. However, because a complete distribution of employment durations for any particular group of workers can range in lengths of up to many decades it is often impossible to compare complete 
distributions of recent groups of workers. Because of this constraint the stochastic dominance tests will be limited to some feasible length, longer for earlier cohorts and shorter for more recent groups. These tests, explained formally below, will answer the question of whether evidence of a secular decline in employment durations exists.

Consider that the duration of employment of different cohorts is observed over time. For example, those who began their employment in the 1950s or 1960s can be observed up until the point when their spells end. The outcome variable of interest is $Y^{\left(C_{t}\right)}$, where $Y^{\left(C_{d_{t}}\right)}$ is the length of the employment duration for cohort $C_{d_{t}}$, where $t$ is the employment commencement period of a given cohort. To ensure correct comparisons between the cohort-specific outcome distributions the data are censored at different comparison levels (12 years, 22 years and 32 years). The use of finite mixtures induces nuisance parameters in the distributions of interest. To deal with this potential problem, the results of the finite mixture decompositions are used to improve the size and power of the stochastic dominance test statistics by employing a parametric bootstrap in computing critical values.

Define the associated cumulative distribution functions as $F^{\left(C_{d_{t}}\right)}$ and the conditional distribution functions

$$
F^{\left(C_{d_{t}}\right)}\left(y \leq y_{c}\right)=P\left[Y^{\left(C_{d_{t}}\right)} \leq y\right]
$$

where $y_{c}$ is the value of the outcome at the censoring point $c$. Let

$$
G_{1}^{\left(C_{d_{t}}\right)}\left(y \leq y_{c}\right)=F^{\left(C_{d_{t}}\right)}(y)
$$


and define the higher orders of $G_{1}$ by

$$
G_{s}^{\left(C_{d_{t}}\right)}\left(y \leq y_{c}\right)=\int_{0}^{y} G_{s-1}^{\left(C_{d_{t}}\right)}(x) d x
$$

Three possibilities are considered for $F^{\left(C_{d_{t}}\right)}$ :

(1) The distributions of the tested comparison cohorts are equal. In this case the null hypothesis is

$$
H_{0}^{(1)}: F^{\left(C_{t_{i}}\right)} \equiv F^{\left(C_{t_{j}}\right)} \text {, where } i \neq j
$$

(2) One of the distributions first order stochastically dominates another. The case of $F^{\left(C_{t_{i}}\right)}(y) \leq F^{\left(C_{t_{j}}\right)}(y)$ for all $y \leq y_{c}$ is considered. Here, the corresponding null hypothesis is

$$
H_{0}^{(2)}: F^{\left(C_{t_{i}}\right)} \leq F^{\left(C_{t_{j}}\right)}
$$

(3) The two distributions intersect, but one distribution second order stochastically dominates the other. In this case the null hypothesis is written as

$$
H_{0}^{(3)}: \int_{0}^{y}(y-x) d F^{\left(C_{t_{i}}\right)}(x) \leq \int_{0}^{y}(y-x) d F^{\left(C_{t_{j}}\right)}(x),
$$

for all $y \leq y_{c}$.

These tests as well as the parametric bootstrap used to obtain the critical values for the stochastic dominance tests are more fully described in the Annex.

\subsection{Data}

The survey data used in this chapter are from the 15th cycle of the Canadian General Social Survey (GSS). These data are complemented by another sample 
obtained from the 20th cycle of the GSS which will be used to conduct a robustness check. The 15th cycle was conducted monthly over the course of 2001. A GSS cycle occurs every year and focuses on different social topics, the data of the 15th cycle comes from the family history cycle which occurs every 5 years. The 2001 GSS contains 24,310 records and yields 14,348 employment spells suitable for use over the period under study.

In the GSS, respondents are asked to retrospectively identify up to 5 work episodes over their life course starting with the first. They are asked, using the 15th cycle questionnaire, "How old were you when you first started working for a period of six months or longer?" (WH01_Q20A) followed by "How old were you when your FIRST absence from work started?" (WP01_Q50A) with an absence defined as having "been away from work for more than 3 months because of a lack of work, sickness, maternity/paternity leave, retirement, or any other reason?" (WP01_Q45). ${ }^{1}$ This information is sufficient to extract details on the duration of employment for individuals. Exit from employment is identified by the respondent providing an exit date. The year of retirement is used as an end date if one is not otherwise provided. In other cases, when respondents refuse to answer, don't know or are not asked the data is dropped. Furthermore, any employment spells of immigrants before immigration as well as students before graduation from their final year of schooling are dropped. Data for ongoing spells, ones which have started but not ended, are retained for testing if the spell length is less than 60 years in

\footnotetext{
${ }^{1}$ The 2001 and 2006 questionnaires of the work history component of the GSS use the same questions regarding employment spells and, as such, are directly comparable to one another.
} 
duration. Using information on each subjects birth date and the information above, employment durations were constructed by obtaining the year in which a particular spell ended and subtracting it from the year it began. Employment spells for all employees, whether full-time or part-time, the self-employed as well as unpaid family workers are included as the study is concerned with overall employment stability and not just that of paid workers.

It should be noted that the data obtained from the GSS is constructed from work interruptions of 3 months or more. The GSS data do not provide information on whether the interruption ended with a return to the same employer or a new employer. Hence, the operational concept of employment will be one of an employment spell rather than a job with the same employer. This differs from a job spell in a particular position, which is the object of analysis in most studies of job tenure. Here, instead, continuous uninterrupted employment with any employer or in any job or number of jobs is observed. Despite these differences, a job separation into unemployment or out of the labour force for a three month duration will lead to an employment spell as defined in the GSS. However, many respondents reported interruptions of less than 3 months as a break. This may be because a change of employer was interpreted as an interruption by workers, despite the lack of a 3 month break. These data were left in the study as the focus is on self-reported employment spells rather than interruption length.

The heterogeneity of the employment tenure distributions is identified semiparametrically using finite mixtures as in equation (2.2). In the ensuing analysis gender is the only observed heterogeneity that is controlled when comparing employ- 
ment tenure distributions across cohorts. Other conditional comparisons such as the level of education could have been of interest and worth pursuing, but they may require more than a binary disaggregation, which means that for a given education group there would be very few observations in early cohorts and the semi-parametric analysis employed would not be appropriate. Furthermore, Farber [10] found that increasing education levels mitigated tenure declines only to a small degree. While the lack of additional controls makes the analysis somewhat less focused it is necessary to not parse the available data too thinly.

A potential data problem that may induce bias in estimation is the fact that many of the survey respondents in question would be well over 60 years old and mortality is a concern. If mortality were a serious issue, the available sample would have characteristics different from the overall population in previous decades (particularly for earlier cohorts). To mitigate this problem and at least partially address the selection bias issue we opt to leave out data associated with tenures begun in the 1930s and 1940s. We thus focus on tenures begun in the 1950s and onward. The mean survey weights by employment cohort and a joint F-test of equality of these mean weights are shown in Tables 2.1 and 2.2. The results of the tests indicate that the cohort and gender specific mean weights are not significantly different in magnitude suggesting a proportionality of the sample used to the population of the preceding census by gender. Because almost all the first employment spells in the dataset, upon which the cohort definitions depend, are begun by around age 20, this limits nearly all of the oldest respondents to be just over 70 years of age in 2001 . Although this is somewhat higher than life expectancy at birth in 1950-52 (66 for 
Table 2.1: Mean survey weights by employment cohort

\begin{tabular}{l|rrr|rrr}
\hline & \multicolumn{3}{|c}{ Men } & \multicolumn{3}{c}{ Women } \\
Cohort & Obs & mean & std.dev & Obs & mean & std.dev \\
\hline $1950-59$ & 858 & 1016.19 & 575.95 & 1048 & 798.99 & 462.70 \\
$1960-69$ & 1245 & 1068.15 & 625.15 & 1876 & 866.34 & 527.80 \\
$1970-79$ & 2199 & 1138.89 & 718.63 & 3277 & 943.49 & 599.68 \\
$1980-89$ & 2872 & 1001.67 & 647.36 & 4644 & 919.49 & 573.09 \\
\hline
\end{tabular}

Table 2.2: Test (for the null) of Equality: mean survey weights of employment cohorts by gender

\begin{tabular}{l|rrr|rrr}
\hline & \multicolumn{3}{|c}{ Men } & \multicolumn{3}{c}{ Women } \\
& F & F critical & P-value & F & F critical & P-value \\
\hline Test & 2.517 & 18.512 & 0.253 & 5.513 & 18.512 & 0.143 \\
\hline
\end{tabular}

men and 71 for women), the 1950s were deemed an appropriate start point for the analysis.

Further selection bias could enter the survey in two ways, selection into the survey or selection into the questions regarding employment. The response rate to the survey was $79.3 \%$. Although men and women have different response rates in the GSS, selection out of the survey by way of direct refusal at the individual level was $7.5 \%$. While, not a trivial sum, the degree of potential bias generated by this is small. Finally, Tables 2.3 and 2.4 show tests of equality of proportions for refusals and "don't know" responses across employment cohorts and between genders. The first of these tests is an indicator of whether selection out of the questionnaire occurred differently for men and women across cohorts. The results indicate that there were a few significant cases, but that these showed no particular pattern in the proportion of refusals between cohorts or genders. The second of 
Table 2.3: Z-tests (for the null) of equality between cohort proportions of nonrespondents by gender

\begin{tabular}{l|rrr|rrr}
\hline & \multicolumn{3}{|c}{ Men } & \multicolumn{3}{c}{ Women } \\
& $p_{50-59}$ & $p_{60-69}$ & $p_{70-79}$ & $p_{50-59}$ & $p_{60-69}$ & $p_{70-79}$ \\
\hline$p_{60-69}$ & 1.877 & & & 1.996 & & \\
$p_{70-79}$ & 0.861 & 1.191 & & 2.001 & 0.162 & \\
$p_{80-89}$ & 2.355 & -0.183 & 1.613 & 0.957 & 1.396 & 1.358 \\
\hline
\end{tabular}

Note 1: $p_{50-59}$ refers to the proportion of interest for cohort 1950-1959.

Note 2: The critical value of two sided test for $95 \%$ confidence level is 1.96 .

Table 2.4: Z-tests (for the null) of equality of proportions for respondents that answered "don't know" by gender

\begin{tabular}{l|rrr|rcc}
\hline & \multicolumn{3}{|c}{ Men } & \multicolumn{3}{c}{ Women } \\
& $p_{50-59}$ & $p_{60-69}$ & $p_{70-79}$ & $p_{50-59}$ & $p_{60-69}$ & $p_{70-79}$ \\
\hline$p_{60-69}$ & -0.025 & & & 2.178 & & \\
$p_{70-79}$ & 0.648 & 0.657 & & 2.294 & 0.085 & \\
$p_{80-89}$ & 0.322 & 0.289 & 0.417 & 3.285 & 0.722 & 1.076 \\
\hline
\end{tabular}

Note 1: $p_{50-59}$ refers to the proportion of interest for cohort 1950-1959.

Note 2: The critical value of two sided test for $95 \%$ confidence level is 1.96 .

these tests, for "don't know" responses, has more relevance to memory effects and is discussed below.

With regards to heaping, Ureta [27] found that the type of question asked results in different answers, questions regarding the length of work suffer from less heaping than those regarding when work started. To preclude these so-called heaping effects, employment durations were aggregated to an annual level. For convenience, employment begun in a particular year was recorded as beginning in that calendar year while employment ending in a particular calendar year was recorded as ending in the subsequent calendar year. Hence, a job which began in June of 1987 
Table 2.5: Z-tests (for the null) of equality of men and women's proportions of non-respondents and "don't know" responses

\begin{tabular}{l|rccc|cccc}
\hline & \multicolumn{7}{|c}{ Women } \\
Men & $p_{50-59}$ & $p_{60-69}$ & $p_{70-79}$ & $p_{80-89}$ & $p_{50-59}$ & $p_{60-69}$ & $p_{70-79}$ & $p_{80-89}$ \\
\hline$p_{50-59}$ & 0.545 & & & & 1.428 & & & \\
$p_{60-69}$ & & 0.467 & & & & 0.438 & & \\
$p_{70-79}$ & & & 2.204 & & & & 1.406 & \\
$p_{80-89}$ & & & & 0.718 & & & & 2.173 \\
\hline
\end{tabular}

Note 1: $p_{50-59}$ refers to the proportion of interest for cohort 1950-1959.

Note 2: The critical value of two sided test for $95 \%$ confidence level is 1.96 .

and ended in August of 1987 would be counted as beginning in 1987 and ending in 1988, producing a duration of 1 year. While it is not necessary to round the years up in this exact method, it is crucial that non-zero and non-negative durations are produced. Furthermore, rounding the separation date up rather than the start date down seems to be more intuitive. Alternatively, monthly data could have been used in computation and rounded up to positive integers but varying the rounding technique did not produce significant differences in the output. Farber [3], in his study of job durations in the U.S. has similar problems with monthly data but opted to use a heaping correction. Because the focus here is on a much longer time frame the loss of monthly information will not significantly affect the conclusions.

Forward telescoping and memory effects are two of the more serious recall problems that can emerge with retrospective data. Descriptions of these effects can be found in Torelli and Trivellato [28]. Forward telescoping occurs when respondents remember past events as occurring nearer the time of the survey than they actually had. While, memory effects occur when respondents forget that an event 
had actually taken place. Forward telescoping would make ongoing employment spells seem shorter than they actually were. As for completed spells, it would depend on the time pattern of the telescoping error. Recall errors are more serious and difficult to adjust for because they are date and saliency-dependent; if workers forget an employment spell entirely (likely an earlier and shorter spell) it would bias down the number of short duration spells. Within the samples obtained, a part of the recall problem can be tested using the "don't know" responses of Tables 2.4 and 2.5. These tests show that, at least for those surveyed, there is no cohort or gender-specific pattern to be observed. With these issues in mind, Figure 2.1 shows that the major change in men's employment durations occurs between spells begun the 1960s and those begun in the 1970s. For this difference to be generated by recall errors some form of unrealistic nonlinearity in memory effects (such as a non-monotonic change over time) would have to have been present. Nevertheless, there does not seem to be a pattern in refusals or an inability to recall as indicated by unanswered or "don’t know" responses.

To test for telescoping errors the 15th and 20th cycles of the GSS were compared. As both are representative of the Canadian population at their respective points in time, a test can be performed of whether the five year gap between them has caused people to recall the year their employment began differently. Specifically, to test for forward telescoping, for each year of birth, a test is performed to determine whether the year the first employment spell begins is significantly further along the time continuum for those surveyed in 2006 than for those surveyed in 2001. The tests were performed by gender, by class of worker and, for the employed, by 
Figure 2.1: Empirical CDF - men by cohort

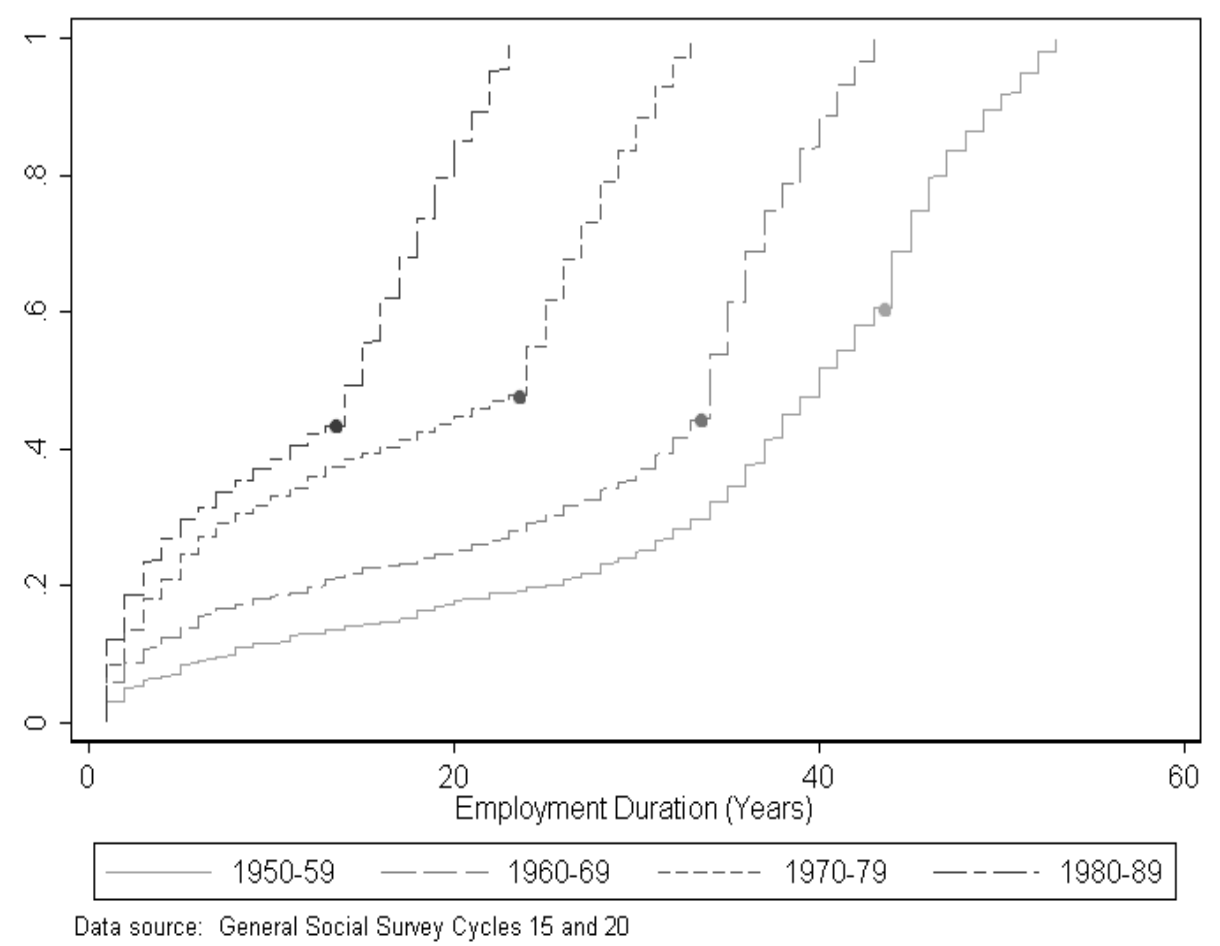

full-time and part-time work status. No clear pattern emerges from this series of tests, signifying that forward telescoping is not a serious concern, at least over that 5 year interval.

\subsection{Results}

In this section the results of the estimation are presented by ten year employment cohort. To determine whether employment spells have declined in length, a ten year groupings of spells which start in a particular decade are compared to one another. This is not an obvious choice as a unit of analysis, as a birth cohort approach would call for a grouping of workers who were born at a particular time. 
However, the same method was recently used by Green and Townsend [29] to construct job cohorts in an evaluation of implicit contracts. To reflect the focus on work rather than workers the cohort grouping uses the employment spell as the unit of analysis. This allows for the same individual to appear multiple times in the same or different cohorts if his employment spells began within or between cohorts. This method, if used on sufficiently fine data, would preclude the possibility of length bias as well as the retention rate approach (although some degree of length bias can enter the decadal cohorts discussed below). More importantly, it ensures the testing regions do not contain any ongoing employment spells. That is, the employment cohort concept ensures that spells beginning in a particular decade always have some minimum and maximum uncensored tenure given the fixed date of the survey.

When comparing empirical CDFs the use of employment cohorts, birth cohorts or even generations yield similar results. To ensure that the results are robust to the cohort selection length, alternate lengths at various intervals were constructed. The results yielded broadly similar conclusions to the ten year employment cohort concept chosen. The cohort length was selected because it allows for an adequate number of observations to occur in the earliest usable cohorts. This is important because there is currently no detailed information available on these groups in the literature. Furthermore, the concept of decades lends itself well to the discussion of the topic at hand.

When performing the finite mixture analysis and dominance testing, the entire distribution of complete employment spells could not be analyzed. This is because there were a number of respondents with ongoing employment spells. When using 
a complete distribution of the data, both uncensored and censored employment spells must be accounted for. Thus, the focus will shift to the number of years that can be tested for a given cohort. That is, for the 1980-89 cohort, observed spells of only up to 12 years can be tested, for the 1970-79 cohort up to 22 testable years exist and so on and so fourth until the 1950-59 cohort where there are 42 testable years. In both the finite mixture analysis and the dominance testing all observed data are accounted for in the following ways: for the mixture analysis the type-specific measures obtained through the decomposition of the distribution of completed spells are weighted by the share of incomplete spells, while for the dominance testing the censored observations are accounted for as mass points in the distributions. These methods of dealing with the censoring are acceptable when the censoring is exogenous, as it is in this case (as the survey date, rather than individual choice, causes the censoring). The incomplete spells were censored using cut-off points that correspond to the 12, 22 and 32 year testing regions.

\subsubsection{Aggregate Data Analysis}

Table 8.6 presents a summary of truncated mean tenures by gender and employment cohort. The patterns appear to show declining tenures for men (over the longer periods) and increasing tenures for women across cohorts. Furthermore, the aggregate patterns of unweighted (which do not account for censoring) and weighted (that account for censoring) means and noise to signal ratios $\left(N S R=\frac{\sigma}{\mu}\right)$ by cohort and gender are examined more closely in Figures 2.2 and 2.3. The graphs of the 
Table 2.6: Mean Employment Durations by Cohort

\begin{tabular}{l|r|rrrr|rrrr}
\hline Max & & \multicolumn{9}{|c}{ Men } & \multicolumn{4}{c}{ Women } \\
Tenure & Cohort & Obs & Obs $^{T}$ & mean & std.dev & Obs & Obs $^{T}$ & mean & std.dev \\
\hline 12 & $1950-59$ & 858 & 106 & 4.122 & 3.203 & 1048 & 574 & 4.529 & 2.767 \\
& $1960-69$ & 1245 & 239 & 3.882 & 2.926 & 1876 & 1040 & 4.35 & 2.794 \\
& $1970-79$ & 2199 & 766 & 3.993 & 2.963 & 3277 & 1866 & 4.638 & 3.066 \\
22 & $1980-89$ & 2872 & 1208 & 3.912 & 3.089 & 4644 & 2983 & 4.660 & 3.063 \\
& $1950-59$ & 858 & 152 & 7.934 & 6.561 & 1048 & 675 & 6.109 & 4.671 \\
& $1960-69$ & 1245 & 332 & 7.259 & 6.167 & 1876 & 1248 & 6.334 & 5.256 \\
32 & $1970-79$ & 2199 & 1036 & 7.183 & 6.142 & 3277 & 2385 & 7.061 & 5.501 \\
& $1950-59$ & 858 & 224 & 14.276 & 10.814 & 1048 & 756 & 8.320 & 7.822 \\
& $1960-69$ & 1245 & 501 & 13.892 & 10.707 & 1876 & 1484 & 9.563 & 8.924 \\
\hline
\end{tabular}

Note: $O b s^{T}=$ abbreviation for truncated observations

weighted measures show the relevance of accounting for censoring in the data as the results of the truncated samples (unweighted measures) are misleading. That is, they show different patterns than the patterns observed in the weighted measures. It should be noted that the value of these weighted means do not have meaning by themselves. Like an index, they are only relevant in comparison with other weighted means in the same category. The graphs of the unweighted measures predict rather stable patterns in mean employment tenures for men by cohort while for women the mean employment duration increases slightly for the latter cohorts. After accounting for censoring a different pattern is observed for men but there seems little change for women. A decrease in the mean employment duration for men can be seen in later cohorts, while for women the mean effects are rather stable across cohorts. The weighted noise to signal charts show a larger reduction in the relative variation for men than for women across cohorts. 
Figure 2.2: Unweighted cohort-specific means and NSR by gender
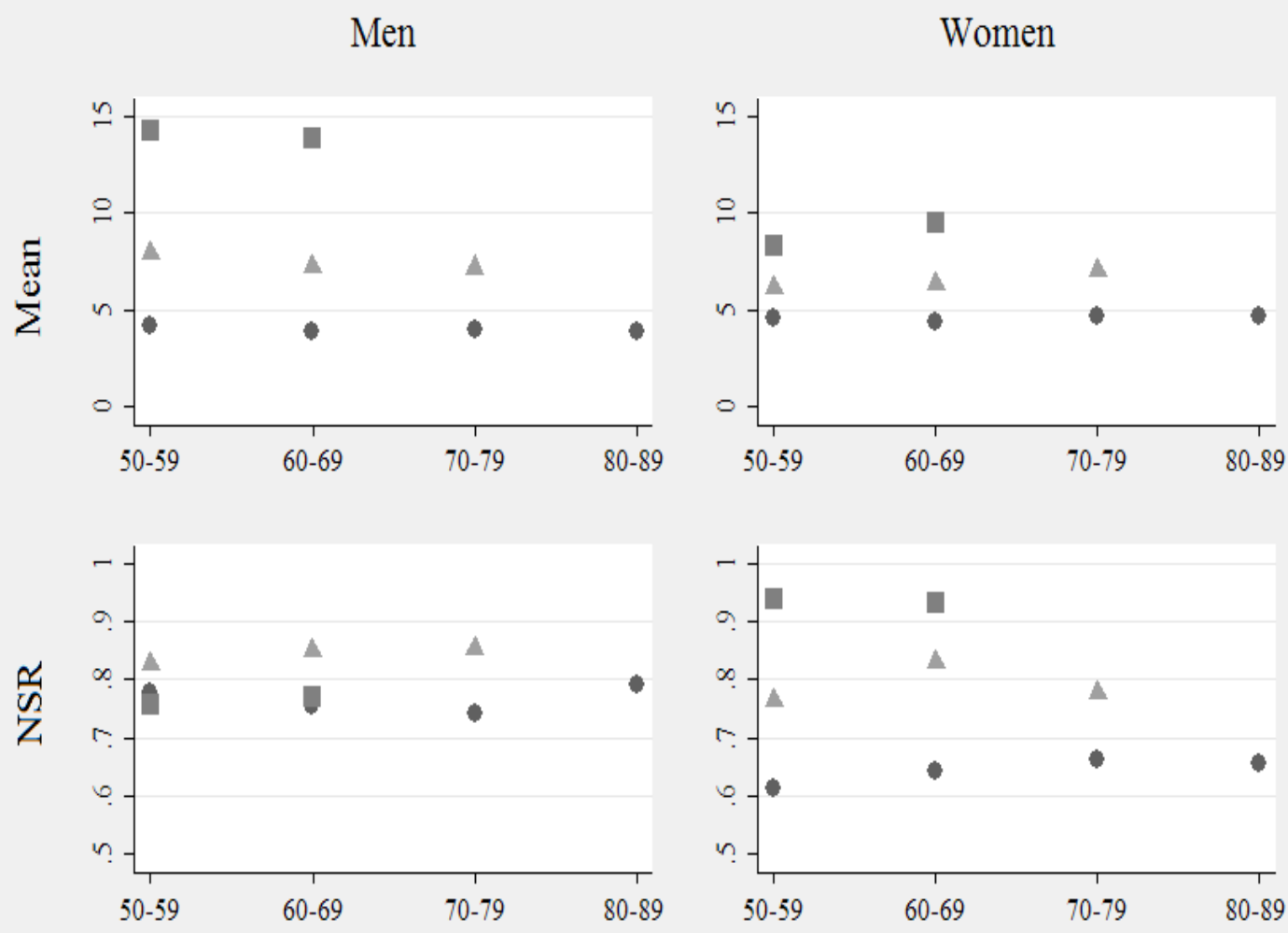

- 12 Year $\quad 22$ Year 32 Year 
Figure 2.3: Weighted cohort-specific means and NSR by gender
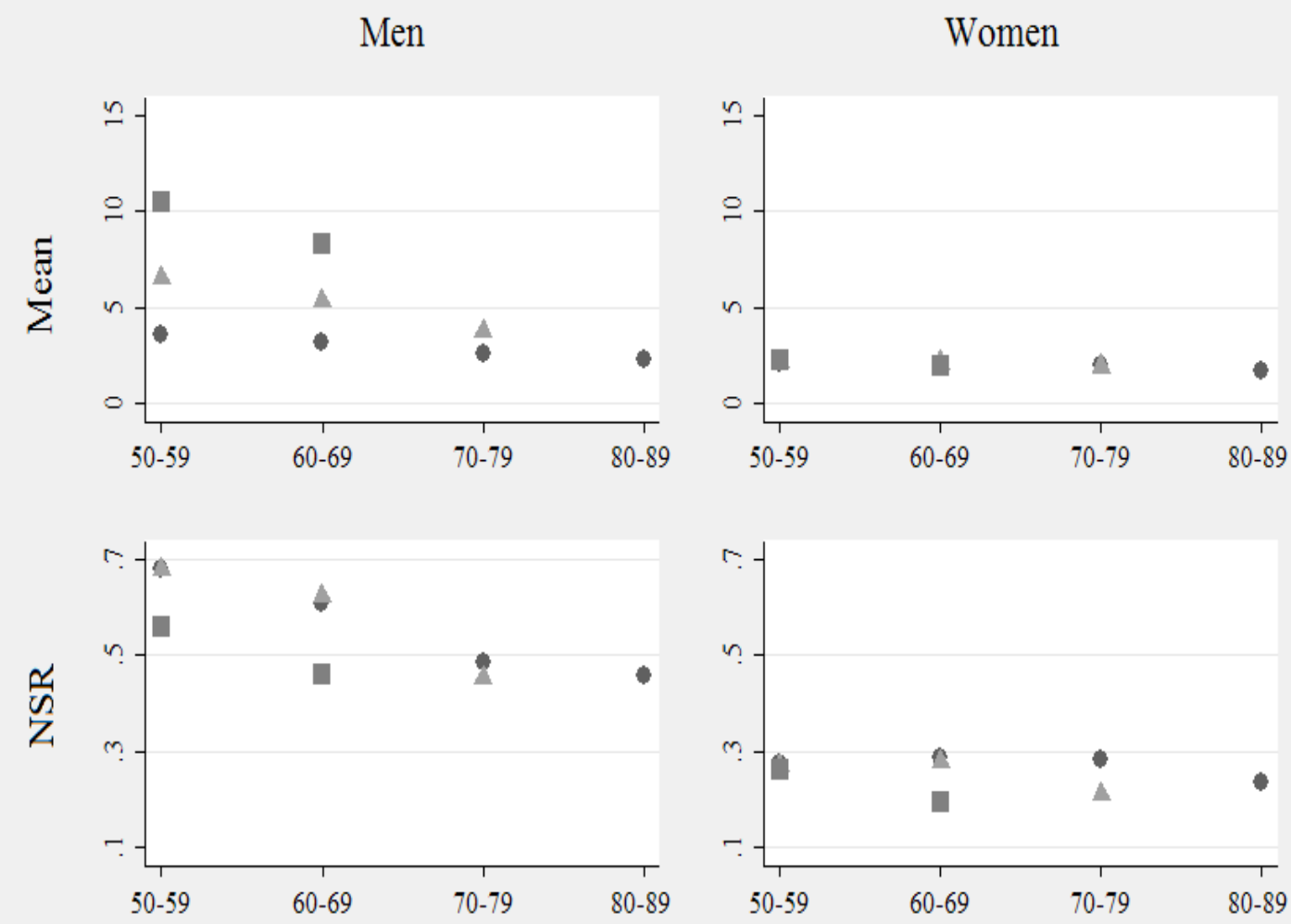

- 12 Year $\quad 22$ Year 32 Year 


\subsubsection{Distribution Analysis}

Kernel density plots show that most of the employment duration distributions by cohort are multimodal. One prominent hump generally occurs near the beginning of the distribution with a second significantly farther out. Figure 2.4 shows an adaptive kernel density plot overlayed with a mixture of log-normal densities for the 1960-69 cohort. The plot identifies that two predominant worker types can be found in the distribution. Furthermore, the distribution can be well approximated by a set of log-normal densities.

Figure 2.4: Adaptive Kernel Density Plot (Total 1960-69 Cohort)

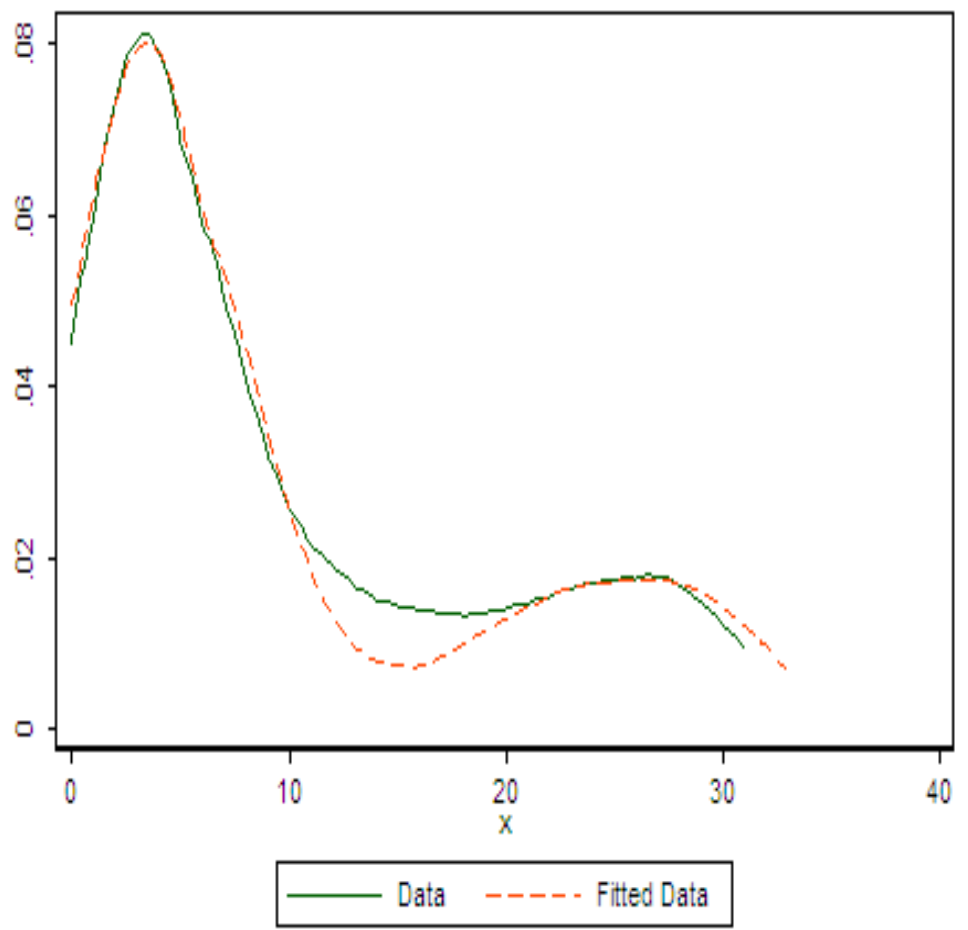




\subsubsection{Identifying Worker Types}

Worker types were identified using finite mixture decomposition for various truncated portions of the distribution. Operationally, worker types are identified by their contribution to the mixture of log-normal distributions which forms the total employment duration distribution. Each type of worker has their own share of the total distribution, showing how common they are and have group-specific mean durations describing their average tenure. The standard deviation is presented to show the breadth to the variation within the group but has no immediate interpretation on worker types. Detailed information about the proportions of different types, the type-specific means and type-specific measures of variation by maximum tenure, cohort and gender are found in Tables 2.7 through 2.12. 


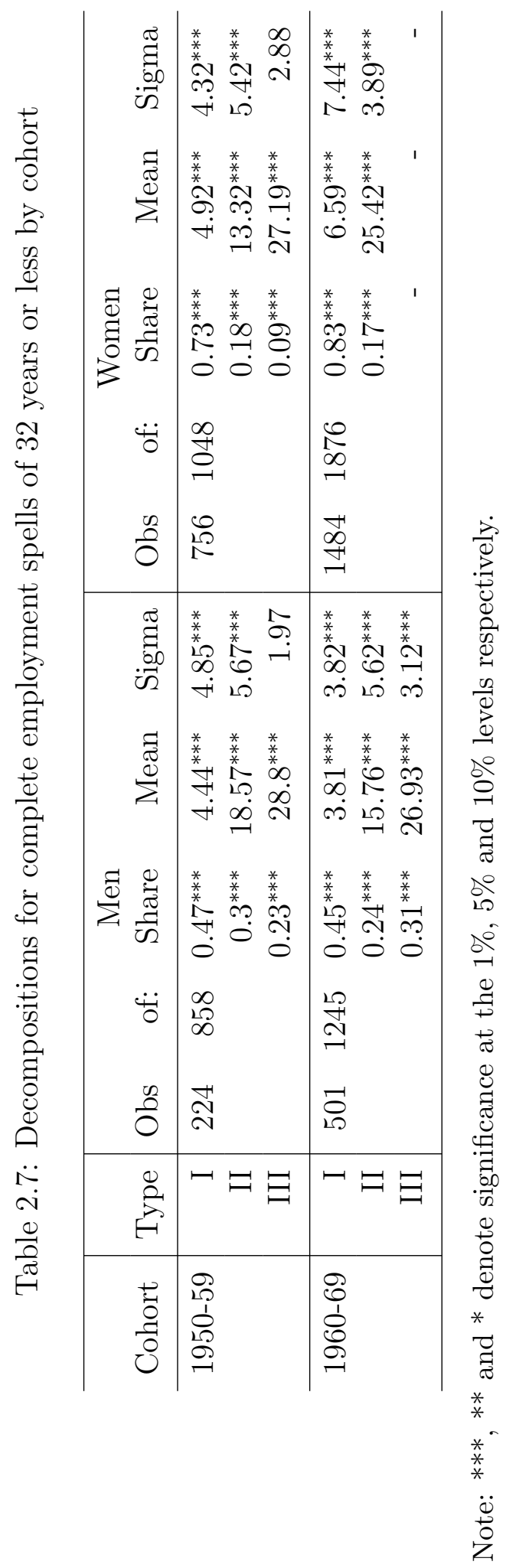


In Table 2.7 the decomposition results for cohorts with durations of at most 32 years are examined. The durations presented are for the 1950-59 cohort and the 1960-69 cohort. The observations identified show the number of uncensored spells with the number in the subsequent column denoting the number of censored spells, with the share of denoting how many of the uncensored observations comprise the type of worker identified. Before comparing worker types across cohorts it is instructive to examine the results from a specific case, say that of men who began working in the 1950s. Here, three heterogeneous worker types were identified. The first, a short-tenured worker type (with a mean duration of fewer than ten years), represented $47 \%$ of completed employment spells in that cohort and had a mean duration of 4.44 years. The second, a medium tenured worker type (with an employment length at least ten years and below twenty years) represented $30 \%$ of completed spells and had a mean employment tenure of 18.57 years. The third and final worker type, a long tenured worker (having employment durations of twenty years or more) represented the remaining $23 \%$ of completed spells and had a mean tenure of 26.93 years. These worker types, along with their individual measures of dispersion, compose the truncated aggregate employment duration distribution (which accounts for only $26 \%$ of employment spells when considering the $74 \%$ of ongoing spells reported for this cohort in Table 2.8).

When considering the truncated distributions, the proportion of long-term employment duration increased between the 1950s and 1960s cohorts for both men and women. The share of shorter-term spells declined slightly for men but increased for women across the two cohorts (although the change in the number of worker types 
Table 2.8: Shares for ongoing employment spells of 33 years or more by cohort

\begin{tabular}{l|rrr|rrr}
\hline Cohort & \multicolumn{3}{|c|}{$\begin{array}{r}\text { Men } \\
\text { of: }\end{array}$} & Share & Obs. & Women \\
\hline $1950-59$ & 634 & 858 & 0.74 & 292 & 1048 & 0.28 \\
$1960-69$ & 744 & 1245 & 0.59 & 392 & 1876 & 0.21 \\
\hline
\end{tabular}

makes interpretation problematic for women). Similarly, the mean duration of the shortest employment spells fell for men but increased for women. For example, the share of type I men decreased from $47 \%$ to $45 \%$ and their mean durations fell from 4.44 to 3.81 years of continuous employment between the 1950-59 and 1960-69 cohorts. This indicates that fewer workers in the distribution were employed for a short duration, but that the duration also declined. Hence, shorter work periods occurred in the latter cohort (a mean length decline of over 15\%) but for a smaller proportion of men ( $4 \%$ fewer).

The degree of heterogeneity, as represented by the number of types of workers stayed constant for men between the 1950s and 1960s cohorts. For women the degree of heterogeneity declined in the 1960s cohort. On the whole, women have a much larger share of short-tenured (under 10 years) spells than do men. In both cohorts at least $70 \%$ of women had completed spells with a mean duration below 10 years. For men, fewer than half of the 1950s and 1960s cohorts showed a mean duration below 10 years.

In Table 2.8 the shares of ongoing spells for the two cohorts described above are shown. The results show that for both men and women the share of workers with ongoing tenures extending beyond 32 years decreased for those beginning work 
in the 1960s compared to those who began in the 1950s. Indeed, for women, this decrease of censored spells offsets almost all the apparent gain in the share of longterm employment described above. 


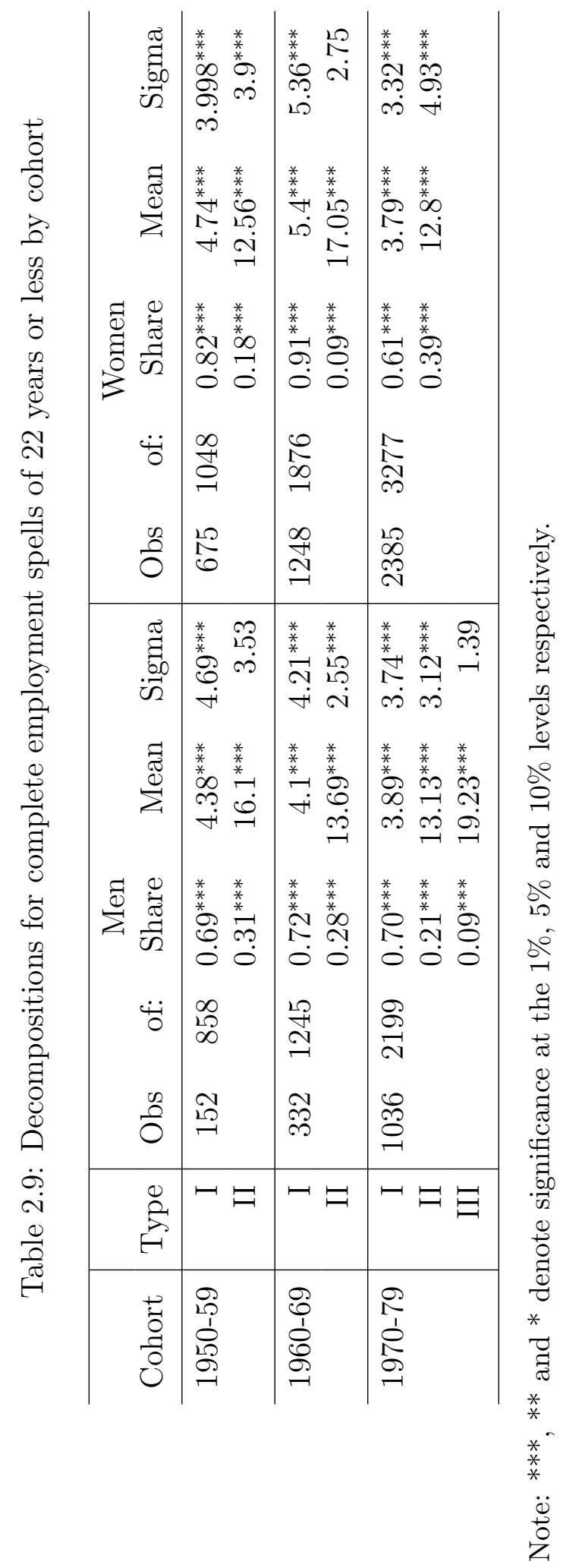


Table 2.10: Shares for ongoing employment spells of 23 years or more by cohort

\begin{tabular}{|c|c|c|c|c|c|c|}
\hline \multirow[b]{2}{*}{ Cohort } & \multicolumn{3}{|c|}{ Men } & \multicolumn{3}{|c|}{ Women } \\
\hline & Obs & of: & Share & Obs & of: & Share \\
\hline $1950-59$ & 706 & 858 & 0.82 & 373 & 1048 & 0.35 \\
\hline 1960-69 & 913 & 1245 & 0.73 & 628 & 1876 & 0.33 \\
\hline 1970-79 & 1163 & 2199 & 0.53 & 892 & 3277 & 0.27 \\
\hline
\end{tabular}

In Table 2.9 the decomposition results for the 22 year testing region of the truncated distributions are presented for all but the 1980-89 cohort. The proportion of medium-term worker types (those whose mean duration is 10 to under 20 years) stay somewhat constant for men. However, the share of long-term worker types, as shown by the censored portion of the distribution in 2.10 , declines steadily across cohorts. Furthermore, another worker type emerges for the 1970-79 cohort, indicating a rise in heterogeneity. For women, the mean tenures and proportions change in no discernible pattern and the number of types remains constant at two. However, the censored spells for women in Table 2.10 show a decline in long-tenure employment. Interestingly, there is a relatively large rise in the share of women employed short-term in the 1960-69 cohort but that share decreases dramatically for the 1970-79 cohort. Furthermore, the share of ongoing spells for women are similar for the 1950-59 and 1960-69 cohorts, but decrease noticeably for the 1970-79 cohort. 


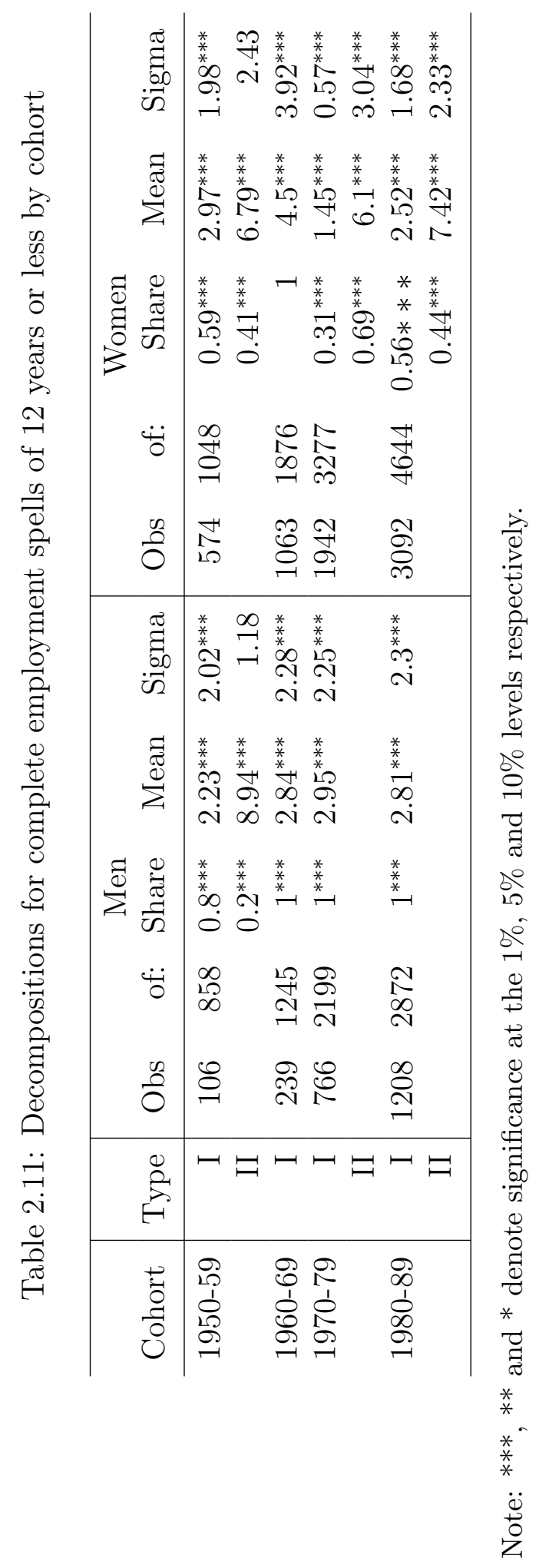


Table 2.12: Shares for ongoing employment spells of 13 years or more by cohort

\begin{tabular}{l|rrr|rrr}
\hline Cohort & Obs & Men & Share & Obs & Women & Share \\
\hline $1950-59$ & 752 & 858 & 0.87 & 474 & 1048 & 0.45 \\
\hline $1960-69$ & 1006 & 1245 & 0.81 & 836 & 1876 & 0.44 \\
\hline $1970-79$ & 1433 & 2199 & 0.65 & 1411 & 3277 & 0.43 \\
\hline $1980-89$ & 1664 & 2872 & 0.58 & 1661 & 4644 & 0.36 \\
\hline
\end{tabular}

In Table 2.11 the decomposition results obtained from all cohorts up until 1980-89 are shown. Here the durations are at most 12 years in length in order to remove all ongoing spells. The analysis reveals that an increase in the proportion of men who were employed for a short period increased for all the cohorts starting with the 1960s. At that point, the number of men's worker types decrease from two to one for all ensuing cohorts. Furthermore, Table 2.12 which shows the share of ongoing spells, indicates a steep decline in medium to long-term spells for men after the 1960s cohort. For women, the patterns in Table 2.11 are not as clear, with the shares and mean tenures of the 1950s and 1980s cohorts looking remarkably similar. In the 1960 s cohort it should be noted that only 1 type emerged. Moreover, the shares of ongoing spells in table 2.12 show almost no change until the 1970s cohort, after which they decline substantially. This change may be related to the enhanced maternity provisions in the unemployment insurance program which were instituted in the early 1970s. These results are largely consistent with the 22 and 32 year results.

In summary, it has been shown that changes in proportions among the com- 
pleted employment spells have occurred. However, the changes among the types have not shown any unambiguous movement towards shorter spell lengths. From Tables 2.8, 2.10 and 2.12 it can be seen that many employment spells were still ongoing at the time of the survey. Among men, these proportions were quite high. Incorporating these ongoing spells into the analysis more formally will permit a test of the overall distribution. This will show whether the overall distribution of employment durations has changed over the latter half of the twentieth century. To capture this effect the complete distribution is examined by accounting for censoring in the decomposition and in the test statistics that will be employed.

The following discussion summarizes the results of the above decomposition using two different measures: the type-specific mean and the type-specific weighted noise to signal ratio $\left(N S_{i}=p_{i} \times \frac{\sigma_{i}}{\mu_{i}}\right.$, with $i=1,2 \ldots, K$, where $K$ is the number of types that are identified and $p_{i}$ is the proportion of each type). To make the interpretation of the results clearer additional plots are provided for these measures. An NS index is introduced to provide information about the relative variation within a given type. Figures 2.5 and 2.6 show these type-specific mean and type-specific NS indices respectively. The charts show that while the mean employment durations and the NS index decreases slightly across cohorts for men, for women there is little change. 
Figure 2.5: Type-specific means by cohort and gender

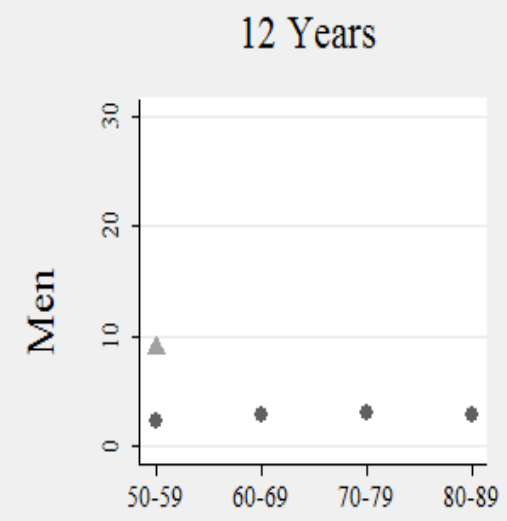

22 Years

32 Years
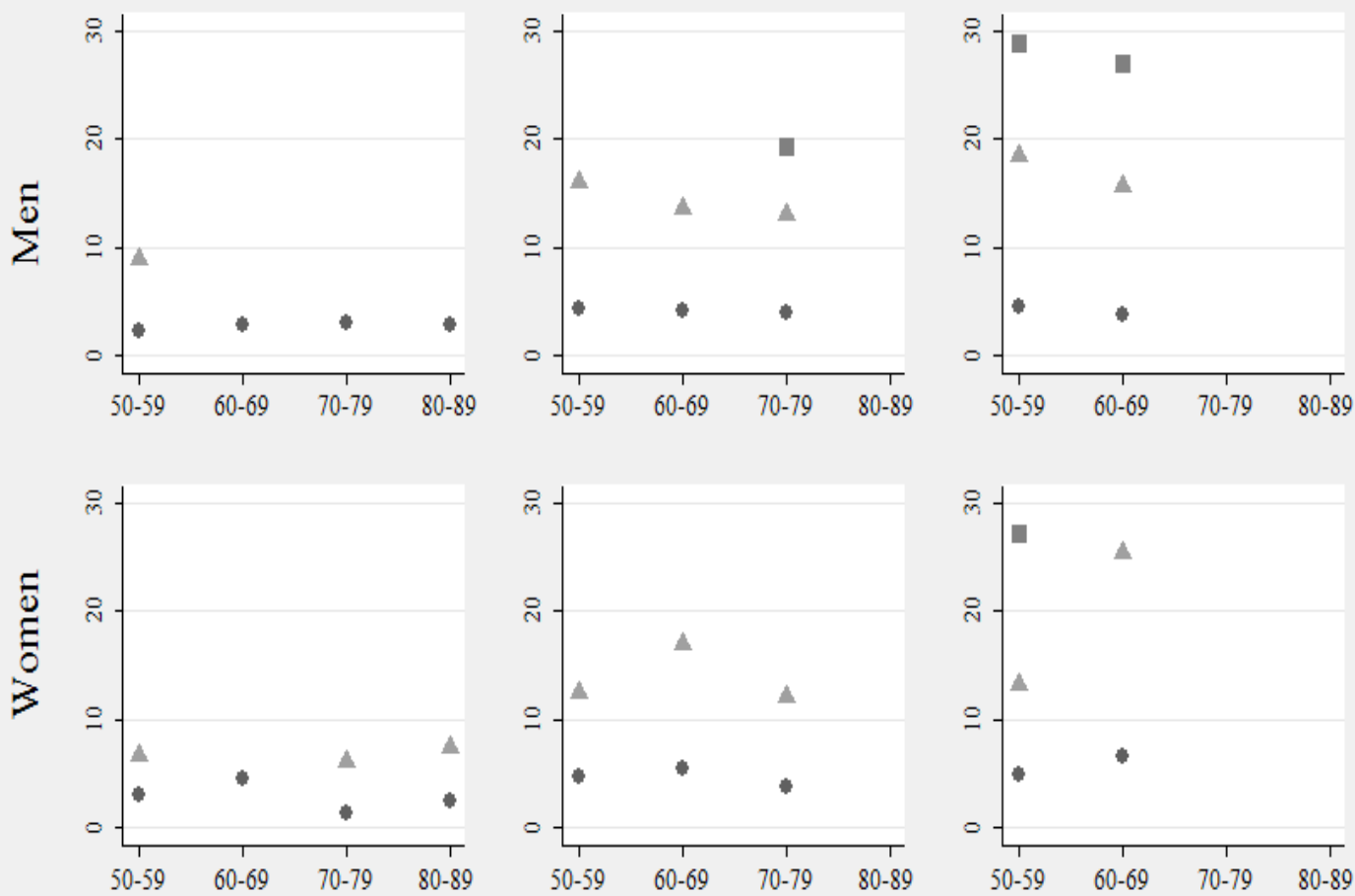

- Type I $\triangle$ Type II $\square$ Type III 
Figure 2.6: Type-specific SNR by cohort and gender

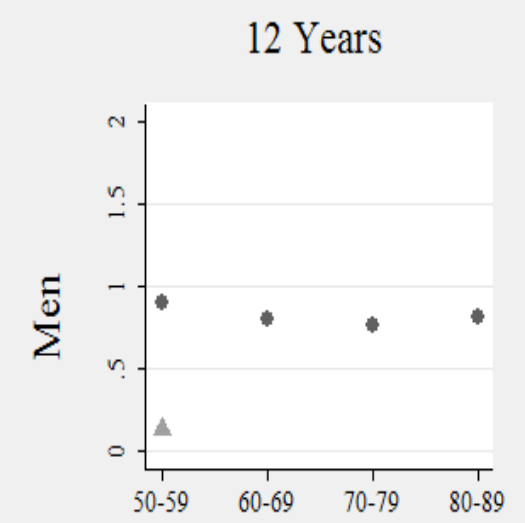

22 Years
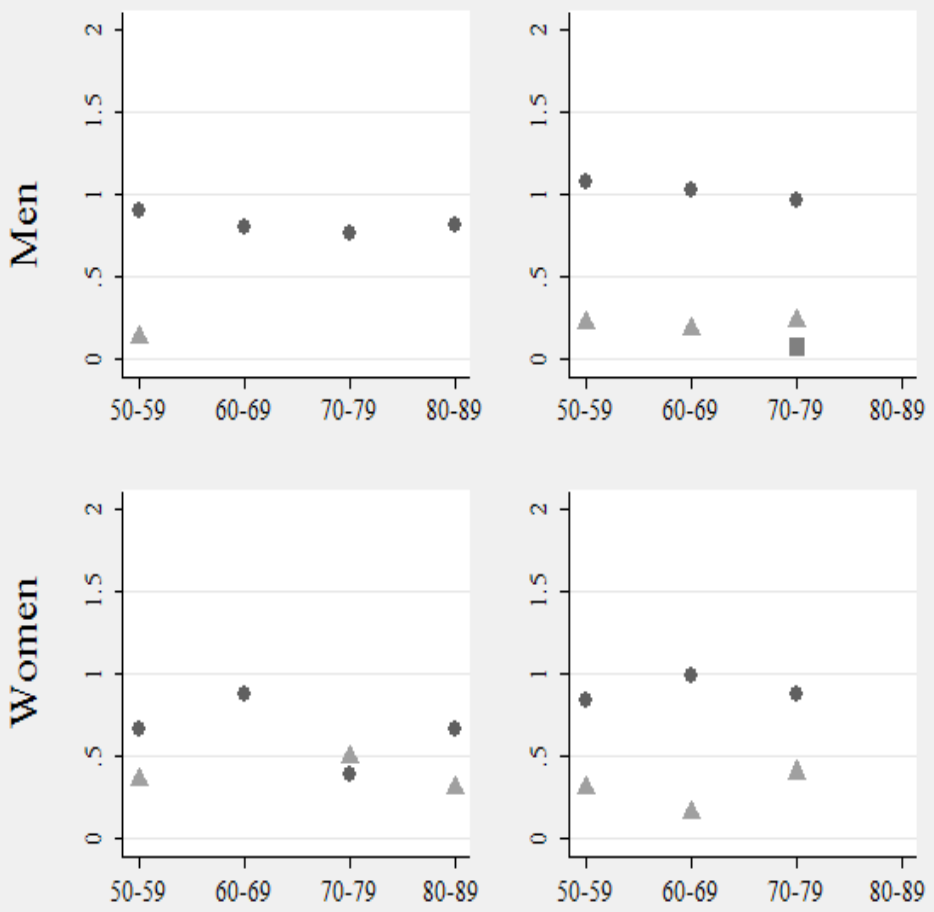

32 Years
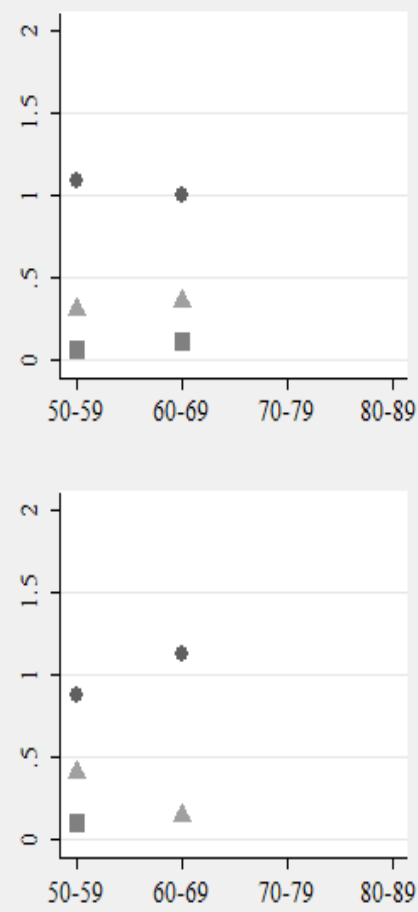

Type I $\Delta$ Type II $\quad$ Type III

\subsubsection{Testing Employment Duration}

Here, the total employment duration distributions by cohort are used to test the hypothesis of decreasing employment tenure at all points along the distribution. Different testing regions (12, 22 and 32 years) were considered to employ stochastic dominance tests across successive employment cohorts. To ensure validity over the 
entire distribution, all continuing jobs were accounted for as a censoring mass. This was done to appropriately weight downwards the right side of each distribution at the censoring point.

To understand the concept being employed, it is useful to look at the empirical CDFs of all employment durations for men, as shown in Figure 2.1. The earliest cohorts display smoother transitions across the entire distribution than the later cohorts. This is because as the cohorts advance, the last ten years of each distribution begin to slope sharply upwards after points along each line (the points are inserted at the 13th, 23rd, 33rd and 43rd year censoring points of the 1980s, 1970s, 1960s and 1950s distributions respectively). This upward slope is the result of a large number of incomplete ongoing durations. These censored portions of each distribution will not be tested but are necessary for an accurate comparison of completed spells. An increasing share of shorter term employment spells can clearly be seen in the distribution of men's tenures across cohorts. But the most interesting result is the width of the gap between the 1960s and 1970s cohorts. That is, those whose employment began in the 1970s appear to have significantly shorter durations across the distribution than those whose employment began in the 1960s. As described in the data section, there is no clearly identifiable increase in recall errors during that period, hence the decline is unlikely to be due these errors. Unidentifiable recall errors may still be a concern, but they would have to fall non-monotonically across time to create such an outsized gap between the 1960s and 1970s cohorts (which does not seem likely if recall errors are time dependent in a systematic fashion).

For men, tests of stochastic dominance are shown in Table 2.13. The table 
Table 2.13: Stochastic Dominance Tests for Employment Duration by Cohort: Men

\begin{tabular}{|c|c|c|c|c|}
\hline & Test Period & Cohort 1 & Cohort 2 & Cohort 3 \\
\hline Cohort 1 1950-59 & - & & & \\
\hline Cohort 2 1960-69 & 33 Years & $\begin{array}{r}\text { Order } 1 \\
(\mathrm{p}<0.01)\end{array}$ & & \\
\hline Cohort 2 1960-69 & 23 Years & $\begin{array}{r}\text { Order } 1 \\
(\mathrm{p}<0.01)\end{array}$ & & \\
\hline Cohort 2 1960-69 & 13 Years & $\begin{array}{r}\text { Order } 1 \\
(\mathrm{p}<0.01)\end{array}$ & & \\
\hline Cohort 3 1970-79 & 23 Years & $\begin{array}{r}\text { Order } 1 \\
(\mathrm{p}<0.01)\end{array}$ & $\begin{array}{r}\text { Order } 2 \\
(\mathrm{p}<0.01)\end{array}$ & \\
\hline Cohort 3 1970-79 & 13 Years & $\begin{array}{r}\text { Order 1 } \\
(\mathrm{p}<0.01)\end{array}$ & $\begin{array}{r}\text { Order } 2 \\
(\mathrm{p}<0.01)\end{array}$ & \\
\hline Cohort 4 1980-89 & 13 Years & $\begin{array}{r}\text { Order } 1 \\
(\mathrm{p}<0.01)\end{array}$ & $\begin{array}{r}\text { Order } 1 \\
(\mathrm{p}<0.01)\end{array}$ & $\begin{array}{r}\text { Order } 1 \\
(\mathrm{p}<0.01)\end{array}$ \\
\hline
\end{tabular}

Note: p-values are in parentheses.

should be read along the columns. Considering the first column, the table reads that Cohort 1 FOSD dominates Cohort 2 for all three testable periods considered in the analysis, Cohort 1 FOSD dominates Cohort 3 for the last two testable periods and Cohort 1 FOSD Cohort 4 for the last testable period. The results underscore that there has been a shift over time to shorter average employment durations. The results clearly show the distributions of earlier cohorts dominating latter cohorts over all testable intervals. In general, for men, each cohort dominates its successor.

To verify this, statistical tests are performed at the average distance between each cohort. Table 2.14 presents the statistical results of the average differences in men's employment durations by cohort. The table should read along the columns. Considering the column labeled Cohort 1, the table reads that Cohort 1 has a higher 
Table 2.14: Mean test results for $H_{0}: \Delta \bar{Y}_{\text {Cohort }} \leq 0$ weighted employment durations by cohort for men

\begin{tabular}{|c|c|c|c|c|}
\hline & Test Period & Cohort 1 & Cohort 2 & Cohort 3 \\
\hline Cohort 1 1950-59 & - & & & \\
\hline Cohort 2 1960-69 & 33 Years & $\begin{array}{r}\text { Reject } \\
(\mathrm{p}=0.000)\end{array}$ & & \\
\hline Cohort 2 1960-69 & 23 Years & $\begin{array}{r}\text { Reject } \\
(\mathrm{p}=0.000)\end{array}$ & & \\
\hline Cohort 2 1960-69 & 13 Years & $\begin{array}{r}\text { Reject } \\
(\mathrm{p}=0.000)\end{array}$ & & \\
\hline Cohort 3 1970-79 & 23 Years & $\begin{array}{r}\text { Reject } \\
(\mathrm{p}=0.000)\end{array}$ & $\begin{array}{r}\text { Reject } \\
(\mathrm{p}=0.000)\end{array}$ & \\
\hline Cohort 3 1970-79 & 13 Years & $\begin{array}{r}\text { Reject } \\
(\mathrm{p}=0.000)\end{array}$ & $\begin{array}{r}\text { Reject } \\
(\mathrm{p}=0.000)\end{array}$ & \\
\hline Cohort 4 1980-89 & 13 Years & $\begin{array}{r}\text { Reject } \\
(\mathrm{p}=0.000)\end{array}$ & $\begin{array}{r}\text { Reject } \\
(\mathrm{p}=0.000)\end{array}$ & $\begin{array}{r}\text { Reject } \\
(\mathrm{p}=0.000)\end{array}$ \\
\hline
\end{tabular}

Notes: $\Delta \bar{Y}_{\text {Cohort }}=\bar{Y}_{\text {current-cohort }}-\bar{Y}_{\text {preceding-cohort }}$, p-values are in parentheses.

weighted average employment duration than Cohort 2 for all the three testable periods considered in the analysis. Cohort 1 has a higher weighted average employment duration than Cohort 3 for the last two testable periods and Cohort 1 has a higher weighted average employment duration than Cohort 4 for the last testable period. These results show that the average weighted duration for any earlier cohort is larger than for any subsequent cohorts in the case of men.

For women the empirical CDFs in Figure 2.7 appear to have far less dramatic differences than those seen in men's durations. Most noteworthy is the fact that a large share of employment spells, no matter the decade in which they began, are shorter in length than those of men.

More formally, the results of the stochastic dominance tests for the employment 
Figure 2.7: Empirical CDF - women by cohort

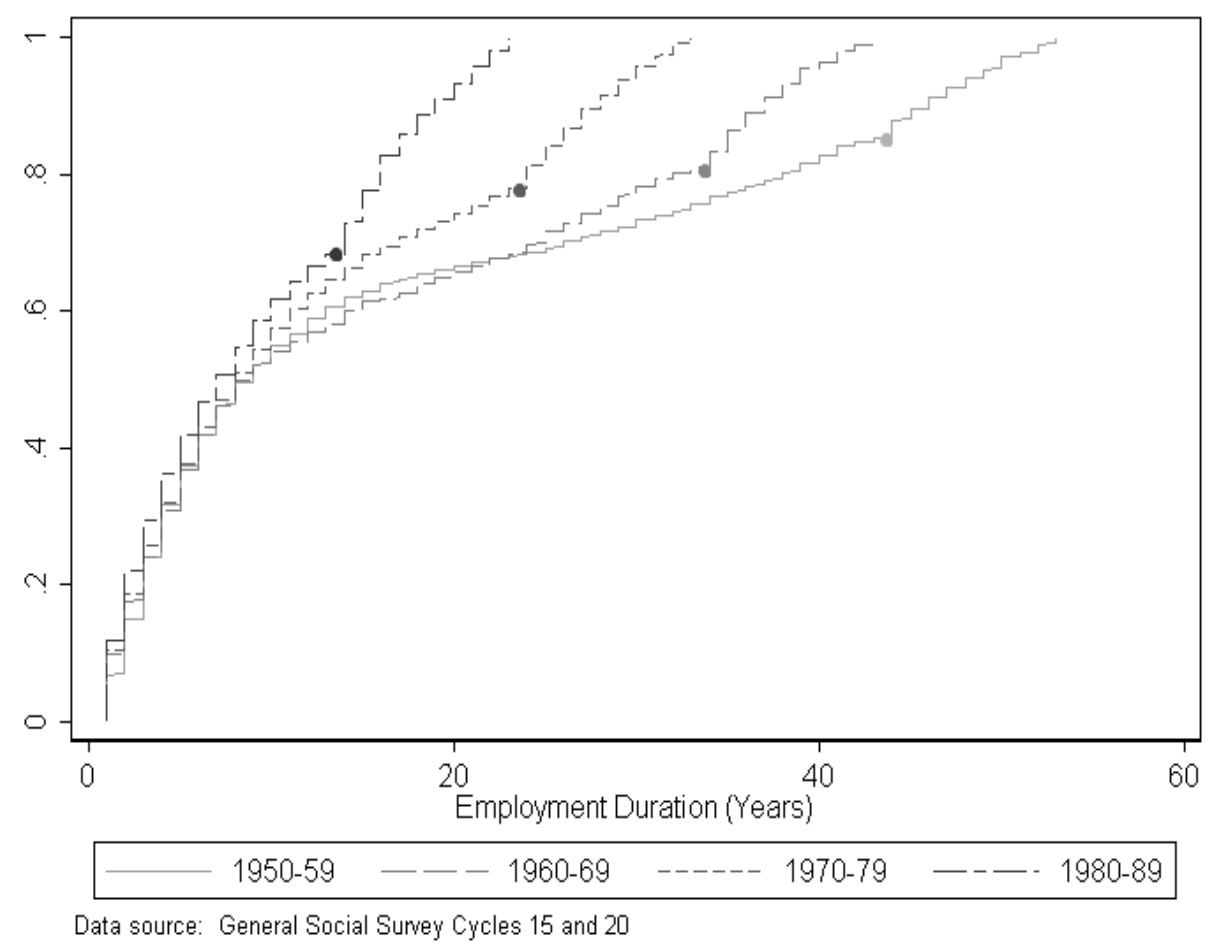

durations of women, seen in Table 2.15, yield different results than those of men. As above, the table should read along the columns. Considering the first column, the table reads that Cohort 1 SOSD dominates Cohort 2 for all three testable periods considered in the analysis, Cohort 1 FOSD dominates Cohort 3 for the last two testable periods and Cohort 1 FOSD Cohort 4 for the last testable period. The results do not show an unambiguous trend across cohorts. For shorter testing regions equality between cohorts cannot be rejected, except in the case of the 1980-89 cohort which is SOSD by all other cohorts. For extended testing regions equality is mostly rejected in favor of SOSD. Hence, there are some indications that women who began work in the 1980s were more likely to have shorter spells than women who began working in previous decades. This could be the result of more generous maternity 
Table 2.15: Stochastic Dominance Test Results for Employment Durations by Cohort: Women

\begin{tabular}{|c|c|c|c|c|}
\hline & Test Period & Cohort 1 & Cohort 2 & Cohort 3 \\
\hline Cohort 1 1950-59 & - & & & \\
\hline Cohort 2 1960-69 & 32 Years & $\begin{array}{r}\text { Order } 2 \\
(\mathrm{p}<0.01)\end{array}$ & & \\
\hline Cohort 2 1960-69 & 22 Years & $\begin{array}{r}\text { Order } 2 \\
(0.01<\mathrm{p}<0.05)\end{array}$ & & \\
\hline Cohort 2 1960-69 & 12 Years & $\begin{array}{l}\text { Equality } \\
(\mathrm{p}>0.01)\end{array}$ & & \\
\hline Cohort 3 1970-79 & 22 Years & $\begin{array}{r}\text { Order } 2 \\
(\mathrm{p}<0.01)\end{array}$ & $\begin{array}{r}\text { Order } 2 \\
(\mathrm{p}<0.01)\end{array}$ & \\
\hline Cohort 3 1970-79 & 12 Years & $\begin{array}{l}\text { Equality } \\
(\mathrm{p}>0.01)\end{array}$ & $\begin{array}{l}\text { Equality } \\
(\mathrm{p}>0.01)\end{array}$ & \\
\hline Cohort 4 1980-89 & 12 Years & $\begin{array}{r}\text { Order } 2 \\
(0.01<\mathrm{p}<0.05)\end{array}$ & $\begin{array}{r}\text { Order } 2 \\
(\mathrm{p}<0.01)\end{array}$ & $\begin{array}{r}\text { Order } 2 \\
(\mathrm{p}<0.01)\end{array}$ \\
\hline
\end{tabular}

Note: p-values are in parentheses.

leave provisions in the UI system or because of the 1990s recession cutting short their tenures. Hence, for women there were some, but not necessarily secular, declines in employment tenures. This long-term divergence between the experience of women and men was also documented in the U.S. by Farber [10] who shows that increased labour market participation had much to do with keeping women's tenures steady while those of men declined.

Table 2.16 shows a test of the average changes in women's durations across cohorts. The statistical results of the average differences of employment durations for women show that differences are the same for shorter spells but differ from zero as the spells increase in length. Despite the statistical significance of the results, 
Table 2.16: Mean test results for $H_{0}: \Delta \bar{Y}_{\text {Cohort }} \leq 0$ weighted employment durations by cohort for women

\begin{tabular}{|c|c|c|c|c|}
\hline & Test Period & Cohort 1 & Cohort 2 & Cohort 3 \\
\hline Cohort 1 1950-59 & - & & & \\
\hline Cohort 2 1960-69 & 32 Years & $\begin{array}{r}\text { Reject } \\
(\mathrm{p}=0.000)\end{array}$ & & \\
\hline Cohort 2 1960-69 & 22 Years & $\begin{array}{r}\text { Do not reject } \\
(\mathrm{p}=0.208)\end{array}$ & & \\
\hline Cohort 2 1960-69 & 12 Years & $\begin{array}{l}\text { Do not reject } \\
\quad(\mathrm{p}=0.110)\end{array}$ & & \\
\hline Cohort 3 1970-79 & 22 Years & $\begin{array}{r}\text { Reject } \\
(\mathrm{p}=0.000)\end{array}$ & $\begin{array}{r}\text { Reject } \\
(\mathrm{p}=0.000)\end{array}$ & \\
\hline Cohort 3 1970-79 & 12 Years & $\begin{array}{l}\text { Do not reject } \\
\left(\mathrm{p}=1.000^{*}\right)\end{array}$ & $\begin{array}{l}\text { Do not reject } \\
\left(\mathrm{p}=0.941^{*}\right)\end{array}$ & \\
\hline Cohort 4 1980-89 & 12 Years & $\begin{array}{l}\text { Do not reject } \\
\quad(\mathrm{p}=0.132)\end{array}$ & $\begin{array}{r}\text { Reject } \\
(\mathrm{p}=0.000)\end{array}$ & $\begin{array}{r}\text { Reject } \\
(\mathrm{p}=0.000)\end{array}$ \\
\hline
\end{tabular}

Notes: $\Delta \bar{Y}_{\text {Cohort }}=\bar{Y}_{\text {current-cohort }}-\bar{Y}_{\text {preceding-cohort }}$, p-values are in parentheses.

${ }^{*}$ Means acceptance of $H_{0}: \Delta \bar{Y}_{\text {Cohort }} \leq 0$, but rejection of $H_{0}: \Delta \bar{Y}_{\text {Cohort }} \geq 0$.

the magnitude of the changes for women are much smaller than those for men.

\subsection{Conclusions}

Evidence was presented that over the latter half of the twentieth century employment tenures declined substantially for men, while for women the results were mixed. Using distribution analysis it was shown that worker heterogeneity had not increased or decreased substantially across cohorts. While shifts in proportions and changes in type-specific means may have played some small part, the decline of long-term employment played the largest part. 
Tests of stochastic dominance on successive employment cohorts starting from the early 1950s confirm that the distributions of completed employment spells have changed. Distributions have shifted towards an increasing concentration of shorterterm employment spells among men while for women the results were more mixed. The largest shift in distributions occurred between those who began work in the 1960s and those who began in the 1970s, perhaps as a result of increasingly generous unemployment insurance coverage, or the often mentioned subsequent breakdown of employer-employee relationships in the 1980s and 1990s.

The reasons for the decline in men's employment durations cannot be identified using nonparametric methods. However, a secular decline in employment durations for men is easily discernible. Moreover, because of the relative stability of women's distributions it can be inferred that the effects driving the decline in employment tenures affected men to a greater extent than they did women. However, other authors have shown that increasing labour market participation on the part of women has likely offset such declines. In the case of men, the decline of the traditionally male-dominated goods producing sector over the last quarter of the twentieth century likely played a significant role. Moreover, the challenging labour market conditions associated with 1980s and 1990s recessions made it likely that those who began working in the 1970s and 1980s may have faced more prolonged bouts of unemployment in their careers than those from preceding cohorts. These factors are all likely to have contributed to the decreasing employment tenures for men over this period.

Although the use of retrospective data introduces some uncertainty into the 
results, the results generally match the existing literature. Moreover, the results conform to the popular consensus of a decline in employment tenure for those who began working before the 1970s, where most studies have not focused. The use of this data provides evidence towards the resolution of a discrepancy in the literature that could not otherwise have been uncovered with other data sources which do not provide as long a retrospective time frame.

In the next chapter the focus will be on individuals rather than jobs or employment cohorts. With this perspective, some insight can be gained on the factors that make a worker move away from or stay in an employment relationship. Moreover an examination of how these factors have evolved over time will be undertaken. 


\section{Chapter 3: First Employment Spells by Birth Cohort}

\subsection{Overview}

In the preceding chapter it was shown that employment stability has decreased over succeeding cohorts, particularly over the last quarter of the twentieth century. As shown in that chapter, the North American evidence on the topic is mixed and criticism is often leveled at weakness in the data. In order to further examine this issue, this chapter will focus on the first employment tenure of workers. Data from both the 15th and 20th cycles of the Canadian General Social Survey (GSS) will be used to analyze the first employment spells of individuals by birth cohort. This data is useful because it can reasonably cover over fifty years of history and can readily generate five ten-year birth cohorts (1930-1939, 1940-1949, 1950-59 1960-1969, and 1970-1979) for comparison. To emphasize the differences between the employment spells found in the GSS and the job spells commonly used in the literature, a comparison with the Canadian Labour Force Survey (LFS) will be performed. Using a semiparametric hazard model, it can be inferred that socio-demographic factors, likely stemming from changing social institutions, contribute to the declines in first employment tenures over the latter half of the twentieth century.

In Chapter 2 the key literature on job stability in North America was reviewed. 
Here a condensed summary of the overarching results will be summarized with respect to where the literature stood on the topic of stability. Following Hall [1], who showed that a significant number of individuals would be in lifetime jobs over the course of their working life, there was some degree of disagreement about stability in the U.S. A number of authors, prominently among them Diebold et al. [2], Farber [3] and Jaeger and Stevens [5], found that jobs remained broadly stable between the 1970s and early 1990s. Conversely, Swinnerton and Wial [6], Ureta [27] and Rose [7] showed that there had been some declines in stability over the 1980s. More recently, Farber [10] using a birth-cohort approach found an increase in short-tenure positions and declines in long-term employment relationships. In particular, Farber's results indicate that mean employment tenure for men has deteriorated by 50 percent after controlling for education between the 1914 and the 1975 birth cohorts. For women the declines were smaller. However, again, it should be noted that the U.S. CPS data suffers from low frequency questionnaires and changes in survey methods that make it difficult to distinguish secular from cyclical changes in job stability.

In the Canadian context, the literature on job stability has largely shown that job tenures have not experienced a secular decline between 1976 and 2000, with evidence for increasing stability after the 1990s. This was largely the case in Green and Riddell [11], Picot, Heisz, and Nakamura [12] and Heisz [4]. The last of these papers, using retention rates obtained from LFS data and existing results form the CPS, showed that there was no period-long drop in Canadian job stability over the 1976 to 2001 period while in the U.S. there were some small declines [4]. The newest in this line of studies, Brochu [14], updated the results of Heisz into the 2000s 
and found consistent increases in job stability, partially stemming from increases in the average age of workers, the increase in womens labour force participation and rising levels of education after the 1990s. Ignaczak and Voia [30] found evidence of decreasing employment tenures for men, over the second half of the twentieth century without providing evidence for the causes of these declines. However, an earlier study by Christofides and McKenna [31], using data from the 1986-87 and 1988-90 Labour Market Activity Study (LMAS), found that older, married heads of households with children, white-collar workers, and individuals in full-time, unionized jobs with pension plans were less likely to leave employment.

It should be noted that one reason to be concerned with first employment spells is that employment tenure displays a high level of persistence. Because of this it is important to understand the initial employment prospects of individuals. Furthermore, looking back over a longer period helps us to identify the differences in stability that may not be apparent in shorter-term analysis. The rest of this chapter is structured in the following way, section 3.2 discusses the data and compares job tenures to employment tenures while section 3.3 lays out the empirical methodology and results. Finally, section 3.4 concludes.

\subsection{Data}

This section is laid out into two parts. The first part looks at the data used for the estimation of the model and some of the features of the dataset. The second part describes areas of commonality between the GSS data used in this study and 
the LFS, the most commonly used data set associated with job stability issues in Canada.

\subsubsection{The Canadian General Social Survey}

The 15th and 20th cycles of the GSS are used to produce estimates of employment tenure. The two surveys were conducted throughout 2001 and 2006 and contain 24,310 and 22,435 records respectively. Although the use of a complex survey design rules out independence of these two samples, the respondents of these two surveys are contacted independently.The datasets are treated as independent samples and yield 16,536 usable records for the purpose of estimation. The variable of interest is the duration of the first employment spell for those who have completed their studies, as such those whose education is incomplete are dropped. Table 3.1 provides weighted summary statistics from the pooled surveys with unweighted observation counts. ${ }^{1}$ At the time of the interview, in either 2001 or 2006 , the mean age of respondents was 43 and the mean birth year was 1962. Just over half of the sample is composed of women, immigrants constitute under one quarter of the sample and just under one-sixth of respondents were married before the employment spell under observation began. Nearly three in five of those in first spells had a post-secondary education, and only 7 per cent had less than a high school education. Just over half of the usable spells come from the 2001 GSS and the largest cohorts are those of the 1960s and 1970s respectively. It should be noted that conditioning on the age when studies ended precludes the presence of students who work from the analysis. This

\footnotetext{
${ }^{1}$ More detailed descriptions of the data can be found in Annex B.
} 
Table 3.1: Summary Statistics of First Employment Spells, 2001 and 2006 GSS data

\begin{tabular}{lccccc} 
Variable & Obs & Mean & Std.Dev. & Min & Max \\
\hline age & 16536 & 42.6 & 13.524 & 16 & 77 \\
year born & 16536 & 1962 & 13.533 & 1930 & 1991 \\
male & 16536 & 0.477 & 0.499 & 0 & 1 \\
age studies end & 16536 & 21.5 & 4.86 & 10 & 59 \\
immigrant & 16536 & 0.235 & 0.424 & 0 & 1 \\
age work began & 16536 & 23.314 & 5.668 & 10 & 63 \\
part-time emp. & 16536 & 0.061 & 0.239 & 0 & 1 \\
edu university & 16536 & 0.294 & 0.455 & 0 & 1 \\
edu comm college & 16536 & 0.296 & 0.457 & 0 & 1 \\
edu high school & 16536 & 0.337 & 0.473 & 0 & 1 \\
edu less than hs & 16536 & 0.073 & 0.26 & 0 & 1 \\
married & 16536 & 0.162 & 0.369 & 0 & 1 \\
parental & 16536 & 0.147 & 0.354 & 0 & 1 \\
work related & 16536 & 0.103 & 0.304 & 0 & 1 \\
emp duration & 16536 & 13.161 & 12.366 & 1 & 59 \\
ur gap & 16536 & -0.368 & 0.997 & -3.01 & 2.43 \\
cohort 1930-39 & 16536 & 0.073 & 0.26 & 0 & 1 \\
cohort 1940-49 & 16536 & 0.129 & 0.335 & 0 & 1 \\
cohort 1950-59 & 16536 & 0.214 & 0.41 & 0 & 1 \\
cohort 1960-69 & 16536 & 0.258 & 0.438 & 0 & 1 \\
cohort 1970-79 & 16536 & 0.236 & 0.424 & 0 & 1 \\
cohort 1980-89 & 16536 & 0.09 & 0.286 & 0 & 1 \\
gss 2001 & 16536 & 0.545 & 0.498 & 0 & 1 \\
\hline
\end{tabular}

is to ensure that the focus is on those who enter the workforce permanently rather than the in-and-out transitions that are more common early in life.

The analysis is based on groupings of ten year birth cohorts. To determine whether the first employment spell has declined in length over different birth cohorts, the first spell of employment of individuals that were born in a particular decade are compared to one another. In the GSS, respondents retrospectively identify up to five work episodes over their life course. This information is sufficient to extract details on the duration of the first employment spell for individuals. Analysis of spells beyond the first will be left to the next chapter. Exit from employment 
is identified by the exit date provided or by the year of retirement if a date is not provided. Data is dropped when respondents refuse to answer, don't know or are not asked. Furthermore, employment spells of immigrants before arrival in Canada and individuals whose studies are incomplete are also dropped. While the labour market experiences of recent immigrants differ substantially from those of the Canadianborn, immigrants are left in the sample. This is because they constitute a sizable proportion of the sample and the exclusion of immigrants from the analysis does not alter the results substantially. Data for ongoing spells, those which have started but not ended, are retained for estimation as they can contribute to the hazard up to the point of censoring. As in the preceding chapter, employment durations were constructed by obtaining the year in which the first spell ended and subtracting it from the year it began. Employment spells for all classes of workers are included in the study.

It should be recognized that the data obtained focuses on work interruptions of three months or more. The data does not permit us to verify whether the interruption ended with a return to the same employer or a new employer. Hence, we must focus on employment stability rather than job stability. Many respondents reported interruptions of less than three months, possibly due to a change of employer being interpreted as an interruption despite the lack of a three month break - these were retained in the sample as the topic of interest is work separations regardless of length.

The previous chapter provided a detailed analysis of the GSS data including the potential problems associated with using retrospective information. This will 
be briefly reviewed below. Most of the tests performed in the preceding chapter indicated that the sample did not suffer from an inordinate degree of bias due to sample selection or memory effects. One potential data problem that is worth restating here is the issue of how mortality could generate a peculiar form of attrition bias in the sample. This would occur because any potential respondent who worked in the past but died before the retrospective survey date would fall out of the sample entirely. The survey samples of the GSS conform to census population benchmarks, so that the age distribution in the GSS matches the Canadian population at the time of the surveys. Because the youngest individual in the pool of usable spells was born in 1930 that individual would be at most 76 years of age in 2006 (or 71 in 2001). Although this is somewhat higher than life expectancy at age 20 in 1951 (71 for men and 74 for women), the 1930s birth cohort were selected as the earliest possible starting point for the analysis. The response rates in the GSS were sufficiently high so that selection bias was assessed as posing a fairly remote possibility. Issues common to retrospective surveys, such as the heaping and memory effects described in Torelli and Trivellato [28], were either corrected for through aggregation or addressed by testing. As stated above, recall errors are date and saliency-dependent and are likely to remain somewhat problematic with this data; if workers forget an employment spell entirely (likely an earlier and shorter spell) it would bias down the number of short duration spells. Tests for forward telescoping were performed on these datasets by comparing responses on employment durations between the 15th and 20th cycles of the survey, no clear pattern emerged from those tests for that 5 year interval. 
The covariates used to analyze the first employment tenure will focus on a series of socio-economic characteristics available within the dataset. These are gender, age at which the spell began, marital status upon commencement of the employment spell, whether the respondent immigrated to Canada, was in part- or full-time employment, whether they left the job for work-related reasons or for parental leave as well as a series of birth cohort effects. The deviation of the unemployment rate from a linear trend unemployment rate (with a mid-1980s break point) is used to capture macroeconomic effects at the end of the employment spell. Furthermore, a series of dummy variables are used to capture the effect of educational attainment on the hazard. The reasons for departure, as well as the cohorts which are more heavily influenced by declines, can help identify the periods in which the changes in the hazard of leaving employment coincide with institutional changes.

\subsubsection{Benchmarking Employment Tenures with Job Tenures}

It is common in the literature to use retention rates to test for the presence job stability over time. Hall [1] and Farber [3] are examples of this approach using American data. In Canada, Heisz [4] and, more recently, Brochu [14] have used the LFS to examine the stability of employment tenures over a thirty year horizon. The most recent of the above papers argues that job stability has increased over time owing largely to the growth in stability of the lowest tenured jobs. In his paper the author argues that the LFS constitutes a superior source of information for the construction of retention rates than does the U.S. Current Population Survey (CPS) 
owing to the consistency and frequency of the questions on job tenure.

In Chapter 2 it was shown using the GSS that employment tenures were declining for successive generations of Canadian workers over the second half of the twentieth century. While this evidence is not directly at odds with the key findings in Brochu [14], whose key results occur largely after the turn of the century, it does run contrary to the findings of overall stability found in much of the literature. One key source of divergence between these results is likely to be found in the data definitions.

Brochu [14] describes the questions asked of individuals in the LFS as related to the current job they hold. These jobs are focused on the positions held with the current employer. The retrospective question relates to when the current job started. Chapter 2 describes the employment spell used in this study as related to a retrospective question regarding an uninterrupted period of work after which a minimum 3 month break occurs. These uninterrupted employment spells can consist of a series of jobs or of a temporary, albeit lengthy, interruption in a single job. While it is likely that in a large number of cases these job and employment spells correspond, it is likely that there are also a significant number of cases where they do not. It is also likely that an employment spell is likely to be longer for individuals than a job spell when they do not correspond. That is, any continuous period of employment is more likely to contain a series of jobs rather than seeing a single job split into many employment spells divided by intervals of three months or greater.

To compare these datasets over the 1976 to 2001 interval, repeat cross sections 
of the LFS were obtained and aggregated to the annual level as done with the GSS. All rotations from the March and September surveys were used in the construction of the data, ensuring that any single individual would not be double counted (as the LFS uses a 6 month panel rotation - a six month gap between samples must be used). An alternative approach would be to use any consistent rotation from each monthly survey, however the choice of sample selection would be unlikely to affect the results. Repeat cross sections are best analyzed using the retention rate approach used by Hall [1]. One year retention rates $(R R)$, as found commonly in the relevant literature ( [13], [4], [14]), were constructed for core-aged workers using the both the LFS and the GSS.

The LFS retention rates, depicted in Equations 3.1 and 3.2 below, are frequency counts of the weighted number of respondents who meet specified criteria. The rates were constructed as the sum of the last periods employment $\left(E M P_{t-1}\right)$ minus the jobs lost to attrition $\left(A T R_{t}\right)$ by the end of the period, over the corresponding employment pool (comprising of employment spells at least 6 months in length) built using a synthetic birth-cohort approach on appropriately weighted $\left(w_{i}\right)$ data. Given that age $(a)$ and tenure $(j)$ information is captured by the LFS consistently each year, using appropriately lagged variables across time will capture the retention behaviour of each birth cohort grouping (with the exception of international mobility while in an ongoing job spell). ${ }^{2}$

\footnotetext{
${ }^{2}$ Subscripts $i$ and $k$ refer to different individuals across time and are there to highlight that individuals cannot be tracked in repeat cross sections.
} 


$$
\begin{gathered}
R R_{t}^{L F S}=100 \times\left[1-\left(\frac{\sum_{j=1}^{J} A T R_{t, j}^{L F S}}{\sum_{j=1}^{J} E M P_{t-1, j-1}^{L F S}}\right)\right] \\
A T R_{t, j}^{L F S}=\sum_{a=25}^{54}\left[\sum_{i=1}^{N}\left(w_{i, t} \times E M P_{i, a, t, j}^{L F S}\right)-\sum_{i=1}^{N}\left(w_{k, t-1} \times E M P_{k, a-1, t-1, j-1}^{L F S}\right)\right], k \neq i
\end{gathered}
$$

For the GSS, the construction of the one year retention rates in Equations 3.3 and 3.4 was slightly more problematic given the entirely retrospective nature of the dataset. All employment spells were used in the construction of retention rates. Employment estimates were produced by selecting employment spells which began on or before the reference year and ended on or before that year. The data are weighted by the 2001 or 2006 survey weights within the GSS and hence employment estimates outside of those years are likely to be weighted improperly to some degree. Overlapping spells by the same individual were dropped from the sample when computing employment but were retained for computing attrition. Attrition numbers were obtained by computing when each individual leaves the current employment spell. GSS retention rates, described below, are obtained by subtracting the ratio of the sums of attrition and the previous period's employment from 1 and multiplying by 100 .

$$
R R_{t}^{G S S}=100 \times\left[1-\left(\frac{\sum_{j=1}^{J} A T R_{t, j}^{G S S}}{\sum_{j=1}^{J} E M P_{t-1, j-1}^{G S S}}\right)\right]
$$




$$
A T R_{t, j}^{G S S}=\sum_{a=25}^{54}\left[\sum_{i=1}^{N} w_{i} \times\left(E M P_{i, a, t, j}^{G S S}-E M P_{i, a-1, t-1, j-1}^{G S S}\right)\right]
$$

Using the same methods, five and ten year retention rates were also constructed. Comparisons of one, five and ten year retention rates as well as total employment between the GSS and LFS can be seen in Figure 3.1. In panel a) Employment is notably larger in the LFS-based sample than in the GSS-based sample, likely due to the selection of only those who have completed their studies. Moreover, the LFS employment sample contains pronounced cyclicality around the recessions of 1982 and 1991. The GSS employment estimate, while possessing some small cyclical movements, can largely be seen as a simple trend in employment. Up until the mid-1990s GSS employment generally grew faster than its LFS-based counterpart but grew more slowly thereafter. It should be noted that the LFS sample pools two survey samples from each year (one from March and one from September) while the GSS-based sample pools together the 2001 and 2006 retrospective surveys. $^{3}$ Hence, the LFS sample will report approximately twice the employment for core-aged workers in each year and the GSS sample will report the pooling of the 2001 and 2006 Canadian population and the corresponding recollection of their employment histories.

Comparative one, five and ten year retention rates are shown in panels b, c and $\mathrm{d}$ of Figure 3.1. The first thing to note is that retention rates in the GSS sample are above those seen in the LFS sample. This corresponds to the fact that employment

\footnotetext{
${ }^{3}$ The LFS features a six month rotating panel structure so that participants are included in 6 consecutive surveys. As such, using all panels from March and September will preclude double counting any one individual within a six month period.
} 
Figure 3.1: Employment and Retention Rates
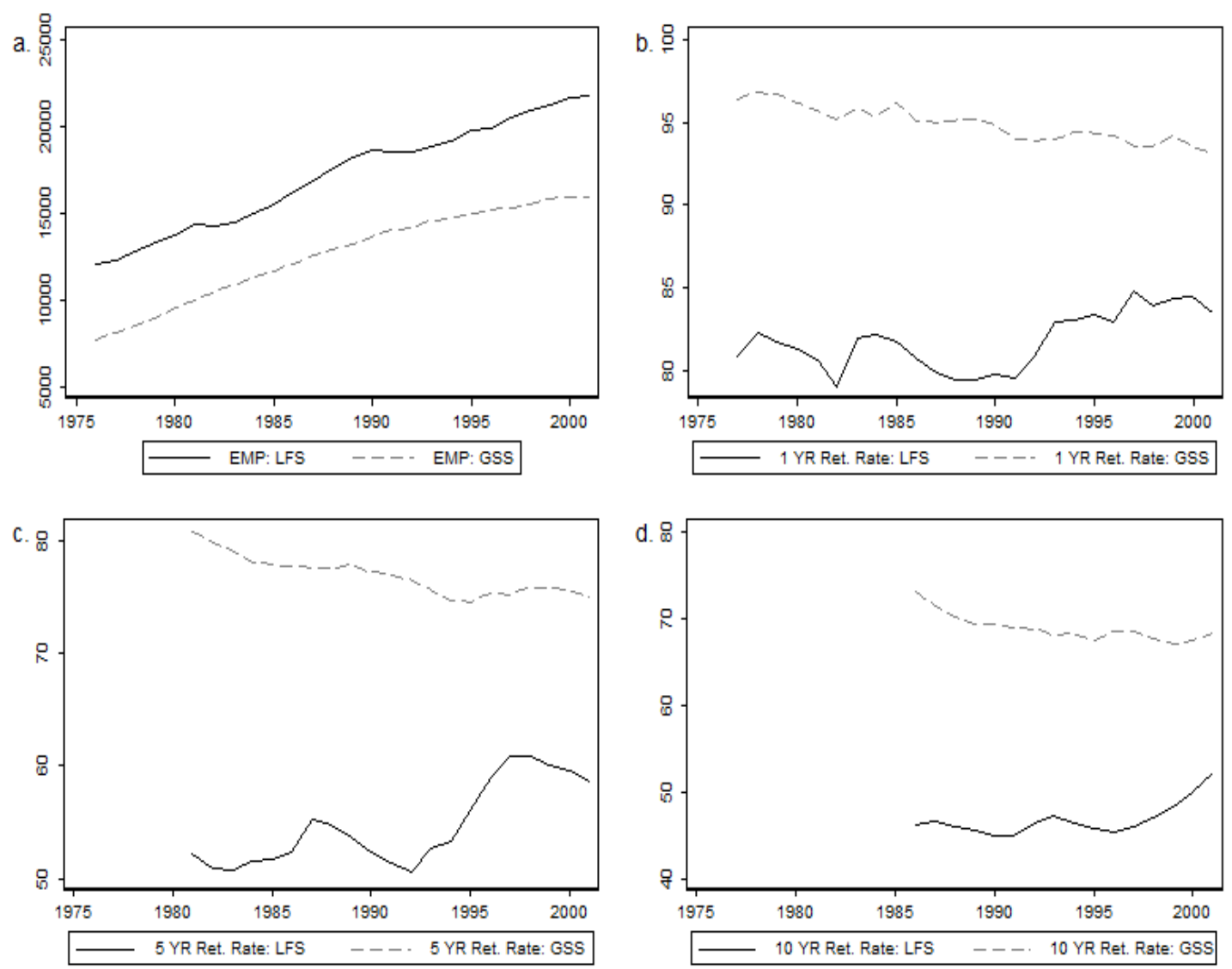

Source: Labour Force Survey and General Social Survey (Cycles 15 and 20) 
Figure 3.2: Comparative Retention Rates
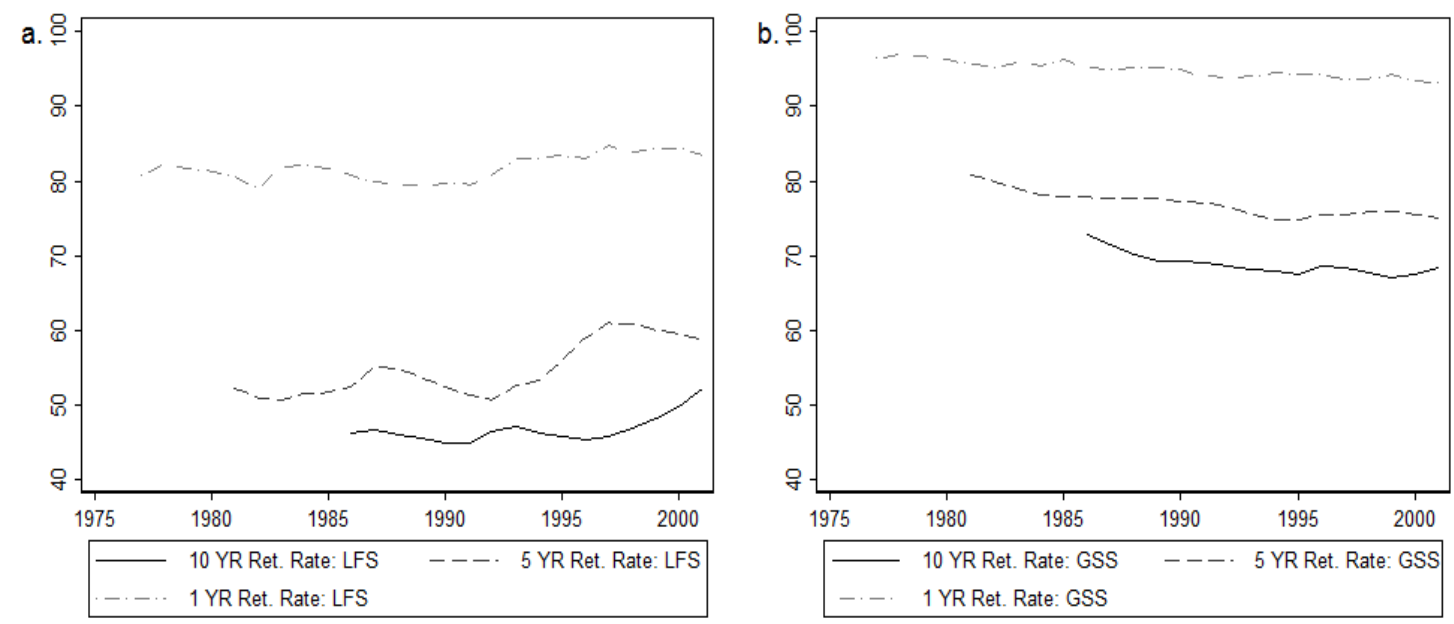

Source: Labour Force Survey and General Social Survey (Cycles 15 and 20)

spells may be composed of multiple job spells. Secondly, there is a divergence in the trends between the LFS and GSS-based rates. The GSS rates have weakly countercyclical negative trends while the LFS-based rates seem to show weakly positive trend growth with a pronounced counter-cyclical aspect. Figure 3.2 compares the retention rates for both the GSS-based and the LFS-based estimates. It should be noted that in both cases one year retention rates exceed the five year retention rate by a wide margin and that the five year retention rates exceed the ten year retention rates by a significantly narrower margin.

Pairwise correlation coefficients between the GSS-based and LFS-based variables are presented in Table 3.2. Unsurprisingly, there is strong positive correlation between employment and attrition in both datasets due to the time trend in em- 
Table 3.2: Correlation between LFS and GSS attrition and retention rates

\begin{tabular}{lcc}
\hline & $\rho$ & p-value \\
\hline Employment & 0.9899 & 0.0000 \\
1 yr attrition & 0.7713 & 0.0000 \\
5 yr attrition & 0.8475 & 0.0000 \\
10 yr attrition & 0.9615 & 0.0000 \\
1 yr ret rate & -0.4435 & 0.0298 \\
5 yr ret rate & -0.6277 & 0.0023 \\
10 yr ret rate & -0.3162 & 0.2327 \\
\hline \hline
\end{tabular}

ployment and attrition levels. The correlation in retention rates, however, present more of a challenge as all correlations appear to be negative (and insignificant in the case of ten year retention rates).

To test whether there is an underlying correspondence between the series that may be masked by time trends an OLS population regression is run for each corresponding retention rate. The results, presented in Table 3.3, show that once the converging trends are controlled for, there is a significant and positive relationship between retention rates for the two series. The convergence of the two series can have different implications. One interpretation can be that work interruptions have become more common over time while job tenures have remained constant or increased on average. An alternate interpretation could be that either an inverse attrition bias in the GSS data or some form of recall errors have generated an artificial decline in retention rates over time. However, these data issues were examined in Chapter 2 with the conclusion that recall errors and attrition bias were unlikely to have caused serious deficiencies in the data. Hence, it is likely that institutional factors and more flexible labour market arrangements, such as increasingly generous 
Table 3.3: Population Regression: GSS and LFS variables

\begin{tabular}{lccc} 
& RR1 GSS & RR5 GSS & RR10 GSS \\
\hline RR1 LFS & $\begin{array}{c}0.112^{* *} \\
(0.052)\end{array}$ & & \\
RR5 LFS & & $0.136^{*}$ & \\
& & $(0.074)$ & \\
RR10 LFS & & & $0.313^{* *}$ \\
& & & $(0.14)$ \\
trend & $-0.152^{* * *}$ & $-0.317^{* * *}$ & $-0.354^{* * *}$ \\
& $(0.012)$ & $(0.043)$ & $(0.057)$ \\
constant & $387.4^{* * *}$ & $700.1^{* * *}$ & $760.2^{* * *}$ \\
& $(22.2)$ & $(83.1)$ & $(108.9)$ \\
\hline T & 25 & 21 & 16 \\
R2 & 0.8978 & 0.8472 & 0.7403 \\
$\mathrm{p}(\mathrm{D})$ & 0.1563 & 0 & 0.3728 \\
\hline \hline
\end{tabular}

Notes: Standard errors are in parentheses. ***,**, and * denote $1 \%, 5 \%$, and $10 \%$ level of significance, respectively. $\mathrm{p}(\mathrm{D})$ represents the p-value of Durbin's alternative test for autocorrelation where no autocorrelation is assumed under the null.

unemployment insurance and parental provisions, have increased work separations while not necessarily decreasing job spell lengths.

\subsection{Empirical Methodology}

A Cox semiparametric hazard model which accounts for right-censoring is used to estimate the hazard of leaving the first employment spell. Only spells with a specified starting date are used, eliminating any left-censoring problems. The following econometric model is considered:

$$
\theta\left(t_{i} \mid x_{i}\right)=\phi\left(x_{i}\right) \lambda\left(t_{i}\right)
$$


where $\theta(\cdot)$ is the hazard rate, $t_{i}$ is the duration of the first employment spell for individual $i, \phi\left(x_{i}\right)=\exp \left(x_{i} \beta\right)$ and $\lambda\left(t_{i}\right)$ is the baseline hazard for individual $i$. The Cox model is a good choice because it is robust to misspecification due to its flexible (nonparametric) baseline hazard.

In order to focus on the specific topic of institutional changes over the period under study a series of competing risks regressions will also be estimated. The competing risks regressions follow the method of Fine and Grey [32] which produces parameter estimates that contribute to the sub-hazard of separation due to a particular risk factor rather than the overall hazard of separation. The sub-hazards of interest are separations due to work-related reasons for men and maternity/parental separation for women. These gender-specific sub-hazards are targeted solely because of the nature of the risks by gender. The high hazard for women early in the spell relative to men is due to issues associated with family formation. For men, the stability literature has focused on structural changes in the market for labour, with a focus on dislocation. The competing risks in both cases will be any reason with the exception of those identified above. All unfinished spells are right censored and no left censoring exists in the dataset. The econometric model describing a competing risks regression is similar to the Cox proportional hazards model and takes the form:

$$
\theta_{1}\left(t_{i} \mid x_{i}\right)=\phi\left(x_{i}\right) \lambda_{1,0}\left(t_{i}\right)
$$

where $\theta_{1}(\cdot)$ is the subhazard rate, $t_{i}$ is the duration of the first employment spell for individual $i, \phi\left(x_{i}\right)=\exp \left(x_{i} \beta\right)$ and $\lambda_{1,0}\left(t_{i}\right)$ is the baseline subhazard for individual 
$i$.

\subsection{Results}

Before moving on to the model results, it is worthwhile to examine the empirical hazard functions graphically. Figure 3.3 presents the smoothed hazard functions of employment duration by gender and cohort at 15 and 45 year intervals. The first thing to note in panels a) and b) is that the hazard rate is generally higher for women than for men. Secondly, when looking over a longer time horizon, in panels c) and d), one generally observes a bimodal distribution, with higher hazards at the beginning and the end of the employment duration distribution. The likely reason for high initial hazards is low match quality between employers and employees in first employment spells while the rising hazard towards the end of the distribution signals movements into retirement. A general decrease in the hazard can be observed in panel a) for succeeding cohorts of men, but the 1970s distribution tends to break from this pattern. While the employment hazards are more complicated for women it can also be recognized that the 1970s cohort also displays a higher hazard towards the beginning of the spell.

\subsubsection{Proportional Hazard Model Results}

The initial Cox proportional hazards model is estimated twelve times. Two

full-sample estimates are made, one for men and the other for women, including cohort-specific information as dummy variables. The ten other estimated equations 
Figure 3.3: Smoothed Hazards
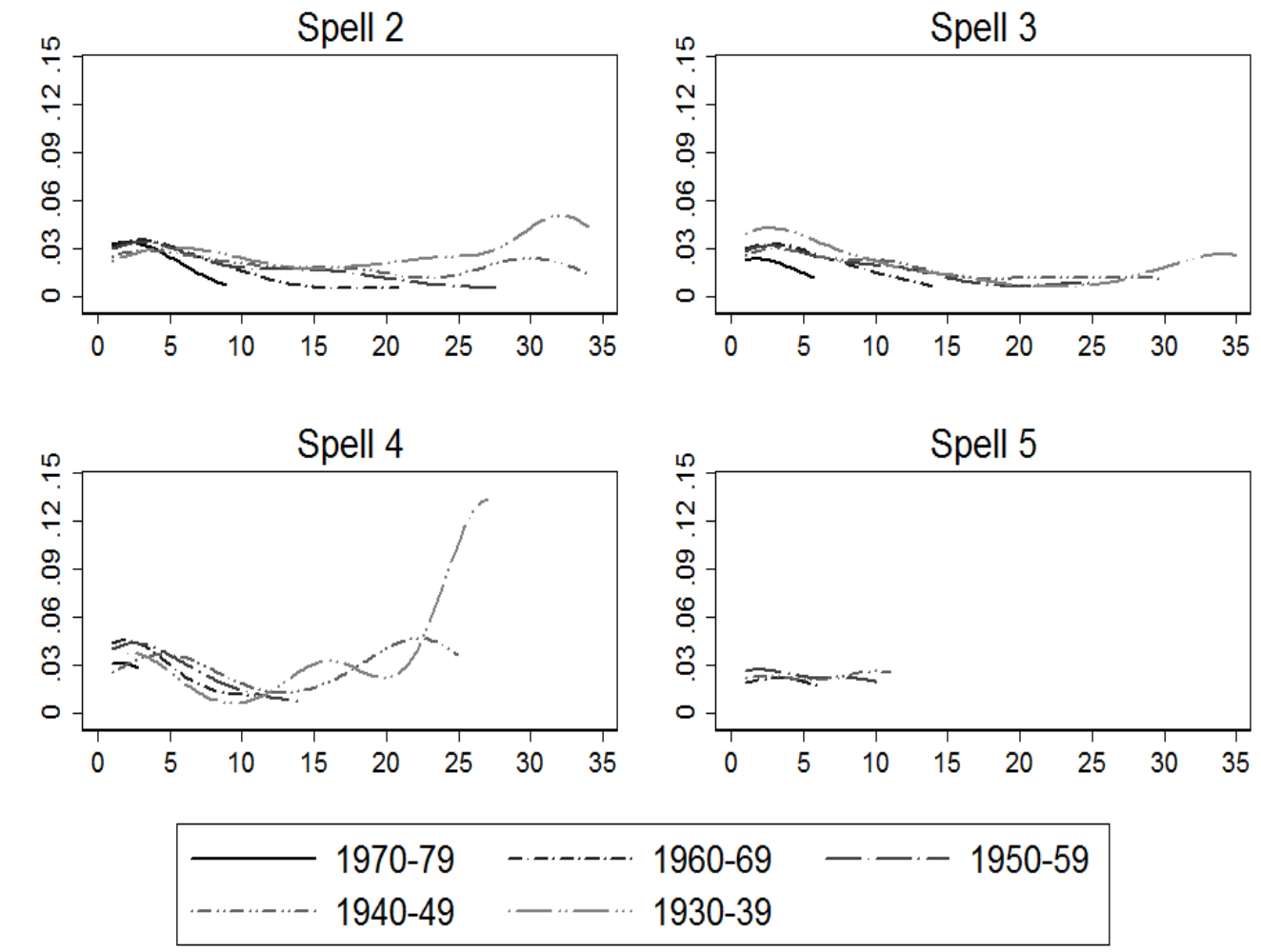

Data source: General Social Survey Cycles 15 and $20(2001,2006)$

Note: The smoothed hazards above are displayed by birth cohort. Panels a. and c. are for men over a period of 15 and of 45 years respectively. Similarly, panels b. and d. are for women showing a 15 and 45 year period respectively. 
consist of 5 cohort-specific equations for both genders, the results can be seen in Tables 3.4 and 3.5. The coefficients in the proportional hazard model show the effect of the particular covariate on the baseline hazard, with positive coefficients denoting an increased hazard and negative coefficients a decline in the hazard. ${ }^{4}$ As most of the covariates identified in Table 3.1 and used in the analysis below are binary, the interpretation is a straight forward proportional increase (or decrease) in the risk of leaving employment for those possessing the characteristic described by that variable. For continuous variables (age began and the unemployment rate gap), the interpretation is more complex, with the implied change to the hazard being a function of the value of the covariate.

The results of the estimation imply that part-time work, the age at which the spell began, parental or work-related separations as well as adverse macroeconomic circumstances (proxied by the unemployment rate gap) raise the hazard for men relative to those men born in the 1980s who have less than a high school education. ${ }^{5}$ Reductions in the hazard for men, relative to the base group, are caused by being an immigrant or married at the start of the spell. The rising cohort effect seen in the aggregate equation for men shows that more recent cohorts of men have a higher hazard of leaving employment. In the cohort-specific equation the increase in work related separation for the 1950s cohort and onward seems to coincide with a reduced

\footnotetext{
${ }^{4}$ Often the hazard ratio is shown rather than coefficients to show the magnitude of the increase or decrease in the risk relative to the baseline hazard.

${ }^{5}$ The base group for all further regressions are those of the same gender who were born in the 1980s and have not completed high school.
} 
unemployment rate gap effect after the 1950s cohort. Furthermore, higher levels of education no longer decrease men's hazard after the 1950s cohort. For women, relative to other women born in the 1980s and without a high school completion, the aggregate hazard rises with part-time employment, the age work began, parental and work related separations, and the UR gap. ${ }^{6}$ Education tends to increase the hazard, but only in the aggregate. Being an immigrant or a worker from an earlier cohort also reduces the hazard. When examining the cohort specific equations for women a clear upward trend can be seen in the contribution of part-time employment to the hazard. The effects from parental leave declined after the 1950s cohort while those of macroeconomic conditions and work related separations became increasingly important.

\footnotetext{
${ }^{6}$ While parental separations and work-related separations are at least partially endogenous to the process, their inclusion controls for specific demand-side and supply-side factors that the other covariates cannot capture. Furthermore, for men the addition of these variables does not create parameter instability in the other estimates. For women, the unemployment rate gap parameters in 2 cohorts, the 1940s and 1950s, switch signs as the effect of plant closures is picked up by the parameters on the unemployment rate gap for those cohorts.
} 
Table 3.4: Cox Semiparametric Estimates of Employment Spells: Men

Total Sample C $\quad$ 1930-39 C 1940-49 C 1950-59 C1960-69 C 1970-79

\begin{tabular}{|c|c|c|c|c|c|c|}
\hline part-time & $\begin{array}{c}1.357^{* * *} \\
(0.126)\end{array}$ & $\begin{array}{l}1.137^{*} \\
(0.643)\end{array}$ & $\begin{array}{l}1.044^{*} \\
(0.594)\end{array}$ & $\begin{array}{c}1.646^{* * *} \\
(0.261)\end{array}$ & $\begin{array}{c}1.574^{* * *} \\
(0.293)\end{array}$ & $\begin{array}{l}1.31^{* * *} \\
(0.198)\end{array}$ \\
\hline immigrant & $\begin{array}{c}-0.113^{* *} \\
(0.053)\end{array}$ & $\begin{array}{c}-0.315^{* *} \\
(0.159)\end{array}$ & $\begin{array}{l}-0.148 \\
(0.133)\end{array}$ & $\begin{array}{c}-0.294^{* * *} \\
(0.11)\end{array}$ & $\begin{array}{c}0.115 \\
(0.095)\end{array}$ & $\begin{array}{l}-0.008 \\
(0.133)\end{array}$ \\
\hline married & $\begin{array}{l}-0.138^{*} \\
(0.076)\end{array}$ & $\begin{array}{l}-0.228 \\
(0.233)\end{array}$ & $\begin{array}{l}-0.037 \\
(0.158)\end{array}$ & $\begin{array}{l}-0.194 \\
(0.141)\end{array}$ & $\begin{array}{c}-0.058 \\
(0.15)\end{array}$ & $\begin{array}{c}-0.511^{* *} \\
(0.223)\end{array}$ \\
\hline age began & $\begin{array}{c}0.059^{* * *} \\
(0.006)\end{array}$ & $\begin{array}{c}0.061^{* * * *} \\
(0.017)\end{array}$ & $\begin{array}{c}0.053^{* * *} \\
(0.012)\end{array}$ & $\begin{array}{c}0.043^{* * *} \\
(0.011)\end{array}$ & $\begin{array}{l}0.08^{* * *} \\
(0.015)\end{array}$ & $\begin{array}{c}0.104^{* * *} \\
(0.022)\end{array}$ \\
\hline parental & $\begin{array}{c}1.662^{* * *} \\
(0.08)\end{array}$ & & & $\begin{array}{c}1.939^{* * *} \\
(0.242)\end{array}$ & $\begin{array}{c}1.648^{* * *} \\
(0.13)\end{array}$ & $\begin{array}{c}1.646^{* * * *} \\
(0.171)\end{array}$ \\
\hline work related & $\begin{array}{c}1.771 * * * \\
(0.049)\end{array}$ & $\begin{array}{c}1.765^{* * * *} \\
(0.214)\end{array}$ & $\begin{array}{c}1.775^{* * *} \\
(0.128)\end{array}$ & $\begin{array}{c}1.945^{* * *} \\
(0.1)\end{array}$ & $\begin{array}{c}1.7^{* * * *} \\
(0.1)\end{array}$ & $\begin{array}{c}1.772^{* * *} \\
(0.099)\end{array}$ \\
\hline ur gap & $\begin{array}{c}0.369^{* * *} \\
(0.032)\end{array}$ & $\begin{array}{c}0.451^{* * * *} \\
(0.088)\end{array}$ & $\begin{array}{c}0.06 \\
(0.096)\end{array}$ & $\begin{array}{c}0.255^{* * *} \\
(0.068)\end{array}$ & $\begin{array}{c}0.471^{* * *} \\
(0.06)\end{array}$ & $\begin{array}{c}0.665^{* * *} \\
(0.069)\end{array}$ \\
\hline high school & $\begin{array}{l}-0.113 \\
(0.091)\end{array}$ & $\begin{array}{c}0.011 \\
(0.222)\end{array}$ & $\begin{array}{c}-0.318^{*} \\
(0.189)\end{array}$ & $\begin{array}{c}-0.472^{* * *} \\
(0.156)\end{array}$ & $\begin{array}{l}-0.022 \\
(0.247)\end{array}$ & $\begin{array}{c}-0.12 \\
(0.297)\end{array}$ \\
\hline college & $\begin{array}{l}-0.089 \\
(0.092)\end{array}$ & $\begin{array}{l}0.402^{*} \\
(0.233)\end{array}$ & $\begin{array}{l}-0.123 \\
(0.186)\end{array}$ & $\begin{array}{c}-0.388^{* *} \\
(0.163)\end{array}$ & $\begin{array}{l}-0.189 \\
(0.245)\end{array}$ & $\begin{array}{l}-0.109 \\
(0.294)\end{array}$ \\
\hline university & $\begin{array}{c}-0.25^{* * *} \\
(0.09)\end{array}$ & $\begin{array}{c}0.311 \\
(0.212)\end{array}$ & $\begin{array}{c}-0.453^{* *} \\
(0.186)\end{array}$ & $\begin{array}{c}-0.638^{* * *} \\
(0.157)\end{array}$ & $\begin{array}{l}-0.169 \\
(0.241)\end{array}$ & $\begin{array}{l}-0.347 \\
(0.293)\end{array}$ \\
\hline C 1930-39 & $\begin{array}{c}-2.725^{* * * *} \\
(0.168)\end{array}$ & & & & & \\
\hline C $1940-49$ & $\begin{array}{c}-2.261^{* * * *} \\
(0.137)\end{array}$ & & & & & \\
\hline C 1950-59 & $\begin{array}{c}-1.763^{* * *} \\
(0.122)\end{array}$ & & & & & \\
\hline C 1960-69 & $\begin{array}{c}-1.312^{* * *} \\
(0.111)\end{array}$ & & & & & \\
\hline C 1970-79 & $\begin{array}{c}-0.65^{* * *} \\
(0.102)\end{array}$ & & & & & \\
\hline Obs & 6980 & 516 & 991 & 1456 & 1886 & 1619 \\
\hline log Likelihood & -19874 & -1506 & -2761 & -3678 & -4543 & -3233 \\
\hline
\end{tabular}

Notes: Standard errors are in parentheses. ${ }^{* * *}, * *$, and $*$ denote $1 \%, 5 \%$, and $10 \%$ level of significance, respectively. C 1930-39 refers to the 1930-1939 birth cohort, similarly, the C 1940-49 to C 1970-79 refer to the birth cohort 1940-1949 to 1970-1979. 
When performing any form of hazard analysis it is important to examine the baseline hazard in order to determine whether duration dependence is present in the model. Zorn [33] describes duration dependence as the extent to which the baseline hazard is increasing or decreasing. When unobserved heterogeneity is present, spurious duration dependence can present a problem as high hazard individuals leave the sample faster than low hazard individuals. This process will leave a characteristic decline in the baseline hazard. However, true duration dependence (state dependence) can also be present in the model causing the baseline hazard to rise or fall as duration in the state affects the probability of a separation event being realized.

The full sample baseline hazard is shown in Figure 3.4. It can be clearly seen that the baseline hazard decreases over the first 20 years and then rapidly increases, thus displaying negative duration dependence over the first 20 years and positive duration dependence thereafter. This pattern is not necessarily a problem as it is, at least in part, due to state dependence regarding the quality of employment matches for shorter spells and issues around retirement in the longer spells. Censoring issues in the last 30 years of the chart may also be affecting the baseline. The estimation is carried out by cohort since the censoring is directly related to the time when workers enter employment. Modeling the gender difference using a Gamma shared frailty term was attempted but led to insignificant results, hence the estimates are also disaggregated by gender.

To check for spurious duration dependence in the disaggregated equations the baseline hazards are examined by gender and cohort in Figures 3.5 and 3.6. With 
Table 3.5: Cox Semiparametric Estimates of Employment Spells: Women

\begin{tabular}{|c|c|c|c|c|c|c|}
\hline & Total Sample & C 1930-39 & C $1940-49$ & C 1950-59 & C1960-69 & C $1970-79$ \\
\hline part-time & $\begin{array}{c}0.675^{* * *} \\
(0.054)\end{array}$ & $\begin{array}{c}0.246 \\
(0.155)\end{array}$ & $\begin{array}{c}0.402^{* * *} \\
(0.156)\end{array}$ & $\begin{array}{c}0.538^{* * *} \\
(0.131)\end{array}$ & $\begin{array}{c}0.826^{* * *} \\
(0.118)\end{array}$ & $\begin{array}{c}0.801^{* * *} \\
(0.101)\end{array}$ \\
\hline immigrant & $\begin{array}{c}-0.11^{* * *} \\
(0.034)\end{array}$ & $\begin{array}{c}-0.202^{* *} \\
(0.087)\end{array}$ & $\begin{array}{c}-0.201^{* *} \\
(0.083)\end{array}$ & $\begin{array}{c}-0.217^{* * *} \\
(0.072)\end{array}$ & $\begin{array}{l}-0.076 \\
(0.069)\end{array}$ & $\begin{array}{l}-0.038 \\
(0.073)\end{array}$ \\
\hline married & $\begin{array}{l}-0.002 \\
(0.046)\end{array}$ & $\begin{array}{l}-0.226 \\
(0.127)\end{array}$ & $\begin{array}{c}-0.081^{*} \\
(0.11)\end{array}$ & $\begin{array}{l}-0.032 \\
(0.093)\end{array}$ & $\begin{array}{c}0.065 \\
(0.087)\end{array}$ & $\begin{array}{c}0.263^{* *} \\
(0.103)\end{array}$ \\
\hline age began & $\begin{array}{c}0.004 \\
(0.003)\end{array}$ & $\begin{array}{c}0.015^{* *} \\
(0.006)\end{array}$ & $\begin{array}{l}0.012^{*} \\
(0.006)\end{array}$ & $\begin{array}{c}0 \\
(0.007)\end{array}$ & $\begin{array}{c}0.032^{* * *} \\
(0.008)\end{array}$ & $\begin{array}{c}0.082^{* * *} \\
(0.012)\end{array}$ \\
\hline parental & $\begin{array}{c}1.223^{* * *} \\
(0.031)\end{array}$ & $\begin{array}{c}1.473^{* * *} \\
(0.104)\end{array}$ & $\begin{array}{c}1.243^{* * *} \\
(0.085)\end{array}$ & $\begin{array}{c}1.373^{* * *} \\
(0.069)\end{array}$ & $\begin{array}{c}1.118^{* * *} \\
(0.061)\end{array}$ & $\begin{array}{c}1.086^{* * *} \\
(0.062)\end{array}$ \\
\hline work related & $\begin{array}{c}1.087^{* * *} \\
(0.048)\end{array}$ & $\begin{array}{c}0.936^{* * *} \\
(0.127)\end{array}$ & $\begin{array}{l}1.02^{* * *} \\
(0.101)\end{array}$ & $\begin{array}{c}1.015^{* * *} \\
(0.095)\end{array}$ & $\begin{array}{c}1.024^{* * *} \\
(0.093)\end{array}$ & $\begin{array}{c}1.225^{* * *} \\
(0.108)\end{array}$ \\
\hline ur gap & $\begin{array}{c}0.025^{* *} \\
(0.012)\end{array}$ & $\begin{array}{c}0.035 \\
(0.028)\end{array}$ & $\begin{array}{c}-0.266^{* * *} \\
(0.043)\end{array}$ & $\begin{array}{c}-0.089^{* * *} \\
(0.023)\end{array}$ & $\begin{array}{c}0.214^{* * *} \\
(0.025)\end{array}$ & $\begin{array}{c}0.457^{* * *} \\
(0.037)\end{array}$ \\
\hline high school & $\begin{array}{l}0.085 \\
(0.06)\end{array}$ & $\begin{array}{l}-0.035 \\
(0.116)\end{array}$ & $\begin{array}{c}0.044 \\
(0.112)\end{array}$ & $\begin{array}{l}-0.071 \\
(0.128)\end{array}$ & $\begin{array}{c}0.124 \\
(0.156)\end{array}$ & $\begin{array}{c}-0.166 \\
(0.274)\end{array}$ \\
\hline college & $\begin{array}{c}0.123^{* *} \\
(0.06)\end{array}$ & $\begin{array}{c}0.079 \\
(0.119)\end{array}$ & $\begin{array}{c}0.08 \\
(0.113)\end{array}$ & $\begin{array}{l}-0.002 \\
(0.129)\end{array}$ & $\begin{array}{c}0.219 \\
(0.155)\end{array}$ & $\begin{array}{c}-0.072 \\
(0.273)\end{array}$ \\
\hline university & $\begin{array}{l}0.111^{*} \\
(0.061)\end{array}$ & $\begin{array}{c}0.096 \\
(0.143)\end{array}$ & $\begin{array}{c}0.029 \\
(0.128)\end{array}$ & $\begin{array}{c}0.083 \\
(0.133)\end{array}$ & $\begin{array}{c}0.102 \\
(0.155)\end{array}$ & $\begin{array}{l}-0.155 \\
(0.268)\end{array}$ \\
\hline C 1930-39 & $\begin{array}{c}-1.229 * * * \\
(0.086)\end{array}$ & & & & & \\
\hline C $1940-49$ & $\begin{array}{c}-1.205^{* * *} \\
(0.079)\end{array}$ & & & & & \\
\hline C 1950-59 & $\begin{array}{c}-1.137^{* * *} \\
(0.075)\end{array}$ & & & & & \\
\hline C 1960-69 & $\begin{array}{c}-0.98^{* * *} * \\
(0.074)\end{array}$ & & & & & \\
\hline C 1970-79 & $\begin{array}{c}-0.615^{* * *} \\
(0.074)\end{array}$ & & & & & \\
\hline Obs & 9556 & 918 & 1404 & 2026 & 2427 & 2156 \\
\hline log Likelihood & -54741 & -4442 & -6918 & -10297 & -12530 & -8949 \\
\hline
\end{tabular}

Notes: Standard errors are in parentheses. $* * *, * *$, and $*$ denote $1 \%, 5 \%$, and $10 \%$ level of significance, respectively. C 1930-39 refers to the 1930-1939 birth cohort, similarly, the C 1940-49 to C 1970-79 refer to the birth cohort 1940-1949 to 1970-1979. 
Figure 3.4: Total Baseline Hazard

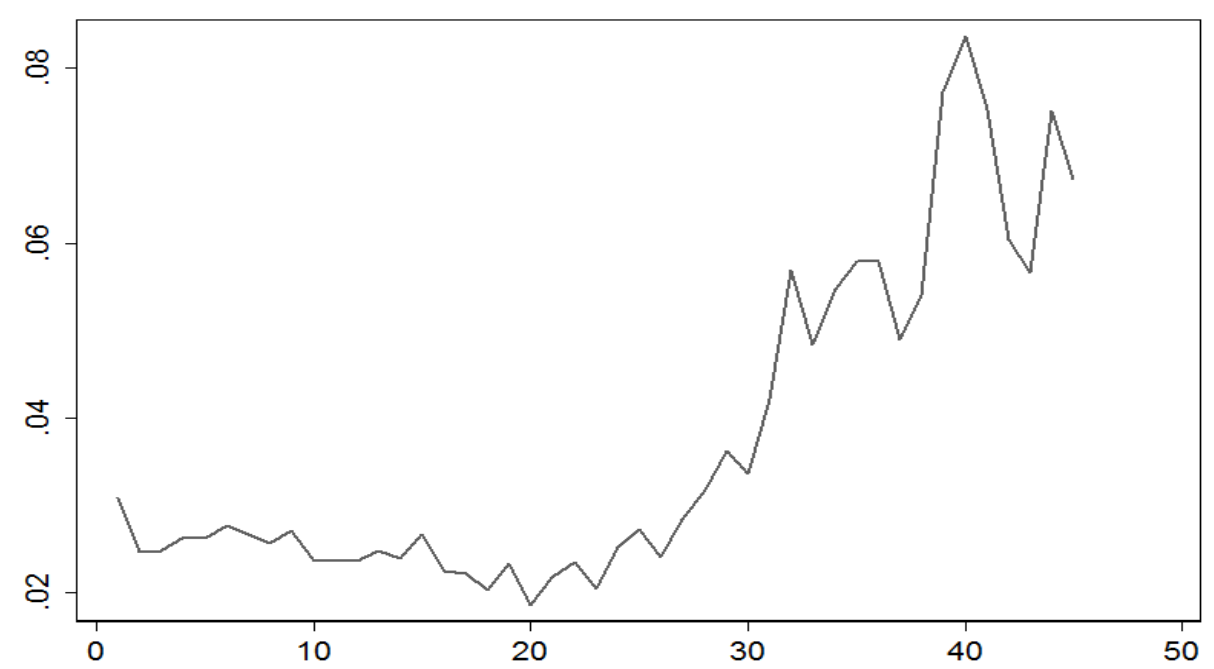

the exception of the first few years, most of the cohort-specific hazards for men do not show any duration dependence (the upward trends at the ends of the baseline hazards for men of the 1960s and 1970s cohort share likely due to censoring issues). In the case of women, the 1930s and 1940s cohorts display rising duration dependence for the first 6-7 years and falling duration dependence for the subsequent 5-8 years. This pattern may be due to the expectation that women of the era would work for a few years before leaving the labour force to raise a family, hence this form of duration dependence is unlikely to be spurious. 
Figure 3.5: Baseline Hazard Plots by Cohort: Men

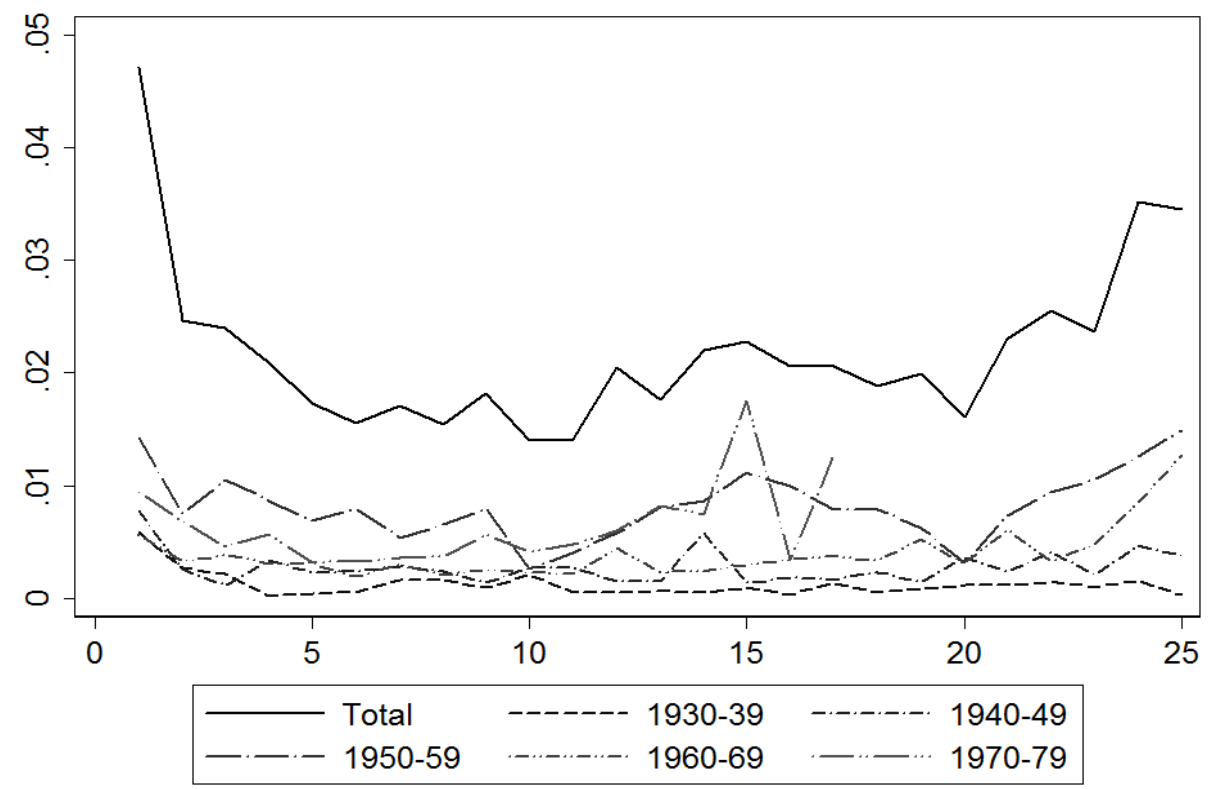

Data source: General Social Survey Cycles 15 and $20(2001,2006)$

Figure 3.6: Baseline Hazard Plots by Cohort: Women

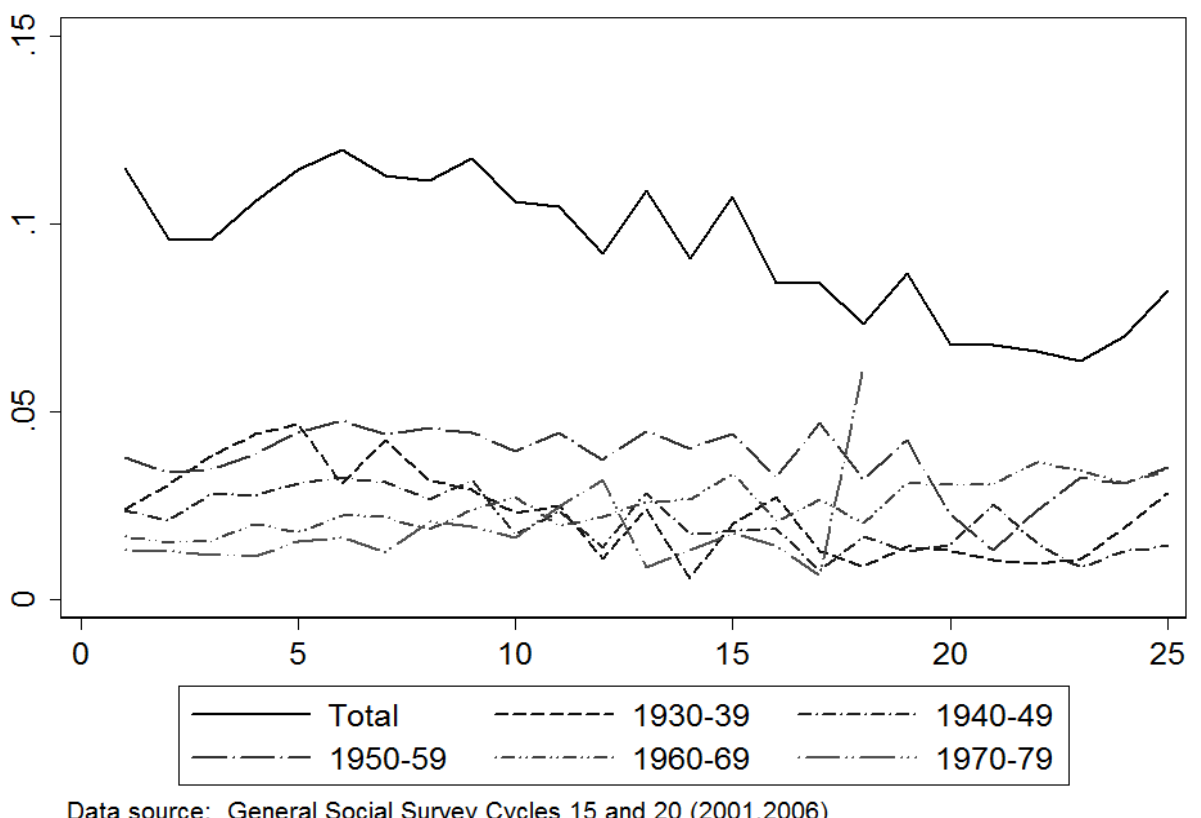

To determine the adequacy of the equation specifications an examination of the 
Schoenfeld Residuals was performed for each covariate in the equations. Table 3.6 contains the p-values for both the global and variable-specific tests of proportionality. The results clearly indicate that many of the covariates fail the proportionality assumption, implying that their effects on the baseline hazard vary with time.

Time dependence is introduced into the models due to a general failure of proportionality in most of the sub-samples. These results should not be entirely surprising due to the length of time under observation, particularly in the full sample and earlier cohorts. Work-related separations and the unemployment rate gap are modeled as time-varying covariates for men. For women, separations for parental reasons are modeled as time-varying. While there were numerous proportionality failures in individual estimation, these variables were specifically chosen due to the consistency in failure across cohorts. Moreover, because of the difficulty in interpreting time-varying covariates [34] standardization of the time varying covariates was important for cross-cohort comparisons.

To examine the hypothesis of decreasing employment tenure, the focus is on employment durations by birth cohort. The results of the estimation, seen in Tables 3.7 and 3.8, show the hazard results for men and women respectively. In total sample estimation (column 1 in both tables) the coefficients on the cohort effects are highly significant. It should be noted that these cohort effects are not proportional at all points of the employment duration distribution, but can be interpreted as cohort average effects. For both men and women the coefficients are negative, indicating a decreasing hazard of leaving employment for each of the cohorts considered when compared to those born in subsequent years. For both genders the cohort effects 
Table 3.6: Probability Values for the Schoenfeld Residual Test of Proportionality

\begin{tabular}{lcccccc} 
& Total Sample & C 1930-39 & C 1940-49 & C 1950-59 & C1960-69 & C 1970-79 \\
\hline part-time & 0.00 & 0.0008 & 0.00 & 0.0581 & 0.00 & 0.0256 \\
immigrant & 0.1281 & 0.2903 & 0.0246 & 0.0525 & 0.7067 & 0.0061 \\
married & 0.1893 & 0.1882 & 0.5376 & 0.3764 & 0.6808 & 0.5006 \\
age began & 0.00 & 0.0014 & 0.00 & 0.00 & 0.00 & 0.0667 \\
parental & 0.0016 & - & - & 0.0086 & 0.4113 & 0.0066 \\
work rel. & 0.00 & 0.0014 & 0.00 & 0.00 & 0.1245 & 0.00 \\
UR gap & 0.00 & 0.0004 & 0.00 & 0.00 & 0.00 & 0.5095 \\
high sch. & 0.4191 & 0.00 & 0.5893 & 0.1261 & 0.0006 & 0.7217 \\
college & 0.5287 & 0.5664 & 0.0414 & 0.3567 & 0.0002 & 0.9148 \\
univ. & 0.0917 & 0.1915 & 0.036 & 0.3012 & 0.0004 & 0.5876 \\
\hline global test & 0.00 & 0.00 & 0.00 & 0.00 & 0.00 & 0.0001 \\
Obs & 6980 & 516 & 991 & 1456 & 1886 & 1619 \\
\hline & & & Women & & & \\
\hline part-time & 0.00 & 0.4524 & 0.0674 & 0.029 & 0.0931 & 0.0366 \\
immigrant & 0.1633 & 0.6461 & 0.3423 & 0.385 & 0.4826 & 0.05 \\
married & 0.2951 & 0.0183 & 0.3442 & 0.5288 & 0.4867 & 0.7347 \\
age began & 0.00 & 0.1227 & 0.0002 & 0 & 0.0886 & 0.8992 \\
parental & 0.00 & 0.00 & 0.00 & 0.00 & 0.00 & 0.00 \\
work rel. & 0.0018 & 0.3042 & 0.0262 & 0 & 0.4625 & 0.0029 \\
UR gap & 0.00 & 0.0039 & 0.00 & 0.00 & 0.0001 & 0.8466 \\
high sch. & 0.0301 & 0.7823 & 0.2515 & 0.8597 & 0.1361 & 0.00 \\
college & 0.0013 & 0.7552 & 0.0022 & 0.1741 & 0.2078 & 0.00 \\
univ. & 0.0007 & 0.8899 & 0.0067 & 0.2711 & 0.6805 & 0.00 \\
\hline global test & 0.00 & 0.00 & 0.00 & 0.00 & 0.00 & 0.00 \\
Obs & 9556 & 918 & 1404 & 2026 & 2427 & 2156 \\
\hline \hline & & & & & \\
\hline
\end{tabular}

Notes: The table reports the p-values of the Schoenfeld Residual Test for individual variables and for the sub-sample as a whole. Proportionality is assumed under the null. Birth cohort dummies are not included in the table for expositional ease but were tested as part of the total sample tests. 
point to a larger hazard for more recent cohorts, with those born in the 1980s (and lacking a high school diploma) having the highest hazard. This can be seen as a decreasingly negative coefficient for succeeding cohorts of both men and women. 
Table 3.7: Cox Semiparametric Estimates of Employment Spells with Time-Varying Covariates: Men

\begin{tabular}{|c|c|c|c|c|c|c|}
\hline & Total Sample & C $1930-39$ & C $1940-49$ & C $1950-59$ & C1960-69 & C $1970-79$ \\
\hline $\begin{array}{l}\text { Time-Invariant } \\
\text { part-time }\end{array}$ & $\begin{array}{c}1.280^{* * *} \\
(0.106)\end{array}$ & $\begin{array}{c}1.008 \\
(0.613)\end{array}$ & $\begin{array}{c}0.886 \\
(0.587)\end{array}$ & $\begin{array}{c}1.227^{* * * *} \\
(0.270)\end{array}$ & $\begin{array}{c}1.551^{* * *} \\
(0.226)\end{array}$ & $\begin{array}{c}1.268^{* * *} \\
(0.153)\end{array}$ \\
\hline immigrant & $\begin{array}{c}-0.121^{* *} \\
(0.055)\end{array}$ & $\begin{array}{l}-0.232 \\
(0.158)\end{array}$ & $\begin{array}{l}-0.172 \\
(0.126)\end{array}$ & $\begin{array}{c}-0.292^{* * *} \\
(0.100)\end{array}$ & $\begin{array}{l}0.157^{*} \\
(0.094)\end{array}$ & $\begin{array}{c}0.131 \\
(0.128)\end{array}$ \\
\hline married & $\begin{array}{c}-0.165^{* *} \\
(0.079)\end{array}$ & $\begin{array}{l}-0.199 \\
(0.244)\end{array}$ & $\begin{array}{l}-0.128 \\
(0.157)\end{array}$ & $\begin{array}{c}-0.408 * * * \\
(0.140)\end{array}$ & $\begin{array}{l}-0.119 \\
(0.164)\end{array}$ & $\begin{array}{c}-0.513^{* *} \\
(0.256)\end{array}$ \\
\hline age began & $\begin{array}{c}0.055^{* * *} \\
(0.006)\end{array}$ & $\begin{array}{c}0.062^{* * *} \\
(0.018)\end{array}$ & $\begin{array}{c}0.073^{* * *} \\
(0.013)\end{array}$ & $\begin{array}{c}0.056^{* * *} \\
(0.011)\end{array}$ & $\begin{array}{c}0.070^{* * *} \\
(0.013)\end{array}$ & $\begin{array}{c}0.084^{* * *} \\
(0.019)\end{array}$ \\
\hline parental & $\begin{array}{c}1.256^{* * *} \\
(0.073)\end{array}$ & & & $\begin{array}{c}1.319^{* * *} \\
(0.224)\end{array}$ & $\begin{array}{c}1.153^{* * *} \\
(0.204)\end{array}$ & $\begin{array}{c}1.442^{* * *} \\
(0.214)\end{array}$ \\
\hline high school & $\begin{array}{c}-0.242^{* * *} \\
(0.092)\end{array}$ & $\begin{array}{l}-0.192 \\
(0.214)\end{array}$ & $\begin{array}{c}-0.516^{* * *} \\
(0.169)\end{array}$ & $\begin{array}{c}-0.474^{* * *} \\
(0.158)\end{array}$ & $\begin{array}{c}-0.418^{* *} \\
(0.198)\end{array}$ & $\begin{array}{c}-0.25 \\
(0.279)\end{array}$ \\
\hline college & $\begin{array}{l}-0.172^{*} \\
(0.092)\end{array}$ & $\begin{array}{c}0.179 \\
(0.233)\end{array}$ & $\begin{array}{l}-0.148 \\
(0.167)\end{array}$ & $\begin{array}{l}-0.276^{*} \\
(0.160)\end{array}$ & $\begin{array}{c}-0.610^{* * *} \\
(0.202)\end{array}$ & $\begin{array}{l}-0.167 \\
(0.279)\end{array}$ \\
\hline university & $\begin{array}{c}-0.374^{* * *} \\
(0.090)\end{array}$ & $\begin{array}{c}0.119 \\
(0.202)\end{array}$ & $\begin{array}{c}-0.531^{* * *} \\
(0.172)\end{array}$ & $\begin{array}{c}-0.535^{* * *} \\
(0.151)\end{array}$ & $\begin{array}{c}-0.431^{* *} \\
(0.192)\end{array}$ & $\begin{array}{l}-0.404 \\
(0.276)\end{array}$ \\
\hline C 1930-39 & $\begin{array}{c}-2.891^{* * *} \\
(0.182)\end{array}$ & & & & & \\
\hline C 1940-49 & $\begin{array}{c}-1.938^{* * *} \\
(0.135)\end{array}$ & & & & & \\
\hline C 1950-59 & $\begin{array}{c}-1.217^{* * *} \\
(0.119)\end{array}$ & & & & & \\
\hline C $1960-69$ & $\begin{array}{c}-0.748^{* * *} \\
(0.109)\end{array}$ & & & & & \\
\hline C 1970-79 & $\begin{array}{c}-0.369 * * * \\
(0.109)\end{array}$ & & & & & \\
\hline $\begin{array}{l}\text { Time-Varying } \\
\text { work related }\end{array}$ & $\begin{array}{c}0.036^{* * *} \\
(0.003)\end{array}$ & $\begin{array}{c}0.026^{* * *} \\
(0.006)\end{array}$ & $\begin{array}{c}0.026^{* * *} \\
(0.004)\end{array}$ & $\begin{array}{c}0.038^{* * *} \\
(0.003)\end{array}$ & $\begin{array}{c}0.051^{* * *} \\
(0.007)\end{array}$ & $\begin{array}{c}0.144^{* * *} \\
(0.024)\end{array}$ \\
\hline ur gap & $\begin{array}{c}0.029^{* * *} \\
(0.001)\end{array}$ & $\begin{array}{c}0.016^{* * *} \\
(0.002)\end{array}$ & $\begin{array}{c}0.024^{* * *} \\
(0.002)\end{array}$ & $\begin{array}{c}0.042^{* * *} \\
(0.002)\end{array}$ & $\begin{array}{c}0.074^{* * *} \\
(0.004)\end{array}$ & $\begin{array}{c}0.205^{* * *} \\
(0.011)\end{array}$ \\
\hline Obs & 6980 & 516 & 991 & 1456 & 1886 & 1619 \\
\hline log Likelihood & -20294 & -1515 & -2754 & -3712 & -4613 & -3253 \\
\hline
\end{tabular}

Notes: Standard errors are in parentheses. ${ }^{* * *},{ }^{* *}$, and $*$ denote $1 \%, 5 \%$, and $10 \%$ level of significance, respectively. C 1930-39 refers to the 1930-1939 birth cohort, similarly, the C 1940-49 to C 1970-79 refer to the birth cohort 1940-1949 to 1970-1979. 
Overall assessments of fit for the re-estimated model are performed using a comparison of the Cox-Snell residuals to the standard exponential distribution with $\lambda(t)=1$. These plots are found in Figures 3.7 and 3.8 for men and women respectively. A model with perfect fit would generate a plot that lies directly on top of the diagonal line. The figures seem to imply that the model results are quite poor for men and latter cohorts of women. However, in Table 3.9 it is shown that the portion of the residual plots with a poor fit (chosen by visual inspection of the Cox-Snell residual plots) is relegated to a number of outlying observations and that, for the most part, these entail fewer than $5 \%$ of observations. Men of the pre-1970s cohorts and women of the post 1950 s cohorts have between $0 \%$ and $4 \%$ of their residuals falling significantly out of line. It should be noted that censoring in the right tails of the employment duration distribution will generate errors around the tails of the Cox-Snell residual plots. 
Table 3.8: Cox Semiparametric Estimates of Employment Spells with Time-Varying Covariates: Women

\begin{tabular}{|c|c|c|c|c|c|c|}
\hline & Total Sample & C 1930-39 & C $1940-49$ & C 1950-59 & C1960-69 & C $1970-79$ \\
\hline $\begin{array}{l}\text { Time-Invar. } \\
\text { part-time }\end{array}$ & $\begin{array}{c}0.613^{* * *} \\
(0.051)\end{array}$ & $\begin{array}{l}0.224 \\
(0.15)\end{array}$ & $\begin{array}{c}0.307^{* *} \\
(0.154)\end{array}$ & $\begin{array}{c}0.534^{* * *} \\
(0.127)\end{array}$ & $\begin{array}{c}0.766^{* * *} \\
(0.108)\end{array}$ & $\begin{array}{c}0.73^{* * *} \\
(0.096)\end{array}$ \\
\hline immigrant & $\begin{array}{c}-0.149 * * * \\
(0.036)\end{array}$ & $\begin{array}{c}-0.194^{* *} \\
(0.093)\end{array}$ & $\begin{array}{c}-0.183^{* *} \\
(0.087)\end{array}$ & $\begin{array}{c}-0.23^{* * *} \\
(0.076)\end{array}$ & $\begin{array}{c}-0.122^{*} \\
(0.07)\end{array}$ & $\begin{array}{l}-0.086 \\
(0.078)\end{array}$ \\
\hline married & $\begin{array}{r}-0.045 \\
(0.05)\end{array}$ & $\begin{array}{c}-0.266^{* *} \\
(0.127)\end{array}$ & $\begin{array}{l}-0.113 \\
(0.113)\end{array}$ & $\begin{array}{l}-0.121 \\
(0.098)\end{array}$ & $\begin{array}{l}-0.039 \\
(0.089)\end{array}$ & $\begin{array}{c}0.336^{* * *} \\
(0.109)\end{array}$ \\
\hline age began & $\begin{array}{c}-0.008^{* *} \\
(0.003)\end{array}$ & $\begin{array}{c}0.009 \\
(0.007)\end{array}$ & $\begin{array}{c}0.002 \\
(0.007)\end{array}$ & $\begin{array}{c}-0.019 * * * \\
(0.007)\end{array}$ & $\begin{array}{c}0.021^{* *} \\
(0.009)\end{array}$ & $\begin{array}{c}0.081^{* * *} \\
(0.013)\end{array}$ \\
\hline work rel. & $\begin{array}{c}0.797^{* * *} \\
(0.041)\end{array}$ & $\begin{array}{c}0.803^{* * *} \\
(0.115)\end{array}$ & $\begin{array}{c}0.786^{* * *} \\
(0.093)\end{array}$ & $\begin{array}{c}0.687^{* * *} \\
(0.081)\end{array}$ & $\begin{array}{c}0.681^{* * *} \\
(0.079)\end{array}$ & $\begin{array}{c}0.978^{* * *} \\
(0.089)\end{array}$ \\
\hline ur gap & $\begin{array}{c}0.056^{* * *} \\
(0.012)\end{array}$ & $\begin{array}{c}0.039 \\
(0.027)\end{array}$ & $\begin{array}{c}-0.388^{* *} \\
(0.045)\end{array}$ & $\begin{array}{c}-0.087^{* *} \\
(0.025)\end{array}$ & $\begin{array}{c}0.315^{* * *} \\
(0.025)\end{array}$ & $\begin{array}{c}0.548^{* * *} \\
(0.038)\end{array}$ \\
\hline high sch. & $\begin{array}{c}0.095 \\
(0.059)\end{array}$ & $\begin{array}{c}-0.02 \\
(0.117)\end{array}$ & $\begin{array}{l}0.075 \\
(0.11)\end{array}$ & $\begin{array}{c}0.003 \\
(0.133)\end{array}$ & $\begin{array}{c}0.249 \\
(0.158)\end{array}$ & $\begin{array}{l}-0.061 \\
(0.247)\end{array}$ \\
\hline college & $\begin{array}{c}0.186^{* * *} \\
(0.06)\end{array}$ & $\begin{array}{c}0.119 \\
(0.119)\end{array}$ & $\begin{array}{c}0.095 \\
(0.111)\end{array}$ & $\begin{array}{c}0.13 \\
(0.134)\end{array}$ & $\begin{array}{c}0.361^{* *} \\
(0.157)\end{array}$ & $\begin{array}{c}0.095 \\
(0.245)\end{array}$ \\
\hline univ. & $\begin{array}{c}0.158^{* * *} \\
(0.061)\end{array}$ & $\begin{array}{c}0.097 \\
(0.144)\end{array}$ & $\begin{array}{c}0.054 \\
(0.129)\end{array}$ & $\begin{array}{c}0.23^{*} \\
(0.139)\end{array}$ & $\begin{array}{c}0.237 \\
(0.157)\end{array}$ & $\begin{array}{l}-0.016 \\
(0.242)\end{array}$ \\
\hline C 1930-39 & $\begin{array}{c}-0.992^{* * *} \\
(0.088)\end{array}$ & & & & & \\
\hline C 1940-49 & $\begin{array}{c}-0.973^{* * *} \\
(0.081)\end{array}$ & & & & & \\
\hline C $1950-59$ & $\begin{array}{c}-0.857 * * * \\
(0.077)\end{array}$ & & & & & \\
\hline C 1960-69 & $\begin{array}{c}-0.663^{* * *} \\
(0.076)\end{array}$ & & & & & \\
\hline C 1970-79 & $\begin{array}{c}-0.345^{* * *} \\
(0.075)\end{array}$ & & & & & \\
\hline $\begin{array}{l}\text { Time-Var. } \\
\text { parental }\end{array}$ & $\begin{array}{c}0.038^{* * * *} \\
(0.003)\end{array}$ & $\begin{array}{c}0.098^{* * *} \\
(0.013)\end{array}$ & $\begin{array}{c}0.027^{* * *} \\
(0.006)\end{array}$ & $\begin{array}{c}0.038^{* * *} \\
(0.005)\end{array}$ & $\begin{array}{c}0.027^{* * *} \\
(0.004)\end{array}$ & $\begin{array}{c}0.077^{* * *} \\
(0.008)\end{array}$ \\
\hline Obs & 9556 & 918 & 1404 & 2026 & 2427 & 2156 \\
\hline log Likelihood & -55474 & -4501 & -7015 & -10501 & -12705 & -9066 \\
\hline
\end{tabular}

Notes: Standard errors are in parentheses. ${ }^{* * *},{ }^{* *}$, and $*$ denote $1 \%, 5 \%$, and $10 \%$ level of significance, respectively. C 1930-39 refers to the 1930-1939 birth cohort, similarly, the C 1940-49 to C 1970-79 refer to the birth cohort 1940-1949 to 1970-1979. 


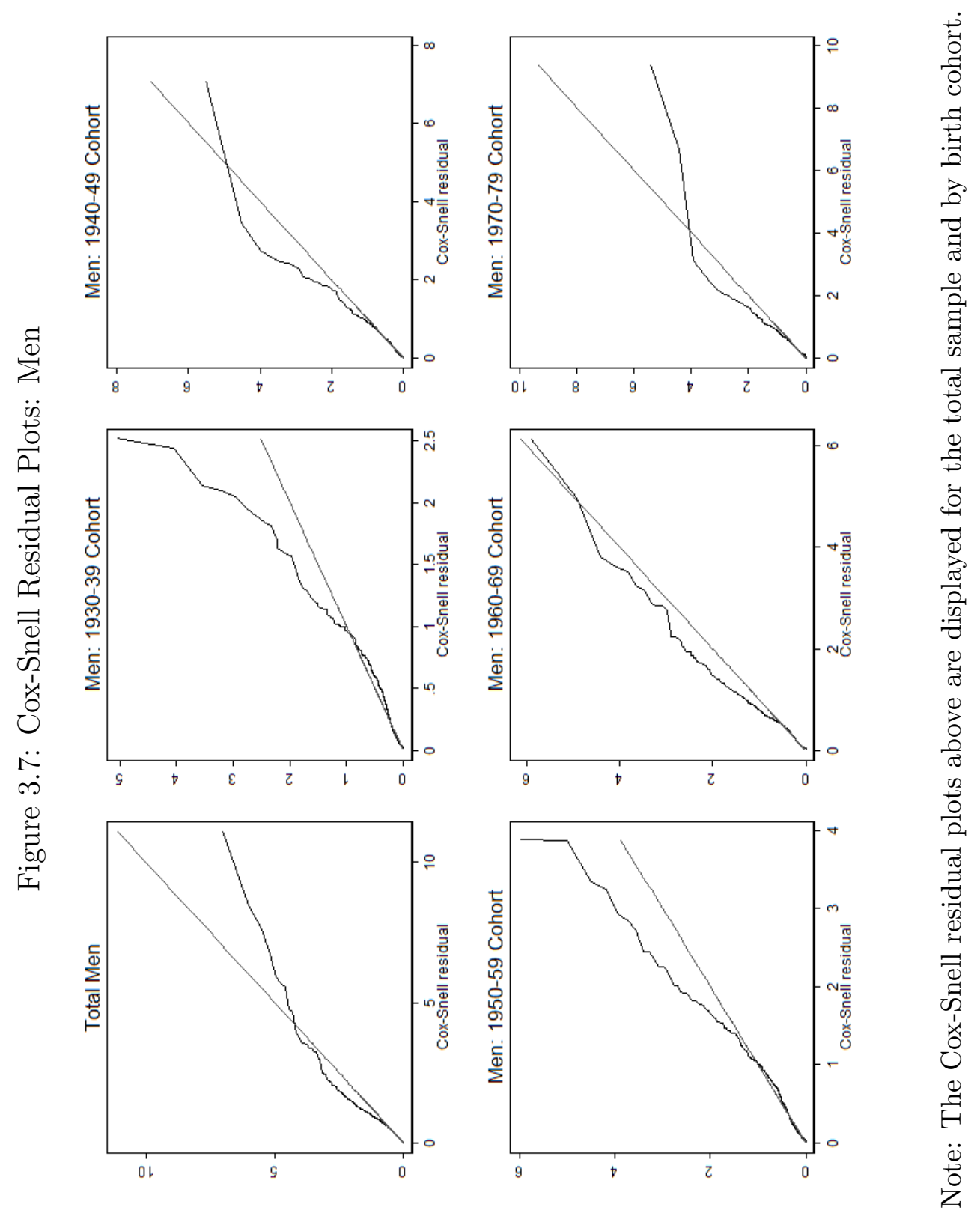




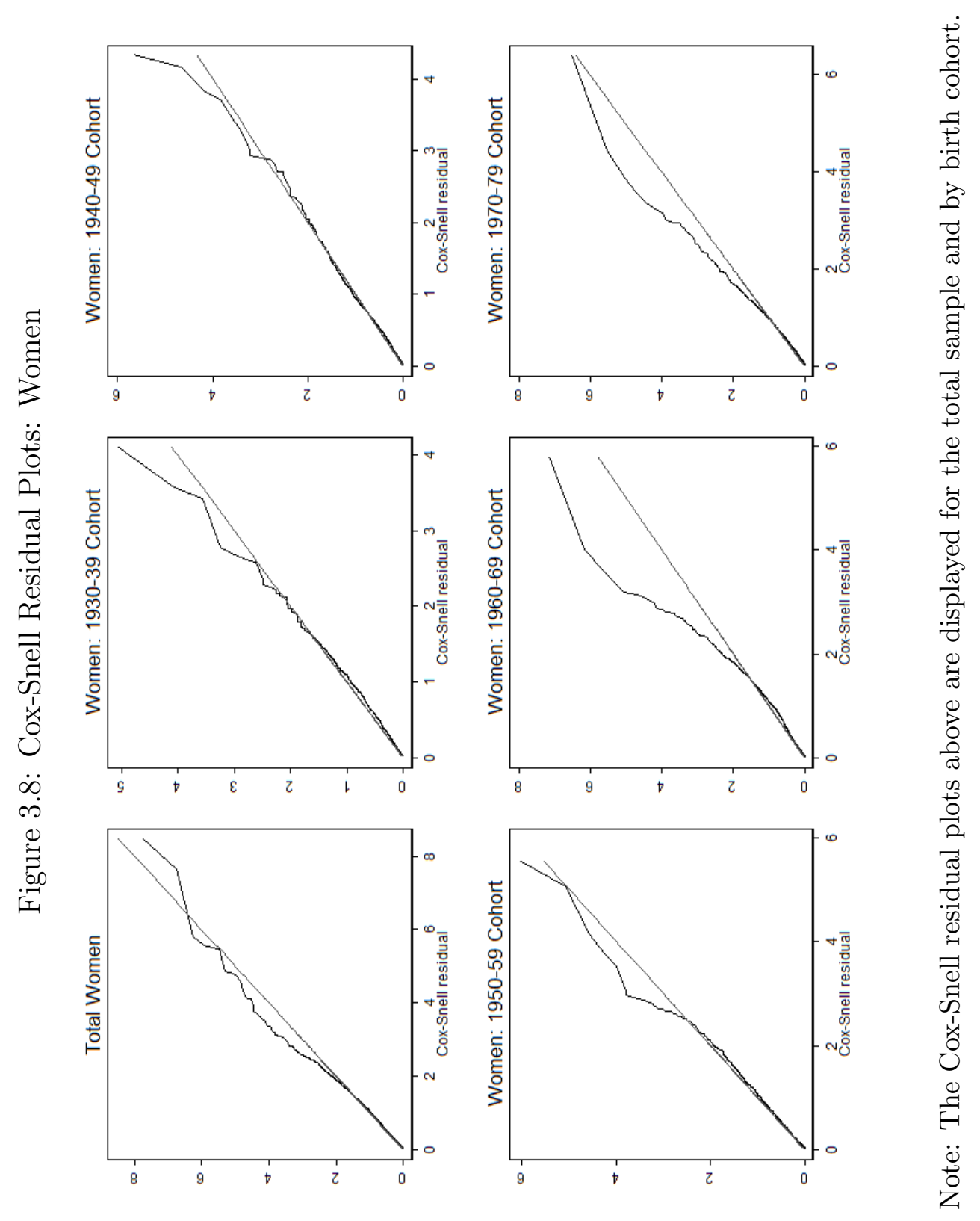


Table 3.9: Cox-Snell Residual Shares

Cut-off value Proportion below cutoff

\begin{tabular}{lcc}
\hline Men Total & 1 & 0.966 \\
Men 1930-39 & 1 & 0.9147 \\
Men 1940-49 & 2 & 0.9889 \\
Men 1950-59 & 1.5 & 0.9718 \\
Men 1960-69 & 1 & 0.9608 \\
Men 1970-79 & 1 & 0.9722 \\
\hline Women Total & 5 & 0.9994 \\
Women 1930-39 & 2.5 & 0.9924 \\
Women 1940-49 & 2.5 & 0.985 \\
Women 1950-59 & 3 & 0.997 \\
Women 1960-69 & 2 & 0.9679 \\
Women 1970-79 & 1.5 & 0.9485 \\
\hline \hline
\end{tabular}

Notes: The table presents the proportion of residual values which fall below a selected cut-off deemed appropriate from examination of the Cox-Snell Residual plots in Figures 3.7 and 3.8 .

For men, it can be observed that being married prior to the commencement of the employment spell decreases the hazard. For women this is true until the 1970s cohort, where marriage raises the hazard. This is likely a selection issue for women of earlier cohorts as it was generally the case that young women would enter the labour market until marriage. This social convention likely no longer held sway by the time women of the 1960s cohort had entered the labour market. The coefficient on the age at which work began also switched signs for women in the 1970s cohort. This set of changes coincides with the major shift of women into the workforce that occurred for cohorts of women born during and after the 1960s. Immigration also reduces the hazard for men born in the 1950s and most cohorts of women.

For those leaving employment for work-related reasons (like plant closures or layoffs) there is a significant increase to the hazard for both men and women. 
The most prominent rise in the contribution to the hazard is for those who were born in the 1970s, the magnitude of the coefficient for the 1970s cohort increases significantly for women and is more than doubled for men. These increases are likely due to the recession of the 1990s when layoffs and unemployment rates spiked and a jobless recovery ensued (the prolonged weakness in the labour market made a separation of over three months more likely). By including a cyclical proxy in the form of the unemployment rate gap at the time of exit, cyclical effects can be controlled - leaving the coefficient on work related separation one which represents the institutional shifts that affected those born in the 1970s (it should be noted that there is some weak correlation between these two variables $\rho \approx 0.15)$. But the impacts of macro conditions and work related departures increase the hazard at an increasing rate across cohorts up to the 1960s cohort. Both coefficients show a discontinuous jump between the 1960s and 1970s cohorts implying that work related departures and macroeconomic conditions had a joint effect for workers of the 1970s cohort. These findings are consistent with the findings of Ostrovsky [35] regarding the effects of recessions on earnings stability.

There is always an increase in the hazard for departures due to parental reasons. For women, a larger increase in the size of the coefficient on parental separations can be seen associated with the 1930s, 1950s and the 1970s birth cohort. The latter increases may be related to the increased generosity of maternity leave provisions in the unemployment insurance program reforms instituted in 1971 (when 15 weeks of maternity leave could for the first time be claimed through unemployment insurance) and the increases to leave provisions in 1990. The 1990 provisions 
provided 10 weeks of parental leave (expanded to 35 weeks in 2001), this coincides with the increase to the hazard observed for women born in the 1970s.

Interestingly, the coefficients on the education levels contribute negatively to the hazard for men but positively for women. However, the effects of education are largely insignificant for women by cohort and only exert marginal influence in the 1950s and 1960s cohorts. These results are in line with Farber [10] who found that increasing education levels mitigated tenure declines only to a small degree. For men, university level educational attainment is found to be significant from the 1940s until the 1960s cohort. For those born in the 1970s the contributions of education disappear.

\subsubsection{Competing Risks Regression Results}

To further analyze the possibility that the effects of recessionary periods and parental provisions are effective for men and women respectively a competing risks analysis was run for both sub-groups, again by cohort. For men, the sub-hazard under analysis was that of separating from employment by way of a work related separation with competing risks of separating for any other reasons. For women, the sub-hazard under analysis was that of a separation induced by separation due to the birth of a child (or adoption) with competing risks of separations for any other reasons.

The results of the competing risks regressions can be seen in Tables 3.10 and 3.11. For men the aggregate sub-hazard of separation due to work related reasons is 
Table 3.10: Competing Risks Regression (Work Related Separation vs. Other Reasons): Men

\begin{tabular}{|c|c|c|c|c|c|c|}
\hline & Total Sample & C 1930-39 & C $1940-49$ & C 1950-59 & C1960-69 & C $1970-79$ \\
\hline part-time & $\begin{array}{l}-0.361 \\
(0.346)\end{array}$ & $\begin{array}{c}-16.965^{* * *} \\
(0.464)\end{array}$ & $\begin{array}{c}-16.682^{* * *} \\
(0.432)\end{array}$ & $\begin{array}{l}-1.669 \\
(1.053)\end{array}$ & $\begin{array}{l}-0.223 \\
(0.552)\end{array}$ & $\begin{array}{c}0.039 \\
(0.469)\end{array}$ \\
\hline married & $\begin{array}{c}-0.329^{* *} \\
(0.155)\end{array}$ & $\begin{array}{l}-0.121 \\
(0.549)\end{array}$ & $\begin{array}{c}-0.799^{* *} \\
(0.384)\end{array}$ & $\begin{array}{c}-0.814^{* * *} \\
(0.294)\end{array}$ & $\begin{array}{c}0.286 \\
(0.282)\end{array}$ & $\begin{array}{l}-0.146 \\
(0.38)\end{array}$ \\
\hline age began & $\begin{array}{c}0.025^{* *} \\
(0.011)\end{array}$ & $\begin{array}{c}0.043 \\
(0.032)\end{array}$ & $\begin{array}{c}0.025 \\
(0.041)\end{array}$ & $\begin{array}{l}0.031^{*} \\
(0.018)\end{array}$ & $\begin{array}{c}0.008 \\
(0.021)\end{array}$ & $\begin{array}{c}0.094^{* *} \\
(0.032)\end{array}$ \\
\hline immigrant & $\begin{array}{c}-0.181^{*} \\
(0.097)\end{array}$ & $\begin{array}{c}0.096 \\
(0.424)\end{array}$ & $\begin{array}{l}-0.081 \\
(0.265)\end{array}$ & $\begin{array}{c}-0.353^{*} \\
(0.189)\end{array}$ & $\begin{array}{l}-0.211 \\
(0.166)\end{array}$ & $\begin{array}{c}0.027 \\
(0.234)\end{array}$ \\
\hline ur gap & $\begin{array}{c}0.48^{* * *} \\
(0.048)\end{array}$ & $\begin{array}{c}0.164 \\
(0.212)\end{array}$ & $\begin{array}{l}-0.055 \\
(0.213)\end{array}$ & $\begin{array}{c}0.264^{* *} \\
(0.109)\end{array}$ & $\begin{array}{c}0.725^{* * *} \\
(0.069)\end{array}$ & $\begin{array}{c}0.933^{* *} \\
(0.106)\end{array}$ \\
\hline high school & $\begin{array}{c}-0.224^{* *} \\
(0.156)\end{array}$ & $\begin{array}{c}-1.094^{* *} \\
(0.454)\end{array}$ & $\begin{array}{c}0.187 \\
(0.422)\end{array}$ & $\begin{array}{l}-0.196 \\
(0.296)\end{array}$ & $\begin{array}{c}-0.461^{* *} \\
(0.296)\end{array}$ & $\begin{array}{c}0.166 \\
(0.601)\end{array}$ \\
\hline college & $\begin{array}{l}-0.219 \\
(0.159)\end{array}$ & $\begin{array}{c}-1.069 * * \\
(0.519)\end{array}$ & $\begin{array}{c}0.495 \\
(0.411)\end{array}$ & $\begin{array}{l}-0.195 \\
(0.306)\end{array}$ & $\begin{array}{c}-0.677^{* *} \\
(0.303)\end{array}$ & $\begin{array}{l}0.31 \\
(0.6)\end{array}$ \\
\hline university & $\begin{array}{c}-0.521^{* * *} \\
(0.157)\end{array}$ & $\begin{array}{l}-1.3^{* *} \\
(0.514)\end{array}$ & $\begin{array}{l}-0.242 \\
(0.413)\end{array}$ & $\begin{array}{c}-0.618^{* *} \\
(0.303)\end{array}$ & $\begin{array}{c}-0.546^{*} \\
(0.294)\end{array}$ & $\begin{array}{l}-0.098 \\
(0.598)\end{array}$ \\
\hline C 1930-39 & $\begin{array}{c}-1.679^{* * *} \\
(0.282)\end{array}$ & & & & & \\
\hline C $1940-49$ & $\begin{array}{c}-1.185^{* * *} \\
(0.246)\end{array}$ & & & & & \\
\hline C 1950-59 & $\begin{array}{c}-0.529^{* *} \\
(0.23)\end{array}$ & & & & & \\
\hline C 1960-69 & $\begin{array}{l}-0.295 \\
(0.224)\end{array}$ & & & & & \\
\hline C 1970-79 & $\begin{array}{l}-0.154 \\
(0.226)\end{array}$ & & & & & \\
\hline Obs & 6980 & 516 & 991 & 1456 & 1886 & 1619 \\
\hline log Likelihood & -7441 & -278 & -729 & -1631 & -2061 & -1218 \\
\hline
\end{tabular}

Notes: Standard errors are in parentheses. ***,**, and * denote $1 \%, 5 \%$, and $10 \%$ level of significance, respectively. C 1930-39 refers to the 1930-1939 birth cohort, similarly, the C 1940-49 to C 1970-79 refer to the birth cohort 1940-1949 to 1970-1979. 
Table 3.11: Competing Risks Regression (Maternity/Parental Related Separation vs. Other Reasons): Women

\begin{tabular}{|c|c|c|c|c|c|c|}
\hline & Total Sample & C 1930-39 & C $1940-49$ & C 1950-59 & C1960-69 & C 1970-79 \\
\hline part-time & $\begin{array}{l}-0.147 \\
(0.123)\end{array}$ & $\begin{array}{l}-1.008 \\
(1.045)\end{array}$ & $\begin{array}{c}-1.241^{* *} \\
(0.612)\end{array}$ & $\begin{array}{l}-0.288 \\
(0.308)\end{array}$ & $\begin{array}{l}-0.008 \\
(0.219)\end{array}$ & $\begin{array}{c}0.013 \\
(0.192)\end{array}$ \\
\hline married & $\begin{array}{l}0.015 \\
(0.095)\end{array}$ & $\begin{array}{c}-1.239^{* *} \\
(0.488)\end{array}$ & $\begin{array}{l}-0.134 \\
(0.292)\end{array}$ & $\begin{array}{l}-0.166 \\
(0.182)\end{array}$ & $\begin{array}{l}-0.117 \\
(0.155)\end{array}$ & $\begin{array}{c}0.707^{* * *} \\
(0.164)\end{array}$ \\
\hline age began & $\begin{array}{c}-0.071^{* * *} \\
(0.007)\end{array}$ & $\begin{array}{l}-0.032 \\
(0.022)\end{array}$ & $\begin{array}{c}-0.071^{* * *} \\
(0.019)\end{array}$ & $\begin{array}{c}-0.079^{* * *} \\
(0.015)\end{array}$ & $\begin{array}{c}-0.046^{* * *} \\
(0.012)\end{array}$ & $\begin{array}{c}0.008 \\
(0.018)\end{array}$ \\
\hline immigrant & $\begin{array}{c}-0.116^{*} \\
(0.061)\end{array}$ & $\begin{array}{c}0.224 \\
(0.223)\end{array}$ & $\begin{array}{l}-0.105 \\
(0.162)\end{array}$ & $\begin{array}{l}-0.107 \\
(0.121)\end{array}$ & $\begin{array}{l}-0.109 \\
(0.111)\end{array}$ & $\begin{array}{c}-0.251^{*} \\
(0.135)\end{array}$ \\
\hline ur gap & $\begin{array}{c}0.056^{* *} \\
(0.022)\end{array}$ & $\begin{array}{l}-0.037 \\
(0.069)\end{array}$ & $\begin{array}{c}-0.492^{* * *} \\
(0.079)\end{array}$ & $\begin{array}{l}-0.045 \\
(0.045)\end{array}$ & $\begin{array}{c}0.297 * * * \\
(0.036)\end{array}$ & $\begin{array}{c}0.297 * * * \\
(0.063)\end{array}$ \\
\hline high sch. & $\begin{array}{c}0.596^{* * * *} \\
(0.156)\end{array}$ & $\begin{array}{c}0.258 \\
(0.328)\end{array}$ & $\begin{array}{c}0.681^{* *} \\
(0.341)\end{array}$ & $\begin{array}{c}0.285 \\
(0.318)\end{array}$ & $\begin{array}{c}0.802^{* *} \\
(0.342)\end{array}$ & $\begin{array}{l}0.85^{*} \\
(0.501)\end{array}$ \\
\hline college & $\begin{array}{c}0.867^{* * * *} \\
(0.155)\end{array}$ & $\begin{array}{l}0.578^{*} \\
(0.313)\end{array}$ & $\begin{array}{c}0.868^{* * *} \\
(0.336)\end{array}$ & $\begin{array}{c}0.597^{*} \\
(0.319)\end{array}$ & $\begin{array}{c}0.956^{* * *} \\
(0.339)\end{array}$ & $\begin{array}{l}1.254^{* *} \\
(0.498)\end{array}$ \\
\hline univ. & $\begin{array}{c}0.898^{* * * *} \\
(0.156)\end{array}$ & $\begin{array}{c}0.185 \\
(0.371)\end{array}$ & $\begin{array}{c}0.806^{* *} \\
(0.359)\end{array}$ & $\begin{array}{c}0.886^{* * *} \\
(0.325)\end{array}$ & $\begin{array}{c}0.991^{* * *} \\
(0.335)\end{array}$ & $\begin{array}{l}1.052^{* *} \\
(0.495)\end{array}$ \\
\hline C 1930-39 & $\begin{array}{l}-0.036 \\
(0.183)\end{array}$ & & & & & \\
\hline C 1940-49 & $\begin{array}{c}0.168 \\
(0.168)\end{array}$ & & & & & \\
\hline C $1950-59$ & $\begin{array}{c}0.432^{* * * *} \\
(0.161)\end{array}$ & & & & & \\
\hline C 1960-69 & $\begin{array}{c}0.61^{* * *} \\
(0.159)\end{array}$ & & & & & \\
\hline C 1970-79 & $\begin{array}{c}0.655^{* * *} \\
(0.161)\end{array}$ & & & & & \\
\hline Obs & 9556 & 918 & 1404 & 2026 & 2427 & 2156 \\
\hline log Likelihood & -22833 & -1072 & -2169 & -4665 & -6287 & -4197 \\
\hline
\end{tabular}

Notes: Standard errors are in parentheses. ***,**, and * denote 1\%, 5\%, and $10 \%$ level of significance, respectively. C 1930-39 refers to the 1930-1939 birth cohort, similarly, the C 1940-49 to C 1970-79 refer to the birth cohort 1940-1949 to 1970-1979. 
reduced if the individual is married or an immigrant relative to the base group of men born in the 1980s and not having completed high school. The hazard falls with higher levels of education and for earlier cohorts of workers. Declines in the hazard are only found for workers of the 1950s cohort and earlier with those of the 1960s cohorts and beyond indistinguishable from the base group. Adverse macroeconomic conditions at separation increase the hazard, the effects are strongest for the 1960s and 1970s cohorts. This suggests that macroeconomic conditions had a significant impact on men's separations for work related reasons at the same time that institutional factors (proxied by cohort effects in the aggregate equation) contributed to a rising hazard for these workers. The extreme magnitude on the coefficients of part-time employment in the 1930 s and 1940s cohorts are largely due to the thinness of the data. For women, the sub-hazard of separation due to parental/maternity based departures is negatively influenced by the age at which work began and positively influenced by the unemployment rate gap and educational attainment. Furthermore, the sub-hazard rises for cohorts after the 1940s, relative to both the base group born in the 1980s and the 1930s and 1940s cohort. This implies that women born in the 1950s had a greater risk of separation for maternity reasons than preceding cohort of women. This is consistent with the hypothesis that maternity-based separations increase in line with the introduction of new support measures.

The combined results above show that major changes occurred for both men and women born into the 1970s cohort due to changing work conditions. Parental provisions also powerfully impacted the ability of women to break up their employment spells and return to the same job in the future for both the 1950s and 1970s 
cohort.

\subsection{Conclusions}

Employment tenures of workers have declined over time and a number of socioeconomic factors have contributed to this phenomena. It has been shown above that successive cohorts of workers have had increasingly shorter first employment durations. This pattern has occurred for both men and women, but the decline has been far more prominent for men. The cohorts of workers who were born after the 1950s were likely to be strongly affected by the recession of 1990 s and its ensuing jobless recovery, this shows up as increasing hazards for both groups. Parental leave increases the probability of separation strongly for women and the increasing hazard by cohort coincides with the increasing generosity of parental benefit provisions. It is likely that this fact plays a large role in explaining he divergence of employment tenures from job tenures as maternity provisions allowed women to break up employment without separating from their jobs in the post 1970 period. Work related issues also increase the probability of separations, even when the business cycle is taken into consideration. This likely implies that firm shutdown and layoffs, particularly with regard to the post-1950s cohorts of workers, have significantly altered the stability of employment for men and women.

Overall, this data implies that there has been a decline in employment stability. The results contribute to the employment stability literature by analyzing five birth cohorts using the GSS data. The use of this retrospective data allows us to 
compare the trends in employment and job stability and find that the relationship has changed over time. In particular, institutional factors have likely contributed to preserve the stability of job tenures while decreasing the stability of continuous employment (which, in the case of parental leave, is likely an improvement rather than impediment to the general welfare).

In the next chapter, spells beyond the first will be examined in order to determine whether their prevalence or specific properties can contribute to explaining the declines in employment tenures over the latter half of the twentieth century. 


\section{Chapter 4: Employment Spells beyond the First}

\subsection{Overview}

In the preceding chapter it was inferred that the primary driver of declining employment tenures for first employment spells were changes in the institutional structure of the labour market which were proxied by a cohort effect. In this chapter the focus will turn to the analysis of employment spells beyond the first for individuals born after 1930 in order to determine whether the prevalence of latter spells contributed to the declines identified in Chapter 2. As before, the analysis will focus on the differences between individuals born in a particular decade with those individuals who were born in succeeding decades.

The focus of the analysis can be broken down into two components. Firstly, it is interesting to determine whether there is a propensity for individuals to hold a greater number of employment spells over time. Secondly, it is interesting to see whether the socio-economic variables which influence first employment spells affect later spells in the same manner.

In the case of the first question, it will be shown that individuals have increased their propensity to hold a larger number of employment spells over time. This

result is more pronounced for men than for women. As to the second object of 
study, the results are more complicated. Overall, cohort effects play a much smaller role for employment tenures after the first spell and almost no effect at all for those beyond the third. However, it will be shown that macroeconomic conditions and the covariates identified in the second chapter tend to have consistent impacts across employment spells. Furthermore, it will be shown that an individuals total time spent in the workforce and the time spent away from the labour market also impact positively on the propensity of individuals to continue in their employment spells beyond the first.

This chapter, as before, is broken down into four distinct sections. The current section, Section 4.1, is comprised of an introduction and literature review. Section 4.2 deals briefly with the data and modeling strategy. The third section, Section 4.3 , presents the overall results and discusses latter employment spells in light of the results presented in Chapter 3 regarding first spells. Finally, section 4.4 concludes.

The literature regarding the debate on job stability was reviewed in the two preceding chapters, hence only literature focused on multiple job spells is presented below. This literature can be, like much of the literature on the topic, traced back to the mover-stayer model of Blumen et al. [17]. However the literature has developed along a number of different avenues. The transitions of workers in the labour market have been analyzed in the context of information asymmetry, wage rigidity as well as public policy.

Much of the literature deals with the impacts of unemployment duration on subsequent employment as well as the impacts on wages. Jackman and Layard [36] showed that long-term unemployment can reduce the chances of finding subsequent 
work. Pissarides [37] proposed that a loss of skills during unemployment is the reason for the negative impact on the ability to find suitable subsequent employment. Lockwood [38], in a matching framework, concludes that the probability of being re-hired depends on the duration of unemployment itself. Gibbons and Katz [39] use a lemons model to show that the reemployment prospects of laid-off workers are worse than those who lose their jobs for other reasons as employers can weed out low productivity workers through the layoff process.

Much of the literature on recurrent job spells deals with youth. This is because the majority of job transitions, as well as earnings growth, occur over the earlier stages of worker's careers. This process is examined in detail by Topel and Ward [40] who provide two reasons for the slowdown in "job hopping" and wage gains for workers over time. The first reason can be interpreted as pure worker heterogeneity following Blumen et. al. [17] in which unobservable characteristics of workers make certain workers more likely to receive training and, in turn, higher wages. This approach is lent support by Gritz [41] who showed that training increases work prospects for women and specifically, it increases spell lengths for both men and women. The second, and empirically supported, reason for job switching and the associated wage gains relies on a model of optimal search, as proposed by Jovanovic [42]. Here, rising wages and increased tenure relies on good employment pairings and rising "returns to search", i.e. wage gains even in the absence of employer sponsored training.

There are numerous policy implications when job tenures and unemployment durations are said to impact future labour market outcomes. One area, summarized 
in Heckman et. al. [43], are active labour market policies enacted by government. There have been numerous studies of these policy interventions, generally showing that providing job search assistance and subsidies provide only short term benefits to recipients and that post-program employment prospects are not strongly responsive to intervention. Doiron and Gorgens [44] show that, in the case of Australia, while past employment increases the probability of future employment, a previous spell of unemployment undoes this boost in labour market outcomes. Conversely, Cockx and Picchio [45] show that even very short first employment spells can lead to much improved subsequent labour market outcomes

The literature reviewed above indicates that multiple spells can be a benefit to some workers, particularly if job match is increased, but that in the instances involuntary separations they can have negative implications for economic outcomes. The literature also tends to find that periods of unemployment can have detrimental impacts on labour market participants. As such, it is important to examine not only workers initial employment spell but the spells that come after. This can shed further light on the degree of decline in worker tenures shown in Chapter 2.

While the current chapter is limited to examining employment tenures, the breaks between employment spells, whether they be through unemployment or temporary exit from the labour force, are also part of the analysis. That is, the employment spells being examined are viewed in light of previous work experience as well as time away from employment. The results show that past labour market experience and increased breaks in employment lead to a lower hazard of work separation conditional on individual participation in an employment spell beyond the first. 


\subsection{Data}

As in Chapter 3, the focus of the current chapter is the employment tenure of an individuals found in 15th and 20th cycles of the General Social Surveys (GSS). The two surveys were conducted throughout 2001 and 2006 and contain a combined 46,745 records. These records contain 19,814 usable spells for the purpose of this chapter; 10,494 second spells, 5,743 third spells, 2,478 fourth spells and 1,099 fifth spells.

In the GSS, respondents retrospectively identify up to five work episodes over their life course, the last four of which will be the focus of this chapter. The survey asks respondents to identify the date and age at which they began their first, second, third, fourth and fifth employment spells spell which lasted at least six months. Respondents are also asked the date and age at which that spell ends. This information is sufficient to extract details on the duration of the second to fifth employment spell for individuals. Entry into employment is self identified by an entry year. Exit is identified by exit date or by the year of retirement if a date is not provided. When respondents refuse to answer, don't know or are not asked for either the entry or exit date, the data are dropped. Furthermore, employment spells of immigrants before arrival in Canada and individuals whose studies are incomplete are also dropped. Data for ongoing spells are kept as they can contribute to the hazard of leaving employment up to the point of censoring. As in the preceding chapters, employment durations were constructed by obtaining the year in which the first spell ended and subtracting it from the year it began. To maintain consistency with the earlier 
analysis, employment spells for all classes of workers are included in the study.

It should be recognized that the data obtained focuses on work interruptions of three months or more. The data does not permit us to verify whether the interruption ended with a return to the same employer or a new employer. Hence, the focus remains on employment stability rather than job stability. As before, those spells with an interruption of fewer than three months were retained in the sample as the length of interruption is not a primary concern for the analysis.

Chapter 2 provided a detailed analysis of the data including the potential problems associated with using this retrospective data. Most of the tests performed on the data in that chapter indicate that the sample did not suffer from any significant bias due to sample selection or memory effects. One potential data problem described there was the issue of how mortality could generate a peculiar form of attrition bias in the sample. The problem would be generated by any potential respondent who worked in the past but died before the retrospective survey date would fall out of the sample. As mentioned in Chapter 2, the survey samples of the GSS conform to census population benchmarks and the age distribution in the GSS matches the Canadian population at the time of the surveys. The youngest individual in the pool of usable spells was born in 1930 and hence would be at most 76 years of age in 2006 (or 71 in 2001) when the surveys were conducted. This is higher than life expectancy at age 20 in 1951 (ages 71 for men and 74 for women). The 1930s birth cohort was, nevertheless, selected as the earliest possible starting point for the analysis.

In Chapter 2 the response rates in the GSS were sufficiently high so that 
selection bias was assessed as posing a fairly remote possibility. Issues common to retrospective surveys, such as the heaping and memory effects described in Torelli and Trivellato [28], were either corrected for through aggregation or addressed by testing. Recall errors are likely to remain a problem with this data; if individuals do not recall an earlier or shorter employment spell it would bias down the number of short duration spells in early cohorts. Tests to account for this possibility were performed between the two datasets used and no clear bias was shown to exist in the data.

Chapter 3 benchmarked the data against the Labour Force Survey and found some discrepancies - although the general patterns between the datasets were similar up to a time trend. The analysis presented there led to the conclusion that overall, it is likely that institutional factors have contributed to the increase in work separations (for periods exceeding 3 months) for first spells while not necessarily decreasing job spell lengths. As in the previous chapters, the analysis is largely based on groupings of ten year birth cohorts. However, significant attention is paid to the spell number of the individual and comparisons across birth cohort are made by spell number. The spell lengths, as before, are compared by birth cohort but with the added emphasis on the prevalence and durations of multiple spells. Tables 4.1 and 4.2 show the distribution of the data by birth cohort and employment spell number for men and for women.

While the distribution by cohort is comparable for men and women the prevalence of employment spells beyond the first is smaller for men indicating that, for those who completed their tenures, men were more likely than women to remain 
Table 4.1: Completed Spell Frequency by Birth Cohort and Spell Number, Women

\begin{tabular}{r|rrrrr|r}
\hline & Spell 1 & Spell 2 & Spell 3 & Spell 4 & Spell 5 & Total \\
\hline $1930-39$ & 4.1 & 2.3 & 0.9 & 0.3 & 0.1 & 7.6 \\
$1940-49$ & 6.6 & 4.5 & 2.0 & 0.8 & 0.4 & 14.3 \\
$1950-59$ & 10.9 & 8.5 & 4.7 & 2.1 & 1.0 & 27.2 \\
$1960-69$ & 12.5 & 10.0 & 5.1 & 2.1 & 0.9 & 30.7 \\
$1970-79$ & 9.2 & 6.4 & 3.0 & 1.1 & 0.4 & 20.1 \\
\hline Total & 43.4 & 31.7 & 15.6 & 6.4 & 2.8 & \\
\hline
\end{tabular}

Table 4.2: Completed Spell Frequency by Birth Cohort and Spell Number, Men

\begin{tabular}{r|rrrr|r}
\hline & Spell 1 & Spell 2 & Spell 3 & Spell 4+ & Total \\
\hline $1930-39$ & 5.7 & 2.1 & 0.6 & 0.2 & 8.5 \\
$1940-49$ & 9.2 & 4.3 & 1.5 & 0.7 & 15.8 \\
$1950-59$ & 13.1 & 8.0 & 3.2 & 2.3 & 26.5 \\
$1960-69$ & 15.3 & 7.5 & 3.3 & 2.0 & 28.1 \\
$1970-79$ & 12.0 & 5.6 & 1.9 & 1.6 & 21.1 \\
\hline Total & 55.3 & 27.5 & 10.5 & 6.7 & \\
\hline
\end{tabular}

consistently attached to the labour market over their life course. Tables 4.3 and 4.4 take the same data but normalize it by cohort so as to determine whether the prevalence of employment spells expanded or diminished by birth cohort. It can be seen that the prevalence of first spells falls to a greater extent for men than for women across cohorts. There is, similarly, a corresponding above-average increase in the prevalence of spells beyond the first for men.

Tables 4.5 and 4.6 show the distribution of the sample by spell number and birth cohort for women and men respectively for ongoing spells. As with completed spells, men are likelier than women to be in earlier spells with only a small portion of the male sample having spells beyond the third. The distribution of observations for men and women across cohorts is similar. 
Table 4.3: Completed Spell Frequency by Birth Cohort, Women

\begin{tabular}{r|rrrrr|r}
\hline & Spell 1 & Spell 2 & Spell 3 & Spell 4 & Spell 5 & Total \\
\hline $1930-39$ & 53.6 & 29.5 & 11.2 & 4.2 & 1.4 & 100 \\
$1940-49$ & 46.2 & 31.5 & 13.9 & 5.8 & 2.5 & 100 \\
$1950-59$ & 40.1 & 31.3 & 17.2 & 7.5 & 3.8 & 100 \\
$1960-69$ & 40.8 & 32.6 & 16.6 & 7.0 & 3.0 & 100 \\
$1970-79$ & 46.0 & 31.9 & 14.8 & 5.2 & 2.1 & 100 \\
\hline
\end{tabular}

Table 4.4: Completed Spell Frequency by Birth Cohort, Men

\begin{tabular}{r|rrrr|r}
\hline & Spell 1 & Spell 2 & Spell 3 & Spell 4+ & Total \\
\hline $1930-39$ & 67.1 & 24.5 & 6.5 & 1.8 & 100 \\
$1940-49$ & 58.4 & 27.4 & 9.7 & 4.6 & 100 \\
$1950-59$ & 49.5 & 30.0 & 11.9 & 8.5 & 100 \\
$1960-69$ & 54.5 & 26.8 & 11.6 & 7.1 & 100 \\
$1970-79$ & 56.7 & 26.4 & 9.2 & 7.6 & 100 \\
\hline
\end{tabular}

Table 4.5: Ongoing Spell Frequency by Birth Cohort and Spell Number, Women

\begin{tabular}{r|rrrrr|r}
\hline & Spell 1 & Spell 2 & Spell 3 & Spell 4 & Spell 5 & Total \\
\hline $1930-39$ & 1.8 & 1.1 & 0.5 & 0.1 & 0.1 & 3.6 \\
$1940-49$ & 3.6 & 3.2 & 2.8 & 1.2 & 0.4 & 11.2 \\
$1950-59$ & 6.6 & 7.4 & 6.8 & 4 & 1.7 & 26.6 \\
$1960-69$ & 7.8 & 8.2 & 8.0 & 4.7 & 2.1 & 30.8 \\
$1970-79$ & 10.7 & 8.1 & 5.8 & 2.4 & 0.9 & 27.8 \\
\hline Total & 30.6 & 27.9 & 23.9 & 12.4 & 5.1 & \\
\hline
\end{tabular}

Table 4.6: Ongoing Spell Frequency by Birth Cohort and Spell Number, Men

\begin{tabular}{r|rrrr|r}
\hline & Spell 1 & Spell 2 & Spell 3 & Spell 4+ & Total \\
\hline $1930-39$ & 3.4 & 1.0 & 0.2 & 0.1 & 4.7 \\
$1940-49$ & 7.3 & 2.9 & 1.4 & 0.4 & 12.1 \\
$1950-59$ & 13.1 & 6.6 & 3.3 & 1.5 & 24.5 \\
$1960-69$ & 17.4 & 8.8 & 3.6 & 1.6 & 31.4 \\
$1970-79$ & 17.6 & 5.8 & 2.8 & 1.1 & 27.4 \\
\hline Total & 58.9 & 25.1 & 11.4 & 4.6 & \\
\hline
\end{tabular}


Table 4.7: Ongoing Spell Frequency by Birth Cohort, Women

\begin{tabular}{l|rrrrr|r}
\hline & Spell 1 & Spell 2 & Spell 3 & Spell 4 & Spell 5 & Total \\
\hline $1930-39$ & 50.6 & 29.9 & 14.9 & 2.8 & 1.8 & 100 \\
$1940-49$ & 32.4 & 28.7 & 24.8 & 10.4 & 3.7 & 100 \\
$1950-59$ & 24.9 & 27.7 & 25.7 & 15.2 & 6.4 & 100 \\
$1960-69$ & 25.3 & 26.5 & 26.0 & 15.4 & 6.8 & 100 \\
$1970-79$ & 38.5 & 29.0 & 20.8 & 8.6 & 3.1 & 100 \\
\hline
\end{tabular}

Table 4.8: Ongoing Spell Frequency by Birth Cohort, Men

\begin{tabular}{r|rrrr|r}
\hline & Spell 1 & Spell 2 & Spell 3 & Spell 4+ & Total \\
\hline $1930-39$ & 72.0 & 21.2 & 5.2 & 1.6 & 100 \\
$1940-49$ & 60.6 & 24.4 & 11.8 & 3.2 & 100 \\
$1950-59$ & 53.6 & 26.9 & 13.5 & 5.9 & 100 \\
$1960-69$ & 55.5 & 28.0 & 11.4 & 5.1 & 100 \\
$1970-79$ & 64.3 & 21.3 & 10.4 & 4.0 & 100 \\
\hline
\end{tabular}

Tables 4.7 and 4.8 show the prevalence of ongoing spells by their respective birth cohort. As with completed spells, the prevalence of ongoing first spells tends to drop off across cohorts while the prevalence of subsequent spells rises for both men and women.

For the first 3 cohorts, and for both men and women, a pattern of decreasing first spells and increasing subsequent spells can be seen. The cohorts for those born after 1960 reverse this pattern. However, this is an artifact of the retrospective data used and is largely a function of the age at which employment spells begin. Summary Table 4.9 below will show that, on average, spells beyond the first begin at age 30 (with a standard deviation of about 8 years, making it almost certain spells beyond the first are yet to be usefully populated by the majority of members of the 1970-79 cohorts). However, before discussing the summary statistics it is 
worthwhile to examine the distribution of ongoing spells within the dataset.

In general, the prevalence of multiple spells seems to increase across cohorts. That is, subsequent cohorts of workers are more likely to see individuals participating in employment spells beyond the first. Table 4.9 presents the weighted means of employment duration and the relevant covariates by spell number.

Employment durations tend to fall across employment spells as the age at which spells began and lifetime experience rises, such that the first spell is often the longest and subsequent spells are shorter. This contrasts with the patterns of job hopping identified in young workers by Topel and Ward [40] and once again brings into contrast the concept of employment spell and job tenure. Men tend to comprise their largest share in the first spell and their share of later spells diminishes. Notably, the share of immigrants in the first few spells is higher than in subsequent spells. The prevalence of part-time employment and the chances that the individual was married at the time of the employment spell increases with the number of spells. The prevalence of community college graduation being the highest level of schooling tends to rise in the number of employment spells. The average length of breaks between spells also declines across spells. Finally, in terms of cohorts, the prevalence of multiple spells rises across cohorts until the 1960-69 cohort.

\subsection{Method and Results}

The purpose of the chapter is to determine whether the covariates which influence first employment spells do the same for subsequent spells and whether the 
Table 4.9: Summary Means for Five Employment Spells

\begin{tabular}{r|rrrrr}
\hline & Spell 1 & Spell 2 & Spell 3 & Spell 4 & Spell 5 \\
\hline Emp. Duration & 14.185 & 7.9 & 7.142 & 5.965 & 6.153 \\
Male & 0.474 & 0.343 & 0.265 & 0.209 & 0.227 \\
Immigrant & 0.244 & 0.205 & 0.18 & 0.158 & 0.162 \\
Ongoing & 0.44 & 0.414 & 0.502 & 0.518 & 0.498 \\
Age began & 23.549 & 31.63 & 34.305 & 36.717 & 38.047 \\
Part-time & 0.057 & 0.124 & 0.151 & 0.152 & 0.154 \\
Married & 0.175 & 0.613 & 0.714 & 0.772 & 0.771 \\
Less than HS & 0.078 & 0.044 & 0.03 & 0.024 & 0.017 \\
High School & 0.328 & 0.289 & 0.277 & 0.266 & 0.272 \\
Comm. College & 0.292 & 0.378 & 0.402 & 0.416 & 0.426 \\
University & 0.302 & 0.289 & 0.291 & 0.294 & 0.285 \\
UR Gap & -0.331 & -0.314 & -0.38 & -0.49 & -0.574 \\
Parental & 0.157 & 0.176 & 0.121 & 0.067 & 0.036 \\
Work. Rel & 0.107 & 0.087 & 0.091 & 0.091 & 0.088 \\
Personal & 0.216 & 0.218 & 0.158 & 0.101 & 0.067 \\
C 1930-39 & 0.08 & 0.058 & 0.038 & 0.027 & 0.023 \\
C 1940-49 & 0.142 & 0.134 & 0.125 & 0.109 & 0.1 \\
C 1950-59 & 0.235 & 0.27 & 0.294 & 0.324 & 0.34 \\
C 1960-69 & 0.284 & 0.312 & 0.326 & 0.35 & 0.36 \\
C 1970-79 & 0.259 & 0.227 & 0.217 & 0.191 & 0.177 \\
C 1980-89 & 0.090 & 0.061 & 0.056 & 0.045 & 0.051 \\
Lifetime Exp. & 14.185 & 16.225 & 18.233 & 19.357 & 20.874 \\
Break 1 Dur & & 1.786 & & & \\
Break 2 Dur & & & 1.086 & & \\
Break 3 Dur & & & & 0.93 & \\
Break 4 Dur & & & & & 0.712 \\
\hline Obs & 16,536 & 10,494 & 5,743 & 2,478 & 1,099 \\
\hline & & & & &
\end{tabular}

Notes: C 1930-39 refers to the 1930-1939 birth cohort, similarly, C 1940-49 to C 1970-79 refer to the 1940-1949 to 1970-1979 birth cohorts. 
differences identified across cohorts hold true for these latter spells. As such, the method for analysis used in the prior chapter will also be employed here but will be extended to account for prior work history and time away from the labour market. Furthermore, the analysis will be performed separately by employment spell.

For the purposes of the analysis a Cox semi-parametric hazard model which accounts for right-censoring is used to estimate the duration of the employment spells beyond the first. As in the previous chapter, only spells with a specified starting date are considered eliminating any left-censoring problems. The econometric model takes the following form:

$$
\theta\left(t_{i} \mid x_{i}, s_{i}\right)=\phi\left(x_{i}, s_{i}\right) \lambda\left(t_{i}, s_{i}\right)
$$

where $\theta(\cdot)$ is the hazard rate, $t_{i}$ is the duration of the $s$ th spell for individual $i$, $\phi\left(x_{i}, s_{i}\right)=\exp \left(x_{i} \beta \mid s_{i}\right)$ and $\lambda\left(t_{i}, s_{i}\right)$ is the baseline hazard for individual $i$ in spell $s$. Once again, the Cox model is chosen for comparability to previous results and because it is robust to misspecification due to its flexible (nonparametric) baseline hazard.

Figure 4.1 presents the smoothed hazard functions of employment duration by spell number for spells beyond the first over their first 35 years. The first thing to note is that while the hazards on the second spell display similar characteristics to those of first spells (shown in Chapter 3) the bumps are of a smaller magnitude than those seen there. For spells beyond the second, the profiles are generally flatter than earlier spells with a rising hazard towards the end. This is because spells beyond 
Figure 4.1: Smoothed Empirical Hazards for Spells Beyond the First
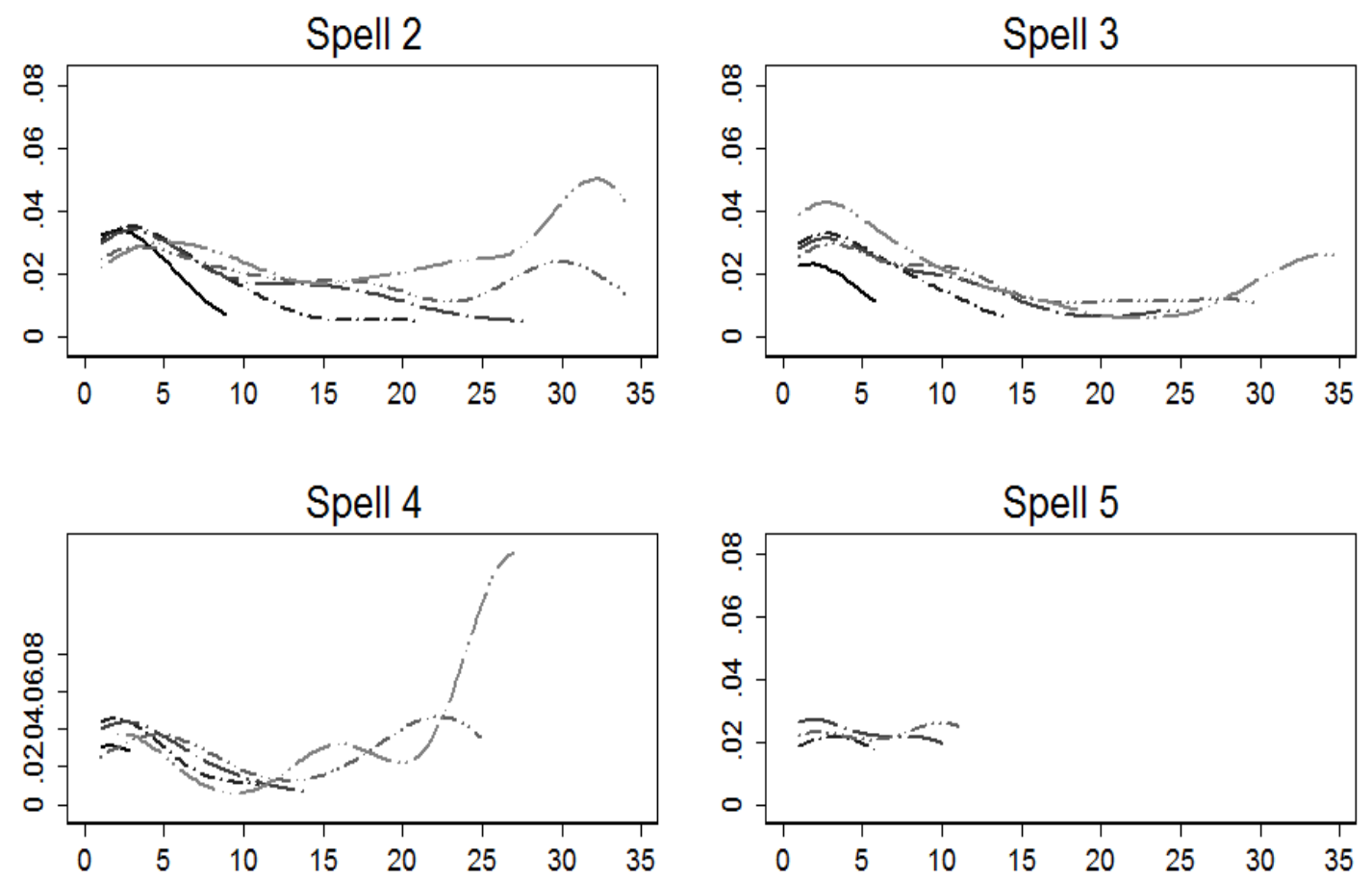

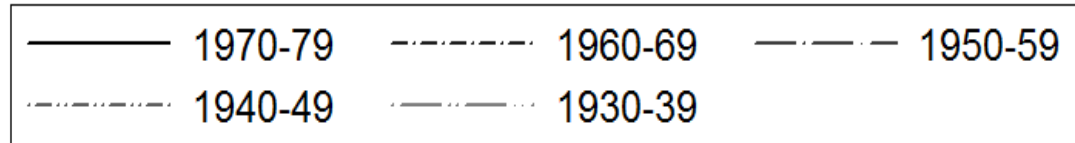

Data source: General Social Survey Cycles 15 and $20(2001,2006)$ 
the first are unlikely to be the lifetime jobs discussed in Chapter 2 and hence, tend not to have the characteristic bimodal distributions seen there.

The model is estimated for both genders together, and by gender for the total sample. Furthermore, this exercise is repeated for each employment spell up to the fifth by individual cohort. Because of lack of data some earlier cohorts could not be estimated for the fourth and fifth spells. The fifth spell for men could not be estimated for the same reason. All told 71 separate equations are estimated and will be presented in groups by spell number.

\subsubsection{Overall Assessment}

Before moving on to the discussion of each individual employment spell an overall discussion of the distinctions between the first and subsequent employment spells will be presented. Tables 4.10 to 4.12 show, a comparison of the model parameters by spell number for each spell-specific subset of the data.

In Table 4.10 the results for both genders together are presented, with a gender dummy used to identify the distinction between men and women across spell numbers. Interestingly, with spells beyond the second, gender does not seem to play an important role in evaluating the risk to terminating an employment spell (with the exception of the fourth where the sign is reversed). With a few notable exceptions, most other variables show results which are consistent with those obtained in Chapter 3. The most notable exception is the lack of significance for the cohort effects in employment spells beyond the first relative to those born in the 1980s 
cohort who had not completed high school.

As would be expected, the age work began plays an increasing positive contribution to the hazard of separation across spells as older beginning ages are consistent with shorter future durations. Conversely, the impact of part time work across spells is dampened for spells beyond the first. Macroeconomic conditions, as proxied by the gap between actual unemployment rates and a trend unemployment rate at the time of separation, have an increased impact on the hazard for spells beyond the third. The total lifetime work experience variable reduces the hazard but at a declining rate over the second to fourth spell. The length of the last work interruption also reduces the hazard across spells (relative to the base group), possibly indicating a reduced willingness to separate for prolonged periods after a longer labour market separation.

Table 4.11 performs the same analysis as above but for men. There were insufficient observations to perform a robust independent estimation for fifth spells, and so the fifth and fourth spells were combined here. As above, the results largely conform to what was found for first spells with the exception of the cohort effects which are no longer significant for the most part, and when they are they show decreasing contributions to the hazard across time. These patterns are likely a result of the inclusion of experience and break durations in the analysis. That is, once cumulative labour market experience and the length of previous separations have been accounted for the general effects for birth years dissipate.

The age at which work began, again, has an increasingly large contribution to the hazard across employment spells. The effect of part-time employment and 
Table 4.10: Cox Proportional Hazard Results: Both Genders by Spell Number

\begin{tabular}{|c|c|c|c|c|c|}
\hline & Spell 1 & Spell 2 & Spell 3 & Spell 4 & Spell 5 \\
\hline \multirow[t]{2}{*}{ male } & $-0.725^{* * *}$ & $-0.082^{* *}$ & 0.028 & $0.245^{* * *}$ & 0.055 \\
\hline & $(0.029)$ & $(0.039)$ & $(0.061)$ & $(0.088)$ & $(0.127)$ \\
\hline \multirow[t]{2}{*}{ age began } & $0.017 * * *$ & $0.065^{* * *}$ & $0.079^{* * *}$ & $0.081^{* * *}$ & $0.136^{* * *}$ \\
\hline & $(0.003)$ & $(0.004)$ & $(0.005)$ & $(0.006)$ & $(0.012)$ \\
\hline \multirow[t]{2}{*}{ part-time } & $0.781^{* * *}$ & $0.272^{* * *}$ & $0.364^{* * *}$ & $0.242^{* * *}$ & 0.108 \\
\hline & $(0.053)$ & $(0.038)$ & $(0.054)$ & $(0.079)$ & $(0.123)$ \\
\hline \multirow[t]{2}{*}{ immigrant } & $-0.104^{* * *}$ & $-0.209 * * *$ & $-0.169^{* * *}$ & -0.09 & -0.185 \\
\hline & $(0.029)$ & $(0.039)$ & $(0.055)$ & $(0.085)$ & $(0.132)$ \\
\hline \multirow[t]{2}{*}{ high sch. } & 0.023 & $0.539 * * *$ & $0.557^{* * *}$ & $0.735^{* * *}$ & 0.274 \\
\hline & $(0.051)$ & $(0.089)$ & $(0.174)$ & $(0.22)$ & $(0.52)$ \\
\hline \multirow[t]{2}{*}{ college } & 0.046 & $0.492^{* * *}$ & $0.528 * * *$ & $0.743^{* * *}$ & 0.188 \\
\hline & $(0.052)$ & $(0.086)$ & $(0.174)$ & $(0.22)$ & $(0.52)$ \\
\hline \multirow[t]{2}{*}{ univ. } & -0.023 & $0.307 * * *$ & $0.313^{*}$ & $0.483^{* *}$ & -0.015 \\
\hline & $(0.051)$ & $(0.085)$ & $(0.175)$ & $(0.221)$ & $(0.521)$ \\
\hline \multirow[t]{2}{*}{ UR gap } & $0.105^{* * *}$ & $0.103^{* * *}$ & $0.128^{* * *}$ & $0.134^{* * *}$ & $0.182^{* *}$ \\
\hline & $(0.012)$ & $(0.011)$ & $(0.021)$ & $(0.032)$ & $(0.082)$ \\
\hline \multirow[t]{2}{*}{ married } & $-0.080 * *$ & $0.160^{* * *}$ & -0.045 & -0.122 & -0.025 \\
\hline & $(0.04)$ & $(0.031)$ & $(0.053)$ & $(0.077)$ & $(0.13)$ \\
\hline \multirow{2}{*}{ work rel. } & $1.470 * * *$ & $0.754^{* * *}$ & $1.040^{* * *}$ & $0.951^{* * *}$ & $1.594^{* * *}$ \\
\hline & $(0.035)$ & $(0.044)$ & $(0.06)$ & $(0.076)$ & $(0.144)$ \\
\hline \multirow[t]{2}{*}{ parental } & $1.307^{* * *}$ & $0.816^{* * *}$ & $1.173^{* * *}$ & $1.057^{* * *}$ & $1.655^{* * *}$ \\
\hline & $(0.031)$ & $(0.035)$ & $(0.051)$ & $(0.083)$ & $(0.185)$ \\
\hline \multirow[t]{2}{*}{ C 1930-39 } & $-1.646^{* * *}$ & $0.208^{*}$ & 0.027 & 0.19 & $-2.456^{* * *}$ \\
\hline & $(0.075)$ & $(0.115)$ & $(0.183)$ & $(0.243)$ & $(0.551)$ \\
\hline \multirow[t]{2}{*}{ C 1940-49 } & $-1.496^{* * *}$ & $0.232^{* *}$ & 0.048 & -0.023 & $-2.465^{* * *}$ \\
\hline & $(0.066)$ & $(0.092)$ & $(0.158)$ & $(0.222)$ & $(0.439)$ \\
\hline \multirow[t]{2}{*}{ C 1950-59 } & $-1.310^{* * *}$ & -0.007 & -0.001 & -0.226 & $-2.143^{* * *}$ \\
\hline & $(0.062)$ & $(0.087)$ & $(0.143)$ & $(0.197)$ & $(0.35)$ \\
\hline \multirow[t]{2}{*}{ C 1960-69 } & $-1.102^{* * *}$ & $-0.164^{* *}$ & -0.136 & $-0.397^{* *}$ & $-1.804^{* * *}$ \\
\hline & $(0.061)$ & $(0.083)$ & $(0.136)$ & $(0.177)$ & $(0.262)$ \\
\hline \multirow[t]{2}{*}{ C 1970-79 } & $-0.664 * * *$ & $-0.192^{* *}$ & -0.126 & $-0.321^{*}$ & $-0.937 * * *$ \\
\hline & $(0.06)$ & $(0.08)$ & $(0.131)$ & $(0.173)$ & $(0.216)$ \\
\hline \multirow[t]{2}{*}{ experience } & & $-0.156^{* * *}$ & $-0.148^{* * *}$ & $-0.145^{* * *}$ & $-0.138^{* * *}$ \\
\hline & & $(0.004)$ & $(0.005)$ & $(0.006)$ & $(0.01)$ \\
\hline \multirow[t]{2}{*}{ break 1} & & $-0.086^{* * *}$ & & & \\
\hline & & $(0.005)$ & & & \\
\hline \multirow[t]{2}{*}{ break 2} & & & $-0.081^{* * *}$ & & \\
\hline & & & $(0.008)$ & & \\
\hline \multirow[t]{2}{*}{ break 3} & & & & $-0.138^{* * *}$ & \\
\hline & & & & $(0.019)$ & \\
\hline \multirow[t]{2}{*}{ break 4} & & & & & $-0.098 * * *$ \\
\hline & & & & & $(0.022)$ \\
\hline Obs & 16536 & 10494 & 5743 & 2478 & 1099 \\
\hline $\ln (\mathrm{L})$ & -77589 & -48251 & -20905 & -8013 & -3122 \\
\hline
\end{tabular}

Notes: Standard errors are in parentheses. ***,**, and * denote $1 \%, 5 \%$, and $10 \%$ level of significance, respectively. C 1930-39 refers to the 1930-1939 birth cohort, similarly, C 1940-49 to C 1970-79 refer to the 1940-1949 to 1970-1979 birth cohorts. 
of being an immigrant both have smaller contributions to the hazard across spells. Lifetime experience causes a fairly constant reduction in the hazard across spells as does the duration of the previous break.

Table 4.12 reproduces these results for women with women born in the 1980s who have not completed high school used as the base group as in all other cases. While the results largely conform to those of men, higher levels of education are significant and consistent contributors to the hazard of separating from employment for women. This pattern in the contribution of education shows an increasing hazard of exiting employment in all spells but the fifth, wherein the contribution becomes insignificant. This may be due to interruptions for family formation in earlier spells combined with an increased tendency to remain in later spells at the end of the fertility period (as the average age of commencement for a fifth spell is around 40). Marriage comes in significantly for spells 2 and 4 but with alternating signs, making it difficult to ascribe a clear meaning to its impact.

Overall, while the dummy variable in Table 4.10 showed little difference between men and women, the patterns seen in the two subsequent tables make it unlikely that the effects on the hazard of leaving employment fall proportionally on men and women. Hence, the remainder of the analysis will continue to include the division between men and women.

Figure 4.2 shows the baseline hazards for men and women by employment spell over the first 12 years. For men, the profiles are flat while for women positive duration dependence exists for spells beyond the first. That is, there is an common increasing probability of leaving employment over time for spells beyond the first. 
Table 4.11: Cox Proportional Hazard Results: Men by Spell Number

\begin{tabular}{|c|c|c|c|c|}
\hline & Spell 1 & Spell 2 & Spell 3 & Spell 4+ \\
\hline \multirow[t]{2}{*}{ age began } & $0.059^{* * *}$ & $0.086^{* * *}$ & $0.120 * * *$ & $0.102^{* * *}$ \\
\hline & $(0.006)$ & (0.008) & $(0.01)$ & $(0.012)$ \\
\hline \multirow[t]{2}{*}{ part-time } & $1.357^{* * *}$ & $0.707 * * *$ & $0.794^{* * *}$ & 0.186 \\
\hline & $(0.126)$ & $(0.12)$ & $(0.202)$ & (0.229) \\
\hline \multirow[t]{2}{*}{ immigrant } & $-0.113^{* *}$ & $-0.344^{* * *}$ & -0.193 & 0.001 \\
\hline & $(0.053)$ & $(0.099)$ & $(0.133)$ & $(0.157)$ \\
\hline \multirow[t]{2}{*}{ high sch. } & -0.113 & $0.470 * * *$ & $0.455^{*}$ & $1.336^{* * *}$ \\
\hline & $(0.091)$ & $(0.151)$ & $(0.247)$ & $(0.323)$ \\
\hline \multirow[t]{2}{*}{ college } & -0.089 & 0.215 & $0.432^{*}$ & $1.211^{* * *}$ \\
\hline & $(0.092)$ & $(0.151)$ & $(0.249)$ & $(0.322)$ \\
\hline \multirow[t]{2}{*}{ univ. } & $-0.250 * * *$ & -0.034 & -0.115 & $0.950 * * *$ \\
\hline & $(0.09)$ & $(0.154)$ & $(0.257)$ & $(0.328)$ \\
\hline \multirow{2}{*}{ UR gap } & $0.369^{* * *}$ & $0.188^{* * *}$ & $0.247^{* * *}$ & -0.018 \\
\hline & $(0.032)$ & $(0.032)$ & $(0.061)$ & $(0.063)$ \\
\hline \multirow[t]{2}{*}{ married } & $-0.138^{*}$ & $0.158^{*}$ & -0.002 & 0.086 \\
\hline & $(0.076)$ & $(0.083)$ & $(0.106)$ & $(0.129)$ \\
\hline \multirow[t]{2}{*}{ work rel. } & $1.771^{* * *}$ & $0.784^{* * *}$ & $1.246^{* * *}$ & $1.060^{* * *}$ \\
\hline & $(0.049)$ & $(0.091)$ & $(0.105)$ & $(0.144)$ \\
\hline \multirow[t]{2}{*}{ parental } & $1.662^{* * *}$ & $1.289 * * *$ & $1.174^{* * *}$ & $0.751^{*}$ \\
\hline & $(0.08)$ & $(0.172)$ & $(0.235)$ & $(0.408)$ \\
\hline \multirow[t]{2}{*}{ C 1930-39 } & $-2.725^{* * *}$ & $0.832^{* * *}$ & -0.228 & \\
\hline & (0.168) & $(0.266)$ & $(0.466)$ & \\
\hline \multirow[t]{2}{*}{ C $1940-49$} & $-2.261^{* * *}$ & $0.497^{* *}$ & -0.046 & -0.098 \\
\hline & (0.137) & $(0.209)$ & $(0.381)$ & $(0.343)$ \\
\hline \multirow[t]{2}{*}{ C 1950-59 } & $-1.763^{* * *}$ & 0.137 & -0.236 & $-0.448^{*}$ \\
\hline & $(0.122)$ & $(0.168)$ & $(0.299)$ & $(0.253)$ \\
\hline \multirow[t]{2}{*}{ C 1960-69 } & $-1.312^{* * *}$ & -0.234 & -0.373 & $-0.759 * * *$ \\
\hline & (0.111) & $(0.144)$ & $(0.256)$ & $(0.2)$ \\
\hline \multirow[t]{2}{*}{ C $1970-79$} & $-0.650 * * *$ & $-0.275^{* *}$ & -0.239 & $-0.630 * * *$ \\
\hline & $(0.102)$ & $(0.135)$ & $(0.236)$ & $(0.183)$ \\
\hline \multirow[t]{2}{*}{ experience } & & $-0.156^{* * *}$ & $-0.143^{* * *}$ & $-0.158 * * *$ \\
\hline & & $(0.007)$ & $(0.011)$ & $(0.012)$ \\
\hline \multirow[t]{2}{*}{ break 1} & & $-0.169 * * *$ & & \\
\hline & & $(0.025)$ & & \\
\hline \multirow[t]{2}{*}{ break 2} & & & $-0.243^{* * *}$ & \\
\hline & & & $(0.058)$ & \\
\hline \multirow[t]{2}{*}{ break $3 / 4$} & & & & $-0.191^{* * *}$ \\
\hline & & & & $(0.067)$ \\
\hline Obs & 6980 & 3218 & 1369 & 691 \\
\hline $\ln (\mathrm{L})$ & -19874 & -9012 & -3014 & -1926 \\
\hline
\end{tabular}

Notes: Standard errors are in parentheses. ${ }^{* * *},{ }^{* *}$, and $*$ denote $1 \%, 5 \%$, and $10 \%$ level of significance, respectively. C 1930-39 refers to the 1930-1939 birth cohort, similarly, C 1940-49 to C 1970-79 refer to the 1940-1949 to 1970-1979 birth cohorts. 
Table 4.12: Cox Proportional Hazard Results: Women by Spell Number

\begin{tabular}{|c|c|c|c|c|c|}
\hline & Spell 1 & Spell 2 & Spell 3 & Spell 4 & Spell 5 \\
\hline \multirow[t]{2}{*}{ age began } & 0.004 & $0.055^{* * *}$ & $0.070 * * *$ & $0.076^{* * *}$ & $0.144^{* * *}$ \\
\hline & $(0.046)$ & $(0.004)$ & $(0.005)$ & $(0.007)$ & $(0.013)$ \\
\hline \multirow[t]{2}{*}{ part-time } & $0.675^{* * *}$ & $0.213^{* * *}$ & $0.326^{* * *}$ & $0.260 * * *$ & 0.039 \\
\hline & $(0.012)$ & $(0.038)$ & $(0.054)$ & $(0.081)$ & $(0.131)$ \\
\hline \multirow[t]{2}{*}{ immigrant } & $-0.110^{* * *}$ & $-0.184^{* * *}$ & $-0.185^{* * *}$ & -0.123 & $-0.291^{*}$ \\
\hline & $(0.003)$ & $(0.041)$ & $(0.061)$ & $(0.093)$ & $(0.149)$ \\
\hline \multirow[t]{2}{*}{ high sch. } & 0.085 & $0.581^{* * *}$ & $0.665^{* * *}$ & $0.544^{* *}$ & -0.284 \\
\hline & $(0.054)$ & $(0.098)$ & $(0.21)$ & $(0.232)$ & $(0.489)$ \\
\hline \multirow[t]{2}{*}{ college } & $0.123^{* *}$ & $0.586^{* * *}$ & $0.630^{* * *}$ & $0.557^{* *}$ & -0.307 \\
\hline & $(0.034)$ & $(0.095)$ & $(0.21)$ & $(0.232)$ & $(0.493)$ \\
\hline \multirow[t]{2}{*}{ univ. } & $0.111^{*}$ & $0.421^{* * *}$ & $0.496^{* *}$ & 0.343 & -0.564 \\
\hline & $(0.048)$ & $(0.094)$ & $(0.21)$ & $(0.23)$ & $(0.492)$ \\
\hline \multirow[t]{2}{*}{ UR gap } & $0.025 * *$ & $0.073^{* * *}$ & $0.114^{* * *}$ & $0.163^{* * *}$ & $0.235^{* *}$ \\
\hline & $(0.031)$ & $(0.012)$ & $(0.022)$ & $(0.034)$ & $(0.105)$ \\
\hline \multirow[t]{2}{*}{ married } & -0.002 & $0.185^{* * *}$ & -0.084 & $-0.254^{* * *}$ & -0.127 \\
\hline & $(0.06)$ & $(0.032)$ & $(0.054)$ & $(0.084)$ & $(0.15)$ \\
\hline \multirow[t]{2}{*}{ work rel. } & $1.087^{* * *}$ & $0.658^{* * *}$ & $0.937^{* * *}$ & $0.978 * * *$ & $1.357^{* * *}$ \\
\hline & $(0.06)$ & $(0.049)$ & $(0.07)$ & $(0.087)$ & $(0.16)$ \\
\hline \multirow[t]{2}{*}{ parental } & $1.223^{* * *}$ & $0.758^{* * *}$ & $1.115^{* * *}$ & $1.035^{* * *}$ & $1.711^{* * *}$ \\
\hline & $(0.061)$ & $(0.034)$ & $(0.052)$ & (0.09) & $(0.208)$ \\
\hline \multirow[t]{2}{*}{ C 1930-39 } & $-1.229 * * *$ & 0.146 & 0.082 & $0.702^{* *}$ & $-2.635 * * *$ \\
\hline & $(0.086)$ & $(0.122)$ & $(0.2)$ & $(0.308)$ & $(0.677)$ \\
\hline \multirow[t]{2}{*}{ C $1940-49$} & $-1.205^{* * *}$ & $0.201^{*}$ & 0.047 & 0.292 & $-2.617^{* * *}$ \\
\hline & $(0.079)$ & $(0.107)$ & $(0.175)$ & $(0.284)$ & $(0.57)$ \\
\hline \multirow[t]{2}{*}{ C 1950-59 } & $-1.137^{* * *}$ & 0.035 & 0.037 & 0.073 & $-2.099^{* * *}$ \\
\hline & $(0.075)$ & $(0.102)$ & $(0.162)$ & $(0.267)$ & $(0.488)$ \\
\hline \multirow[t]{2}{*}{ C 1960-69 } & $-0.980^{* * *}$ & -0.038 & -0.1 & -0.061 & $-1.670^{* * *}$ \\
\hline & $(0.074)$ & $(0.1)$ & $(0.157)$ & $(0.249)$ & $(0.417)$ \\
\hline \multirow[t]{2}{*}{ C 1970-79 } & $-0.615^{* * *}$ & -0.111 & -0.133 & 0.016 & $-0.811^{* *}$ \\
\hline & $(0.074)$ & $(0.098)$ & $(0.152)$ & $(0.244)$ & $(0.378)$ \\
\hline \multirow[t]{2}{*}{ experience } & & $-0.165^{* * *}$ & $-0.158^{* * *}$ & $-0.153^{* * *}$ & $-0.137^{* * *}$ \\
\hline & & $(0.004)$ & $(0.005)$ & $(0.007)$ & $(0.011)$ \\
\hline \multirow[t]{2}{*}{ break 1} & & $-0.073^{* * *}$ & & & \\
\hline & & $(0.005)$ & & & \\
\hline \multirow[t]{2}{*}{ break 2} & & & $-0.070 * * *$ & & \\
\hline & & & $(0.007)$ & & \\
\hline \multirow[t]{2}{*}{ break 3} & & & & $-0.133^{* * *}$ & \\
\hline & & & & $(0.02)$ & \\
\hline \multirow[t]{2}{*}{ break 4} & & & & & $-0.085^{* * *}$ \\
\hline & & & & & $(0.02)$ \\
\hline Obs & 9556 & 7276 & 4374 & 2013 & 873 \\
\hline $\ln (\mathrm{L})$ & -54741 & -36778 & -16791 & -6203 & -2313 \\
\hline
\end{tabular}

Notes: Standard errors are in parentheses. ${ }^{* * *},{ }^{* *}$, and $*$ denote $1 \%, 5 \%$, and $10 \%$ level of significance, respectively. C 1930-39 refers to the 1930-1939 birth cohort, similarly, C 1940-49 to C 1970-79 refer to the 1940-1949 to 1970-1979 birth cohorts. 
Figure 4.2: Baseline Hazards by Spell Number and Gender

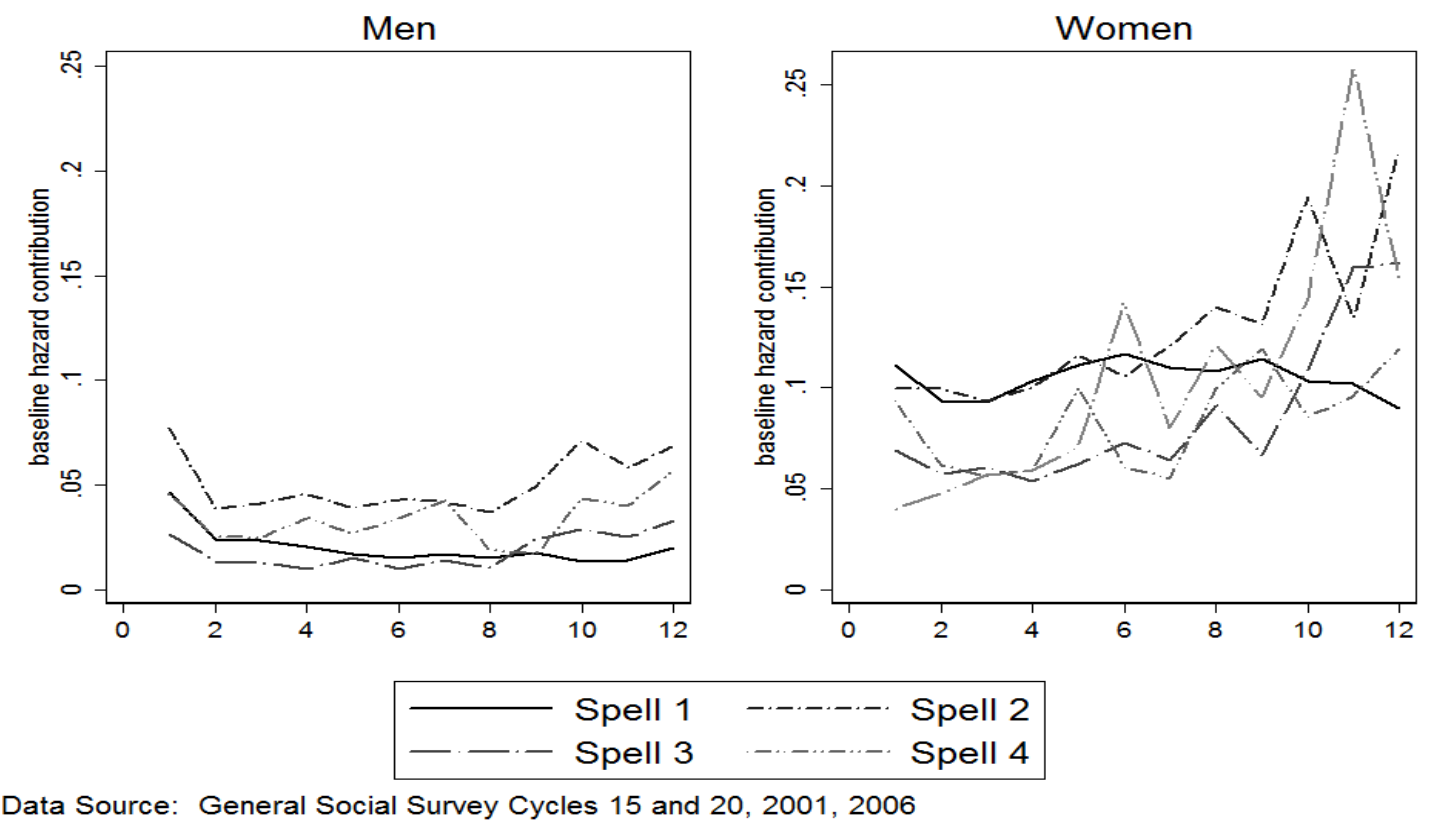




\subsubsection{The Second Spell}

In the GSS the prevalence of second spells is about two-thirds that of first spells, indicating that about one in three first continuous employment spells are the sole spell over a working life or are still in progress. The two thirds of the sample that continues into a second spell has slightly different characteristics than those who remain in a first spell. Employment durations in second spells are half the length of first spells on average. Two thirds of those in second spells are women (compared to one-half in first spells) and they are 3 times as likely to be married. Second spells are begun at an age 10 years later than first spells and are twice as likely to be in part-time employment. Finally, those in second spells are about a third more likely to be college educated than those in first spells.

Table 4.13 shows the estimation results for the sample containing both men and women in relation to those born in the 1980s who had not completed high school. Overall, being a man in earlier cohorts, the age at which the spell began, being a part-time worker, weak macroeconomic conditions, work-related issues or parental responsibilities all contribute significantly and positively to the hazard of employment separation for the second spell. Conversely being an immigrant and being a man born in a latter cohort and having longer first spell tenure and a longer separation between the first and second spell contribute negatively to the hazard. When looking at the results by cohort in isolation these patterns tend to hold in general. However, the age that work began, part-time work, work-related separations and parental responsibilities have a more pronounced positive contribution across 
cohorts while the reduction in the hazard due to the time away from work following the first spell also increases in magnitude across cohorts.

Because of the significance of the gender coefficients in Table 4.13 and the changes in signs across cohorts, Tables 4.14 and 4.15 re-estimate the model by gender. While the patterns by gender generally conform to the overall results in Table 4.13 some differences are present. For men, whose results are shown in Table 4.14, the age at the beginning of the spell does not show an increasing impact across cohorts as it did in the overall sample. Being an immigrant decreases the hazard of separation from the second spell for men between the 1940s to the 1960s cohorts. In addition, the negative impact on the hazard of having additional years of experience and the length of separation after their first spell becomes more pronounced for men of later cohorts.

For women, whose second spells are treated in Table 4.15, a more pronounced departure from the results of the estimates on the pooled sub-sample presented in Table 4.9 are evident. In particular, the role of education in increasing the hazard of separation distinguishes women from men on the second spell. Interestingly, having high school education increases the hazard of separation for all cohorts. However, the increase in the hazard caused by post secondary education dissipates across cohorts between the 1940s and the 1970s birth cohort for women.

Finally, Figure 4.4 presents the baseline hazards over the first 12 years for the estimates in Tables 4.14 and 4.15. It can immediately be seen that women have a positive duration dependence in the case of the second spell. While the baseline hazards start at a similar degree of risk, the instantaneous probability of separation 
Table 4.13: Cox Proportional Hazard Results: Second Spells for Both Genders by Birth Cohort

\begin{tabular}{|c|c|c|c|c|c|c|}
\hline & Total & C 1930-39 & C 1940-49 & C 1950-59 & C 1960-69 & C $1970-79$ \\
\hline \multirow[t]{2}{*}{ Male } & $-0.082^{* *}$ & $0.465^{* * *}$ & $0.197^{*}$ & -0.02 & $-0.261 * * *$ & $-0.202^{* *}$ \\
\hline & $(0.039)$ & $(0.151)$ & $(0.119)$ & $(0.081)$ & $(0.07)$ & $(0.079)$ \\
\hline \multirow[t]{2}{*}{ age began } & $0.065 * * *$ & $0.041^{* * *}$ & $0.060 * * *$ & $0.065^{* * *}$ & $0.077^{* * *}$ & $0.092^{* * *}$ \\
\hline & $(0.004)$ & $(0.007)$ & (0.007) & $(0.006)$ & (0.007) & $(0.01)$ \\
\hline \multirow[t]{2}{*}{ part-time } & $0.272^{* * *}$ & $0.204^{*}$ & $0.253^{* * *}$ & $0.287^{* * *}$ & $0.263^{* * *}$ & $0.347^{* * *}$ \\
\hline & $(0.038)$ & $(0.106)$ & $(0.084)$ & $(0.075)$ & $(0.082)$ & $(0.076)$ \\
\hline \multirow[t]{2}{*}{ immigrant } & $-0.209^{* * *}$ & -0.151 & -0.039 & $-0.223^{* * *}$ & $-0.264^{* * *}$ & $-0.326^{* * *}$ \\
\hline & $(0.039)$ & $(0.135)$ & $(0.086)$ & $(0.084)$ & $(0.068)$ & $(0.081)$ \\
\hline \multirow[t]{2}{*}{ high sch. } & $0.539 * * *$ & $0.391^{* *}$ & $0.853^{* * *}$ & $0.278^{*}$ & $0.562^{* * *}$ & $0.696^{* * *}$ \\
\hline & $(0.089)$ & $(0.179)$ & $(0.156)$ & $(0.16)$ & $(0.189)$ & $(0.228)$ \\
\hline \multirow[t]{2}{*}{ college } & $0.492^{* * *}$ & 0.228 & $0.720^{* * *}$ & $0.425^{* * *}$ & $0.481^{* * *}$ & $0.579^{* *}$ \\
\hline & $(0.086)$ & $(0.158)$ & $(0.155)$ & $(0.153)$ & $(0.184)$ & $(0.226)$ \\
\hline \multirow[t]{2}{*}{ univ. } & $0.307^{* * *}$ & 0.248 & $0.563^{* * *}$ & 0.034 & 0.217 & $0.390^{*}$ \\
\hline & $(0.085)$ & $(0.183)$ & $(0.165)$ & $(0.155)$ & $(0.183)$ & $(0.225)$ \\
\hline \multirow[t]{2}{*}{ UR gap } & $0.103^{* * *}$ & -0.014 & 0.027 & $0.092^{* * *}$ & $0.134^{* * *}$ & $0.069^{*}$ \\
\hline & $(0.011)$ & $(0.033)$ & $(0.031)$ & $(0.02)$ & $(0.02)$ & $(0.041)$ \\
\hline \multirow[t]{2}{*}{ married } & $0.160^{* * *}$ & 0.152 & $0.268^{* * *}$ & $0.267^{* * *}$ & $0.130^{* *}$ & -0.021 \\
\hline & $(0.031)$ & $(0.15)$ & $(0.102)$ & $(0.061)$ & $(0.051)$ & $(0.061)$ \\
\hline \multirow[t]{2}{*}{ work rel. } & $0.754^{* * *}$ & 0.25 & $0.472^{* * *}$ & $0.515^{* * *}$ & $0.859^{* * *}$ & $1.073^{* * *}$ \\
\hline & $(0.044)$ & $(0.16)$ & $(0.117)$ & $(0.081)$ & $(0.08)$ & $(0.075)$ \\
\hline \multirow[t]{2}{*}{ parental } & $0.816^{* * *}$ & $0.662^{* * *}$ & $0.477^{* * *}$ & $0.524^{* * *}$ & $0.803^{* * *}$ & $1.098^{* * *}$ \\
\hline & $(0.035)$ & & & & & \\
\hline \multirow[t]{2}{*}{ C 1930-39 } & $0.208^{*}$ & & & & & \\
\hline & $(0.115)$ & & & & & \\
\hline \multirow[t]{2}{*}{ C $1940-49$} & $0.232^{* *}$ & & & & & \\
\hline & $(0.092)$ & & & & & \\
\hline \multirow[t]{2}{*}{ C 1950-59 } & -0.007 & & & & & \\
\hline & $(0.087)$ & & & & & \\
\hline \multirow[t]{2}{*}{ C 1960-69 } & $-0.164^{* *}$ & & & & & \\
\hline & $(0.083)$ & & & & & \\
\hline \multirow[t]{2}{*}{ C $1970-79$} & $-0.192^{* *}$ & & & & & \\
\hline & $(0.08)$ & & & & & \\
\hline \multirow[t]{2}{*}{ experience } & $-0.156^{* * *}$ & $-0.131^{* * *}$ & $-0.135^{* * *}$ & $-0.165^{* * *}$ & $-0.190^{* * *}$ & $-0.232^{* * *}$ \\
\hline & $(0.004)$ & $(0.009)$ & $(0.007)$ & $(0.006)$ & $(0.007)$ & $(0.012)$ \\
\hline \multirow[t]{2}{*}{ break 1} & $-0.086^{* * *}$ & $-0.047 * * *$ & $-0.078^{* * *}$ & $-0.112^{* * *}$ & $-0.112^{* * *}$ & $-0.192^{* * *}$ \\
\hline & $(0.005)$ & $(0.007)$ & $(0.007)$ & $(0.01)$ & $(0.014)$ & $(0.026)$ \\
\hline Obs & 10494 & 663 & 1495 & 2549 & 3084 & 2220 \\
\hline $\ln (\mathrm{L})$ & -48251 & -2412 & -5649 & -9927 & -12159 & -7864 \\
\hline
\end{tabular}

Notes: Standard errors are in parentheses. ${ }^{* *},{ }^{* *}$, and $*$ denote $1 \%, 5 \%$, and $10 \%$ level of significance, respectively. C 1930-39 refers to the 1930-1939 birth cohort, similarly, C 1940-49 to C 1970-79 refer to the 1940-1949 to 1970-1979 birth cohorts. 
Table 4.14: Cox Proportional Hazard Results: Second Spells for Men by Birth Cohort

\begin{tabular}{|c|c|c|c|c|c|c|}
\hline & Total & C 1930-39 & C 1940-49 & C 1950-59 & C 1960-69 & C $1970-79$ \\
\hline \multirow[t]{2}{*}{ age began } & $0.086^{* * *}$ & $0.092^{* * *}$ & $0.072^{* * *}$ & $0.089 * * *$ & $0.116^{* * *}$ & $0.062^{* *}$ \\
\hline & $(0.008)$ & $(0.014)$ & $(0.013)$ & $(0.013)$ & $(0.015)$ & $(0.026)$ \\
\hline \multirow[t]{2}{*}{ part-time } & $0.707^{* * *}$ & 0.372 & $0.673^{* *}$ & 0.539 & $0.616^{* * *}$ & $0.747^{* * *}$ \\
\hline & $(0.12)$ & $(0.486)$ & $(0.341)$ & $(0.345)$ & $(0.186)$ & $(0.269)$ \\
\hline \multirow[t]{2}{*}{ immigrant } & $-0.344^{* * *}$ & 0.325 & $-0.375^{*}$ & $-0.449^{* *}$ & $-0.545^{* * *}$ & -0.25 \\
\hline & $(0.099)$ & $(0.248)$ & $(0.22)$ & $(0.209)$ & $(0.159)$ & $(0.204)$ \\
\hline \multirow{2}{*}{ high sch. } & $0.470^{* * *}$ & $1.006^{* *}$ & $0.750 * * *$ & 0.218 & 0.45 & $0.627^{* *}$ \\
\hline & $(0.151)$ & $(0.431)$ & $(0.278)$ & $(0.255)$ & $(0.309)$ & $(0.318)$ \\
\hline \multirow[t]{2}{*}{ college } & 0.215 & 0.529 & 0.295 & 0.081 & 0.426 & 0.403 \\
\hline & $(0.151)$ & $(0.383)$ & $(0.292)$ & $(0.245)$ & $(0.306)$ & $(0.317)$ \\
\hline \multirow[t]{2}{*}{ univ. } & -0.034 & 0.019 & 0.146 & -0.301 & -0.244 & 0.295 \\
\hline & $(0.154)$ & $(0.419)$ & $(0.332)$ & $(0.24)$ & $(0.305)$ & $(0.324)$ \\
\hline \multirow[t]{2}{*}{ UR gap } & $0.188^{* * *}$ & 0.141 & $0.166^{* *}$ & $0.174^{* * *}$ & $0.200^{* * *}$ & -0.055 \\
\hline & $(0.032)$ & $(0.101)$ & $(0.071)$ & $(0.059)$ & $(0.053)$ & $(0.095)$ \\
\hline \multirow[t]{2}{*}{ married } & $0.158^{*}$ & 0.244 & $0.355^{*}$ & $0.352^{* *}$ & -0.123 & 0.197 \\
\hline & $(0.083)$ & $(0.27)$ & $(0.19)$ & $(0.138)$ & $(0.144)$ & (0.178) \\
\hline \multirow[t]{2}{*}{ work rel. } & $0.784^{* * *}$ & -0.717 & $0.425^{*}$ & $0.663^{* * *}$ & $0.840^{* * *}$ & $1.234^{* * *}$ \\
\hline & $(0.091)$ & $(0.673)$ & $(0.239)$ & (0.138) & $(0.114)$ & $(0.128)$ \\
\hline \multirow[t]{2}{*}{ parental } & $1.289^{* * *}$ & $2.423 * * *$ & $0.854^{* *}$ & $1.570 * * *$ & $1.797^{* * *}$ & 0 \\
\hline & $(0.172)$ & & & & & \\
\hline \multirow[t]{2}{*}{ C 1930-39 } & $0.832^{* * *}$ & & & & & \\
\hline & $(0.266)$ & & & & & \\
\hline \multirow[t]{2}{*}{ C $1940-49$} & $0.497^{* *}$ & & & & & \\
\hline & $(0.209)$ & & & & & \\
\hline \multirow[t]{2}{*}{ C 1950-59 } & 0.137 & & & & & \\
\hline & $(0.168)$ & & & & & \\
\hline \multirow[t]{2}{*}{ C 1960-69 } & -0.234 & & & & & \\
\hline & $(0.144)$ & & & & & \\
\hline \multirow[t]{2}{*}{ C 1970-79 } & $-0.275^{* *}$ & & & & & \\
\hline & $(0.135)$ & & & & & \\
\hline \multirow[t]{2}{*}{ experience } & $-0.156^{* * *}$ & $-0.138^{* * *}$ & $-0.120^{* * *}$ & $-0.166^{* * *}$ & $-0.239 * * *$ & $-0.292^{* * *}$ \\
\hline & $(0.007)$ & $(0.014)$ & $(0.013)$ & $(0.011)$ & $(0.015)$ & (0.027) \\
\hline \multirow{2}{*}{ break 1} & $-0.169^{* * *}$ & $-0.082^{* * *}$ & $-0.119^{* * *}$ & $-0.172^{* * *}$ & $-0.219^{* * *}$ & $-0.353^{* * *}$ \\
\hline & $(0.025)$ & $(0.03)$ & $(0.046)$ & $(0.043)$ & $(0.052)$ & $(0.081)$ \\
\hline Obs & 3218 & 170 & 454 & 820 & 952 & 646 \\
\hline $\ln (\mathrm{L})$ & -9012 & -347 & -1046 & -1914 & -1868 & -1372 \\
\hline
\end{tabular}

Notes: Standard errors are in parentheses. $* * *, * *$, and $*$ denote $1 \%, 5 \%$, and $10 \%$ level of significance, respectively. C 1930-39 refers to the 1930-1939 birth cohort, similarly, C 1940-49 to C 1970-79 refer to the 1940-1949 to 1970-1979 birth cohorts. 
Table 4.15: Cox Proportional Hazard Results: Second Spells for Women by Birth Cohort

\begin{tabular}{|c|c|c|c|c|c|c|}
\hline & Total & C 1930-39 & C 1940-49 & C 1950-59 & C 1960-69 & C $1970-79$ \\
\hline age began & $0.055^{* * *}$ & $0.020^{* *}$ & $0.056^{* * *}$ & $0.056^{* * *}$ & $0.071^{* * *}$ & $0.097^{* * *}$ \\
\hline \multirow{2}{*}{ part-time } & $0.213^{* * *}$ & $\begin{array}{r}(0.008) \\
0.145\end{array}$ & $\begin{array}{r}(0.006) \\
0.229^{* * *}\end{array}$ & $0.244^{* * *}$ & $0.201^{* *}$ & $0.279^{* * *}$ \\
\hline & $(0.038)$ & $(0.11)$ & $(0.085)$ & $(0.074)$ & $(0.084)$ & $(0.079)$ \\
\hline \multirow[t]{2}{*}{ immigrant } & $-0.184^{* * *}$ & -0.23 & 0.06 & $-0.189^{* *}$ & $-0.201^{* * *}$ & $-0.313^{* * *}$ \\
\hline & $(0.041)$ & $(0.147)$ & $(0.091)$ & $(0.089)$ & $(0.072)$ & $(0.085)$ \\
\hline \multirow[t]{2}{*}{ high sch. } & $0.581^{* * *}$ & $0.332^{*}$ & $0.879^{* * *}$ & $0.479^{* *}$ & $0.477^{* *}$ & $0.638^{* *}$ \\
\hline & $(0.098)$ & $(0.178)$ & $(0.185)$ & $(0.208)$ & $(0.204)$ & $(0.287)$ \\
\hline \multirow[t]{2}{*}{ college } & $0.586^{* * *}$ & 0.234 & $0.828 * * *$ & $0.703^{* * *}$ & $0.413^{* *}$ & $0.559^{* *}$ \\
\hline & $(0.095)$ & $(0.167)$ & $(0.18)$ & $(0.202)$ & $(0.2)$ & $(0.285)$ \\
\hline \multirow[t]{2}{*}{ univ. } & $0.421^{* * *}$ & $0.368^{*}$ & $0.734^{* * *}$ & 0.322 & 0.207 & 0.333 \\
\hline & (0.094) & $(0.19)$ & $(0.186)$ & $(0.204)$ & $(0.198)$ & $(0.283)$ \\
\hline \multirow[t]{2}{*}{ UR gap } & $0.073^{* * *}$ & -0.006 & -0.003 & $0.076^{* * *}$ & $0.114^{* * *}$ & $0.098^{* *}$ \\
\hline & $(0.012)$ & $(0.032)$ & $(0.034)$ & $(0.021)$ & $(0.021)$ & $(0.044)$ \\
\hline \multirow[t]{2}{*}{ married } & $0.185^{* * *}$ & 0.082 & 0.07 & $0.256^{* * *}$ & $0.231^{* * *}$ & -0.02 \\
\hline & $(0.032)$ & $(0.145)$ & (0.09) & $(0.066)$ & $(0.054)$ & $(0.064)$ \\
\hline \multirow[t]{2}{*}{ work rel. } & $0.658^{* * *}$ & $0.321^{* *}$ & $0.543^{* * *}$ & $0.442^{* * *}$ & $0.776^{* * *}$ & $0.962^{* * *}$ \\
\hline & $(0.049)$ & $(0.13)$ & $(0.104)$ & $(0.095)$ & $(0.1)$ & $(0.086)$ \\
\hline \multirow[t]{2}{*}{ parental } & $0.758 * * *$ & $0.340^{* *}$ & $0.355^{* * *}$ & $0.499^{* * *}$ & $0.843^{* * *}$ & $1.063^{* * *}$ \\
\hline & $(0.034)$ & & & & & \\
\hline \multirow[t]{2}{*}{ C 1930-39 } & 0.146 & & & & & \\
\hline & $(0.122)$ & & & & & \\
\hline \multirow[t]{2}{*}{ C 1940-49 } & $0.201^{*}$ & & & & & \\
\hline & $(0.107)$ & & & & & \\
\hline \multirow[t]{2}{*}{ C 1950-59 } & 0.035 & & & & & \\
\hline & $(0.102)$ & & & & & \\
\hline \multirow[t]{2}{*}{ C 1960-69 } & -0.038 & & & & & \\
\hline & $(0.1)$ & & & & & \\
\hline \multirow[t]{2}{*}{ C $1970-79$} & -0.111 & & & & & \\
\hline & $(0.098)$ & & & & & \\
\hline \multirow[t]{2}{*}{ experience } & $-0.165^{* * *}$ & $-0.167^{* * *}$ & $-0.156^{* * *}$ & $-0.165^{* * *}$ & $-0.177^{* * *}$ & $-0.213^{* * *}$ \\
\hline & $(0.004)$ & $(0.014)$ & $(0.009)$ & $(0.007)$ & (0.007) & $(0.012)$ \\
\hline \multirow{2}{*}{ break 1} & $-0.073^{* * *}$ & $-0.039^{* * *}$ & $-0.076^{* * *}$ & $-0.103^{* * *}$ & $-0.095^{* * *}$ & $-0.146^{* * *}$ \\
\hline & $(0.005)$ & $(0.008)$ & $(0.008)$ & $(0.011)$ & $(0.015)$ & $(0.028)$ \\
\hline Obs & 7276 & 493 & 1041 & 1729 & 2132 & 1574 \\
\hline $\ln (\mathrm{L})$ & -36778 & -1823 & -4143 & -7277 & -9694 & -6002 \\
\hline
\end{tabular}

Notes: Standard errors are in parentheses. $* * *, * *$, and $*$ denote $1 \%, 5 \%$, and $10 \%$ level of significance, respectively. C 1930-39 refers to the 1930-1939 birth cohort, similarly, C 1940-49 to C 1970-79 refer to the 1940-1949 to 1970-1979 birth cohorts. 
increases for women over time while for men this is not the case. This result is, in part due to the fact that women are more likely than men to go on to a further employment spell.

Figure 4.3: Baseline Hazards: Second Spells by Gender and Birth Cohort

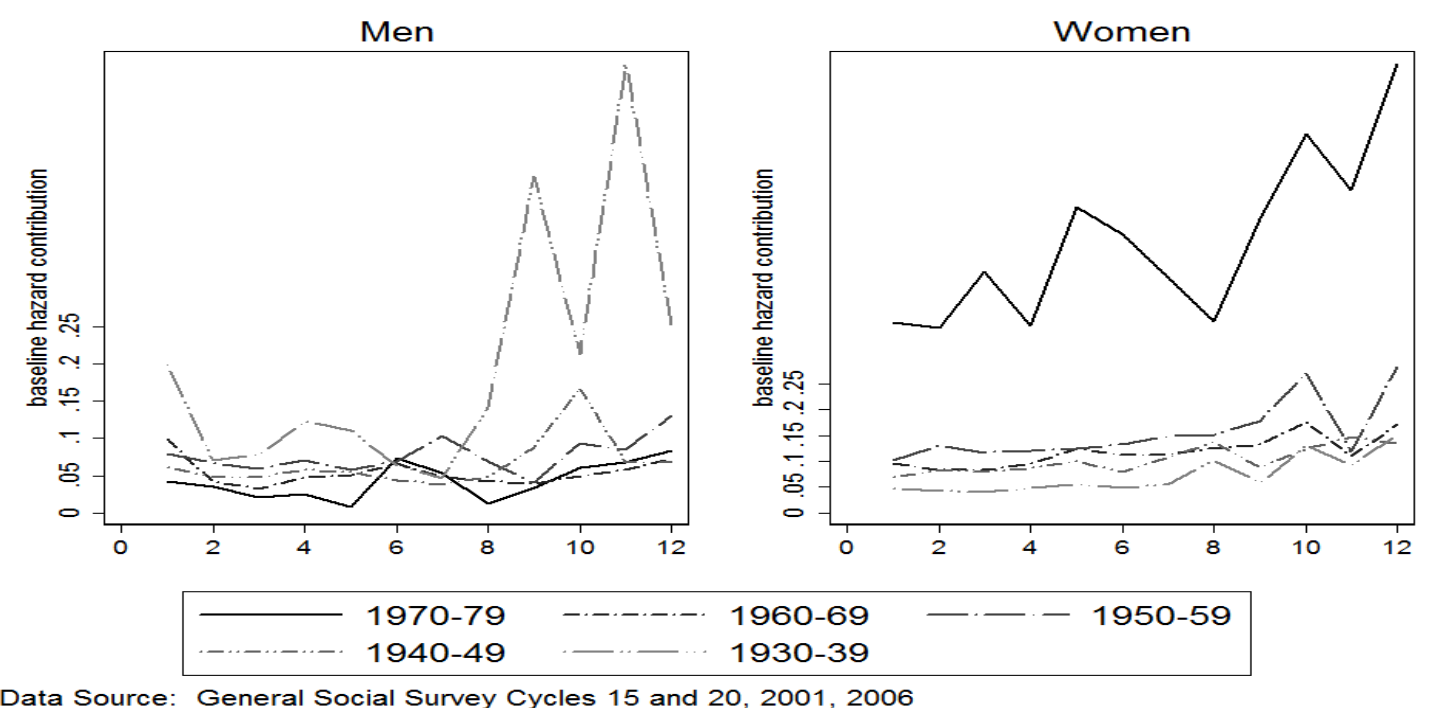

In general, the major contributors to the hazard identified for first spells in Chapter 3 tend to hold in the second spell. However, the role of gender is more complicated as the contribution of being a man to the hazard of separation changed across birth cohorts from positive in early cohorts to negative in the 1960 s and 1970s cohorts. Furthermore, higher educated women no longer had the higher rates of separation seen in earlier cohorts. That is, gender's contribution to the hazard evolved across successive cohorts in the case of second spells. 


\subsubsection{The Third Spell}

In the GSS approximately half of all those who had a second spell will have a third spell. Third spells are similar in length to second spells but are begun by those 3 years older on average. Nearly three quarters of those engaged in a third spell are women, 15 per cent of whom work part-time with 70 per cent of them married by the time the spell had begun. For spells after the second, the prevalence of separations for work-related and parental reasons begins to decline rapidly while the regression coefficients associated with of macroeconomic conditions become increasingly positive and significant - indicating an increased correlation with economic cycles.

As with second spells we will examine the model results in turn, first for the total sub-sample of third employment spells and then for men and women separately. Table 4.16 presents the regression results for all third spells together and can be interpreted in relation to those born in the 1980s who had not completed high school. The results are consistent with those of second spells overall with the role of gender producing mixed signals across cohorts when it is significant. However, cohort effects essentially play no role in the overall equation.

In Table 4.17, the regression results for the hazard of leaving the third spell among men are presented. The sample sizes become quite small for men and significance of many individual parameters begins to trail off after the second spell. Most of the coefficients in the equations are insignificant. The signs, when significant, remain the same but with somewhat altered magnitudes. As in spell two, 
Table 4.16: Cox Proportional Hazard Results: Third Spells for Both Genders by Birth Cohort

\begin{tabular}{|c|c|c|c|c|c|c|}
\hline & Total & C 1930-39 & C 1940-49 & C 1950-59 & C 1960-69 & C $1970-79$ \\
\hline \multirow[t]{2}{*}{ Male } & 0.028 & $0.691^{* *}$ & $0.516^{* * *}$ & 0.148 & $-0.217^{* *}$ & -0.153 \\
\hline & $(0.061)$ & $(0.282)$ & $(0.186)$ & $(0.11)$ & $(0.107)$ & $(0.128)$ \\
\hline \multirow[t]{2}{*}{ age began } & $0.079^{* * *}$ & $0.061^{* * *}$ & $0.072^{* * *}$ & $0.089^{* * *}$ & $0.094^{* * *}$ & $0.109^{* * *}$ \\
\hline & $(0.005)$ & $(0.012)$ & $(0.008)$ & $(0.007)$ & $(0.011)$ & $(0.016)$ \\
\hline \multirow[t]{2}{*}{ part-time } & $0.364^{* * *}$ & $0.407^{* *}$ & $0.295^{* *}$ & $0.421^{* * *}$ & $0.359^{* * *}$ & $0.278^{* * *}$ \\
\hline & $(0.054)$ & $(0.18)$ & $(0.125)$ & $(0.115)$ & $(0.087)$ & $(0.107)$ \\
\hline \multirow[t]{2}{*}{ immigrant } & $-0.169^{* * *}$ & 0.095 & $-0.238^{*}$ & -0.116 & $-0.300^{* * *}$ & $-0.321^{* *}$ \\
\hline & $(0.055)$ & $(0.183)$ & $(0.142)$ & $(0.103)$ & $(0.105)$ & $(0.125)$ \\
\hline \multirow[t]{2}{*}{ high sch. } & $0.557^{* * *}$ & $0.943^{* * *}$ & 0.287 & 0.391 & 0.127 & 0.71 \\
\hline & $(0.174)$ & $(0.313)$ & $(0.215)$ & $(0.246)$ & $(0.173)$ & $(0.566)$ \\
\hline \multirow[t]{2}{*}{ college } & $0.528^{* * *}$ & $0.795^{* * *}$ & $0.584^{* * *}$ & $0.445^{*}$ & -0.083 & 0.547 \\
\hline & $(0.174)$ & $(0.272)$ & $(0.207)$ & $(0.247)$ & $(0.17)$ & $(0.564)$ \\
\hline \multirow[t]{2}{*}{ univ. } & $0.313^{*}$ & $1.056^{* * *}$ & 0.105 & 0.129 & -0.254 & 0.296 \\
\hline & $(0.175)$ & $(0.26)$ & $(0.231)$ & $(0.247)$ & $(0.17)$ & $(0.562)$ \\
\hline \multirow[t]{2}{*}{ UR gap } & $0.128 * * *$ & $0.221^{* * *}$ & $0.122^{* * *}$ & $0.088^{* *}$ & $0.209^{* * *}$ & $0.161^{* *}$ \\
\hline & $(0.021)$ & $(0.08)$ & $(0.045)$ & $(0.035)$ & $(0.036)$ & $(0.069)$ \\
\hline \multirow[t]{2}{*}{ married } & -0.045 & 0.536 & $-0.278^{*}$ & -0.034 & $-0.143^{*}$ & -0.045 \\
\hline & $(0.053)$ & $(0.351)$ & $(0.155)$ & $(0.092)$ & $(0.075)$ & $(0.088)$ \\
\hline \multirow[t]{2}{*}{ work rel. } & $1.040 * * *$ & $1.036^{* * *}$ & $0.844^{* * *}$ & $0.827^{* * *}$ & $1.086^{* * *}$ & $1.362^{* * *}$ \\
\hline & $(0.06)$ & $(0.224)$ & $(0.14)$ & $(0.124)$ & $(0.088)$ & (0.119) \\
\hline \multirow[t]{2}{*}{ parental } & $1.173^{* * *}$ & $1.656^{* * *}$ & $1.319^{* * *}$ & $1.039 * * *$ & $1.029^{* * *}$ & $1.376^{* * *}$ \\
\hline & $(0.051)$ & & & & & \\
\hline \multirow[t]{2}{*}{ C 1930-39 } & 0.027 & & & & & \\
\hline & $(0.183)$ & & & & & \\
\hline \multirow[t]{2}{*}{ C $1940-49$} & 0.048 & & & & & \\
\hline & $(0.158)$ & & & & & \\
\hline \multirow[t]{2}{*}{ C 1950-59 } & -0.001 & & & & & \\
\hline & $(0.143)$ & & & & & \\
\hline \multirow[t]{2}{*}{ C 1960-69 } & -0.136 & & & & & \\
\hline & $(0.136)$ & & & & & \\
\hline \multirow[t]{2}{*}{ C $1970-79$} & -0.126 & & & & & \\
\hline & $(0.131)$ & & & & & \\
\hline \multirow[t]{2}{*}{ experience } & $-0.148^{* * *}$ & $-0.135^{* * *}$ & $-0.132^{* * *}$ & $-0.157^{* * *}$ & $-0.186^{* * *}$ & $-0.184^{* * *}$ \\
\hline & $(0.005)$ & $(0.012)$ & $(0.009)$ & $(0.008)$ & $(0.011)$ & $(0.015)$ \\
\hline \multirow[t]{2}{*}{ break 2} & $-0.081^{* * *}$ & $-0.039^{* * *}$ & $-0.060^{* * *}$ & $-0.110^{* * *}$ & $-0.116^{* * *}$ & $-0.123^{* * *}$ \\
\hline & $(0.008)$ & $(0.013)$ & $(0.01)$ & $(0.017)$ & $(0.022)$ & $(0.038)$ \\
\hline Obs & 5743 & 243 & 770 & 1508 & 1811 & 1191 \\
\hline $\ln (\mathrm{L})$ & -20905 & -688 & -2148 & -4682 & -5699 & -3225 \\
\hline
\end{tabular}

Notes: Standard errors are in parentheses. ***,**, and * denote $1 \%, 5 \%$, and $10 \%$ level of significance, respectively. C 1930-39 refers to the 1930-1939 birth cohort, similarly, C 1940-49 to C 1970-79 refer to the 1940-1949 to 1970-1979 birth cohorts. 
the age work began contributes positively to the hazard, however the magnitude of the impact clearly declines across cohorts. The unemployment gap also increases the hazard - but with diminishing magnitude across cohorts until it is no longer significant beyond the 1950s cohort. Work related separations and parental responsibilities also increase the hazard as before. Finally, lifetime experience tends to diminish the hazard at an increasing rate across cohorts.

Table 4.18, presents the results for women. Here the sample sizes remain fairly robust and the parameters remain significant. The results are largely similar to the second spell with the exception of a weaker increase in the hazard across cohorts stemming from educational attainment. Moreover, the impacts of adverse macroeconomic conditions seem to take on a more prominent role in earlier cohorts than seen in second spells for women. Lastly, work related separations contribute more positively to the hazard for third spells than they do for the second. All in all, for women, it appears that in the case of third spells, economic factors seem to play a more important role than they did for second spells.

Figure 4.4 presents the baseline hazard plots of the equations by gender for the estimates above. For men, with perhaps the exception of the 1940s cohort, the baseline hazards are relatively flat indicating no duration dependence. For women, in general, positive duration dependence again seems to be present. This likely stems from the greater likelihood of women than men to separate from the labor market for a prolonged period.

Overall, the hazard of leaving the third spell is much the same as leaving the second spell. For men, the age work began has a more positive impact on the 
Table 4.17: Cox Proportional Hazard Results: Third Spells for Men by Birth Cohort

\begin{tabular}{|c|c|c|c|c|c|c|}
\hline & Total & C 1930-39 & C $1940-49$ & C 1950-59 & C 1960-69 & C $1970-79$ \\
\hline \multirow[t]{2}{*}{ age began } & $0.120^{* * *}$ & $0.156^{* * *}$ & $0.152^{* * *}$ & $0.121^{* * *}$ & $0.107^{* * *}$ & $0.100 * * *$ \\
\hline & $(0.01)$ & $(0.041)$ & $(0.025)$ & $(0.015)$ & $(0.023)$ & $(0.036)$ \\
\hline \multirow[t]{2}{*}{ part-time } & $0.794^{* * *}$ & 2.374 & -0.375 & $1.244^{* * *}$ & 0.58 & 0.685 \\
\hline & $(0.202)$ & $(1.467)$ & $(0.524)$ & $(0.391)$ & $(0.367)$ & $(0.428)$ \\
\hline \multirow[t]{2}{*}{ immigrant } & -0.193 & 0.516 & -0.163 & -0.206 & -0.14 & -0.521 \\
\hline & $(0.133)$ & $(0.785)$ & $(0.276)$ & $(0.274)$ & $(0.219)$ & $(0.32)$ \\
\hline \multirow[t]{2}{*}{ high sch. } & $0.455^{*}$ & $2.418^{* *}$ & 0.283 & 0.057 & 0.337 & 0.233 \\
\hline & $(0.247)$ & $(1.055)$ & $(0.351)$ & $(0.356)$ & $(0.317)$ & $(0.582)$ \\
\hline \multirow[t]{2}{*}{ college } & $0.432^{*}$ & $2.335^{* *}$ & 0.585 & 0.312 & 0.032 & 0.252 \\
\hline & $(0.249)$ & (1.09) & $(0.358)$ & $(0.343)$ & $(0.344)$ & $(0.531)$ \\
\hline \multirow[t]{2}{*}{ univ. } & -0.115 & 1.559 & -0.742 & -0.329 & -0.359 & -0.052 \\
\hline & $(0.257)$ & $(0.95)$ & $(0.472)$ & $(0.351)$ & $(0.328)$ & $(0.559)$ \\
\hline \multirow[t]{2}{*}{ UR gap } & $0.247^{* * *}$ & $0.676^{* *}$ & $0.241^{*}$ & $0.226^{* *}$ & 0.184 & 0.211 \\
\hline & $(0.061)$ & $(0.281)$ & $(0.125)$ & $(0.111)$ & $(0.125)$ & $(0.255)$ \\
\hline \multirow[t]{2}{*}{ married } & -0.002 & 1.471 & -0.102 & 0.078 & 0.081 & -0.001 \\
\hline & $(0.106)$ & $(1.422)$ & $(0.201)$ & $(0.194)$ & $(0.189)$ & $(0.271)$ \\
\hline \multirow[t]{2}{*}{ work rel. } & $1.246^{* * *}$ & 1.421 & $1.489^{* * *}$ & $1.092^{* * *}$ & $1.284^{* * *}$ & $1.232^{* * *}$ \\
\hline & $(0.105)$ & $(0.984)$ & $(0.259)$ & $(0.202)$ & $(0.186)$ & $(0.203)$ \\
\hline \multirow[t]{2}{*}{ parental } & $1.174^{* * *}$ & & & $0.812^{* *}$ & $0.849^{* * *}$ & $2.016^{* * *}$ \\
\hline & $(0.235)$ & & & 0.057 & 0.337 & 0.233 \\
\hline \multirow[t]{2}{*}{ C 1930-39 } & -0.228 & & & & & \\
\hline & $(0.466)$ & & & & & \\
\hline \multirow[t]{2}{*}{ C $1940-49$} & -0.046 & & & & & \\
\hline & $(0.381)$ & & & & & \\
\hline \multirow[t]{2}{*}{ C $1950-59$} & -0.236 & & & & & \\
\hline & $(0.299)$ & & & & & \\
\hline \multirow[t]{2}{*}{ C 1960-69 } & -0.373 & & & & & \\
\hline & $(0.256)$ & & & & & \\
\hline \multirow[t]{2}{*}{ C $1970-79$} & -0.239 & & & & & \\
\hline & $(0.236)$ & & & & & \\
\hline \multirow[t]{2}{*}{ experience } & $-0.143^{* * *}$ & $-0.137^{* * *}$ & $-0.165^{* * *}$ & $-0.162^{* * *}$ & $-0.179 * * *$ & $-0.213^{* * *}$ \\
\hline & $(0.011)$ & (0.033) & $(0.027)$ & $(0.014)$ & $(0.024)$ & $(0.04)$ \\
\hline \multirow[t]{2}{*}{ break 2} & $-0.243^{* * *}$ & -0.288 & -0.162 & $-0.284^{* * *}$ & $-0.125^{*}$ & -0.119 \\
\hline & $(0.058)$ & $(0.216)$ & $(0.113)$ & $(0.082)$ & $(0.074)$ & $(0.088)$ \\
\hline Obs & 1369 & 38 & 190 & 367 & 406 & 285 \\
\hline $\ln (\mathrm{L})$ & -3014 & -48 & -289 & -655 & -731 & -437 \\
\hline
\end{tabular}

Notes: Standard errors are in parentheses. ${ }^{* * *},{ }^{* *}$, and $*$ denote $1 \%, 5 \%$, and $10 \%$ level of significance, respectively. C 1930-39 refers to the 1930-1939 birth cohort, similarly, C 1940-49 to C 1970-79 refer to the 1940-1949 to 1970-1979 birth cohorts. 
Table 4.18: Cox Proportional Hazard Results: Third Spells for Women by Birth Cohort

\begin{tabular}{|c|c|c|c|c|c|c|}
\hline & Total & C 1930-39 & C 1940-49 & C 1950-59 & C 1960-69 & C $1970-79$ \\
\hline age began & $\begin{array}{r}0.070 * * * \\
(0.005)\end{array}$ & $\begin{array}{r}0.048^{* * *} * \\
(0.012)\end{array}$ & $\begin{array}{r}0.059 * * * \\
(0.009)\end{array}$ & $\begin{array}{r}0.080^{* * *} * \\
(0.008)\end{array}$ & $\begin{array}{r}0.090 * * * \\
(0.013)\end{array}$ & $\begin{array}{r}0.112^{* * *} \\
(0.018)\end{array}$ \\
\hline part-time & $\begin{array}{r}0.326^{* * *} \\
(0.054)\end{array}$ & $\begin{array}{c}0.372^{*} \\
(0.199)\end{array}$ & $\begin{array}{r}0.358^{* * *} \\
(0.129)\end{array}$ & $\begin{array}{r}0.339^{* * *} \\
(0.111)\end{array}$ & $\begin{array}{r}0.350^{* * *} \\
(0.089)\end{array}$ & $\begin{array}{r}0.256^{* *} \\
(0.11)\end{array}$ \\
\hline immigrant & $\begin{array}{r}-0.185^{* * *} \\
(0.061)\end{array}$ & $\begin{array}{r}0.149 \\
(0.192)\end{array}$ & $\begin{array}{r}-0.175 \\
(0.162)\end{array}$ & $\begin{array}{r}-0.143 \\
(0.108)\end{array}$ & $\begin{array}{r}-0.342^{* * *} \\
(0.12)\end{array}$ & $\begin{array}{r}-0.250^{*} \\
(0.14)\end{array}$ \\
\hline high sch. & $\begin{array}{r}0.665^{* * *} \\
(0.21)\end{array}$ & $\begin{array}{r}0.956^{* * *} \\
(0.324)\end{array}$ & $\begin{array}{r}0.373 \\
(0.264)\end{array}$ & $\begin{array}{r}0.709^{* *} \\
(0.305)\end{array}$ & $\begin{array}{r}0.099 \\
(0.19)\end{array}$ & $\begin{array}{r}0.832 \\
(0.798)\end{array}$ \\
\hline college & $\begin{array}{r}0.630^{* * *} \\
(0.21)\end{array}$ & $\begin{array}{r}0.777^{* *} \\
(0.303)\end{array}$ & $\begin{array}{r}0.673^{* * *} \\
(0.258)\end{array}$ & $\begin{array}{r}0.746^{* *} \\
(0.305)\end{array}$ & $\begin{array}{r}-0.089 \\
(0.184)\end{array}$ & $\begin{array}{r}0.586 \\
(0.796)\end{array}$ \\
\hline univ. & $\begin{array}{r}0.496^{* *} \\
(0.21)\end{array}$ & $\begin{array}{r}1.300^{* * *} \\
(0.307)\end{array}$ & $\begin{array}{r}0.381 \\
(0.264)\end{array}$ & $\begin{array}{r}0.497 \\
(0.303)\end{array}$ & $\begin{array}{r}-0.209 \\
(0.184)\end{array}$ & $\begin{array}{r}0.378 \\
(0.792)\end{array}$ \\
\hline UR gap & $\begin{array}{r}0.114^{* * * *} \\
(0.022)\end{array}$ & $\begin{array}{r}0.189^{* *} \\
(0.08)\end{array}$ & $\begin{array}{r}0.115^{* *} \\
(0.05)\end{array}$ & $\begin{array}{c}0.067^{*} \\
(0.036)\end{array}$ & $\begin{array}{r}0.214^{* * *} * \\
(0.038)\end{array}$ & $\begin{array}{r}0.171^{* *} \\
(0.071)\end{array}$ \\
\hline married & $\begin{array}{r}-0.084 \\
(0.054)\end{array}$ & $\begin{array}{r}0.027 \\
(0.396)\end{array}$ & $\begin{array}{r}-0.446^{* *} \\
(0.198)\end{array}$ & $\begin{array}{r}-0.07 \\
(0.102)\end{array}$ & $\begin{array}{r}-0.202^{* * *} \\
(0.077)\end{array}$ & $\begin{array}{c}-0.068 \\
(0.092)\end{array}$ \\
\hline work rel. & $\begin{array}{r}0.937^{* * *} \\
(0.07)\end{array}$ & $\begin{array}{r}0.923^{* * *} \\
(0.222)\end{array}$ & $\begin{array}{r}0.643^{* * *} \\
(0.156)\end{array}$ & $\begin{array}{r}0.775^{* * *} \\
(0.148)\end{array}$ & $\begin{array}{r}1.019^{* * *} \\
(0.1)\end{array}$ & $\begin{array}{r}1.342^{* * *} \\
(0.145)\end{array}$ \\
\hline parental & $\begin{array}{r}1.115^{* * *} \\
(0.052)\end{array}$ & $1.425^{* * *}$ & $1.127^{* * *}$ & $1.013^{* * *}$ & $1.003^{* * *}$ & $1.392^{* * *}$ \\
\hline C 1930-39 & $\begin{array}{r}0.082 \\
(0.2)\end{array}$ & & & & & \\
\hline C 1940-49 & $\begin{array}{r}0.047 \\
(0.175)\end{array}$ & & & & & \\
\hline C 1950-59 & $\begin{array}{r}0.037 \\
(0.162)\end{array}$ & & & & & \\
\hline C 1960-69 & $\begin{array}{r}-0.1 \\
(0.157)\end{array}$ & & & & & \\
\hline C 1970-79 & $\begin{array}{r}-0.133 \\
(0.152)\end{array}$ & & & & & \\
\hline experience & $\begin{array}{r}-0.158^{* * *} \\
(0.005)\end{array}$ & $\begin{array}{r}-0.158^{* * *} \\
(0.014)\end{array}$ & $\begin{array}{r}-0.140^{* * *} \\
(0.01)\end{array}$ & $\begin{array}{r}-0.162^{* * *} \\
(0.009)\end{array}$ & $\begin{array}{r}-0.192^{* * *} \\
(0.012)\end{array}$ & $\begin{array}{r}-0.171^{* * *} \\
(0.016)\end{array}$ \\
\hline break 2 & $\begin{array}{r}-0.070^{* * *} \\
(0.007)\end{array}$ & $\begin{array}{r}-0.034^{* * *} \\
(0.013)\end{array}$ & $\begin{array}{r}-0.057^{* * *} \\
(0.011)\end{array}$ & $\begin{array}{r}-0.094^{* * *} \\
(0.016)\end{array}$ & $\begin{array}{r}-0.111^{* * *} \\
(0.023)\end{array}$ & $\begin{array}{r}-0.113^{* * *} \\
(0.042)\end{array}$ \\
\hline Obs & 4374 & 205 & 580 & 1141 & 1405 & 906 \\
\hline $\ln (\mathrm{L})$ & -16791 & -575 & -1667 & -3676 & -4616 & -2594 \\
\hline
\end{tabular}

Notes: Standard errors are in parentheses. $* * *, * *$, and $*$ denote $1 \%, 5 \%$, and $10 \%$ level of significance, respectively. C 1930-39 refers to the 1930-1939 birth cohort, similarly, C 1940-49 to C 1970-79 refer to the 1940-1949 to 1970-1979 birth cohorts. 
Figure 4.4: Baseline Hazards: Third Spells by Gender and Birth Cohort

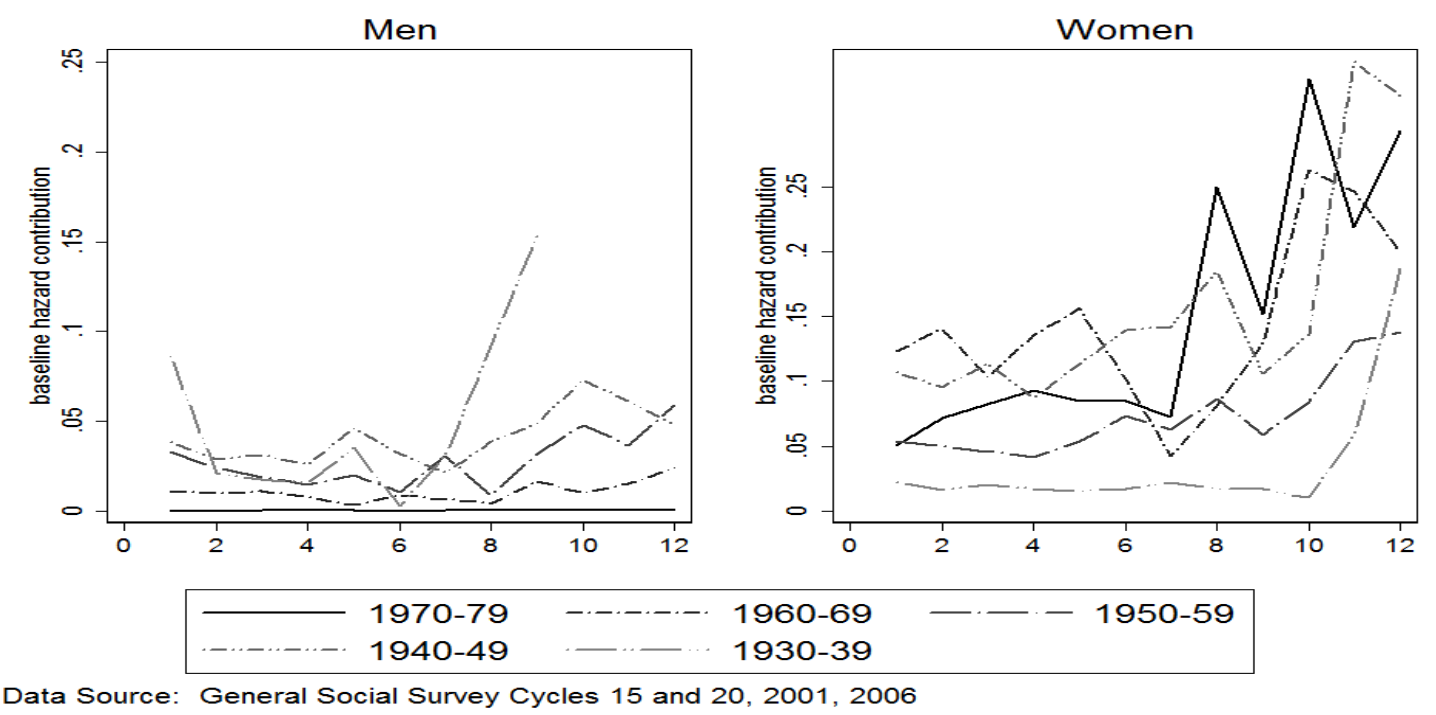

hazard and for women economic conditions become more important contributors to the hazard than in the case of the second spell.

\subsubsection{The Fourth Spell}

Fewer than half of those in the sample who experienced a third spell will have a fourth spell. Fourth spells are the shortest spells (just under 6 years in duration on average) in the sample and are begun by those 3 years older on average than the third spell. The ratio of men to women in the sample also declines to its lowest - with 5 women to each one man experiencing a fourth spell. Beyond this, the prevalence of parental responsibilities or personal reasons for departure are much less frequent than for second or third spells. 
Table 4.19 presents the regression results for the total sub-sample of fourth spells. The patterns evident in third spells are also present in fourth spells. Overall, the results suggest an increased hazard from being a man, the age work began, parttime status, higher levels of education as well as work-related and parental reasons. As before, work experience and the length of the previous separation negatively impact the hazard in relation to those born in the 1980s who had not completed high school.

For men in Table 4.19, the quality of the cohort-based estimates deteriorate due to small sample sizes. The total estimate is of sufficient size to identify the nowtypical pattern seen in the other regressions, with the age employment began, higher education, and work-related issues increasing the hazard while lifetime experience and the previous break from employment decrease the hazard. Interestingly, the cohort effects from later decades reduce the hazard of separation. That is, men born in latter generations are at lower risk of separating from employment in their fourth spell than those of previous generations.

For women, the sample sizes are sufficient to identify the same patterns as seen above. The only major distinction between third and fourth spells for women is the reduced impact of part-time work, in magnitudes (when significant). The positive contribution of part-time status to the probability of separation deteriorates across cohorts for fourth spells. This is the reverse of the patterns observed for first spells in Chapter 3.

Figure 4.5 shows the baseline hazards of the regressions. For men, of the 1970 s cohort there is clear evidence of positive duration dependence. This is also the case 
Table 4.19: Cox Proportional Hazard Results: Fourth Spells for Both Genders by Birth Cohort

\begin{tabular}{|c|c|c|c|c|c|c|}
\hline & Total & C 1930-39 & C 1940-49 & C 1950-59 & C 1960-69 & C $1970-79$ \\
\hline \multirow[t]{2}{*}{ Male } & $0.245^{* * *}$ & -1.216 & $0.586^{* *}$ & $0.506^{* * *}$ & 0.078 & -0.042 \\
\hline & $(0.088)$ & $(0.833)$ & $(0.262)$ & $(0.155)$ & (0.158) & $(0.179)$ \\
\hline \multirow[t]{2}{*}{ age began } & $0.081^{* * *}$ & $0.139 * * *$ & $0.070 * * *$ & $0.085^{* * *}$ & $0.087^{* * *}$ & $0.065^{* *}$ \\
\hline & $(0.006)$ & $(0.027)$ & $(0.011)$ & $(0.01)$ & $(0.015)$ & $(0.025)$ \\
\hline \multirow[t]{2}{*}{ part-time } & $0.242^{* * *}$ & $0.774^{* *}$ & $0.487^{* *}$ & 0.144 & $0.321^{* *}$ & 0.223 \\
\hline & $(0.079)$ & $(0.36)$ & $(0.224)$ & (0.139) & $(0.136)$ & $(0.238)$ \\
\hline \multirow[t]{2}{*}{ immigrant } & -0.09 & 0.059 & $-0.380^{*}$ & 0.042 & -0.248 & 0.029 \\
\hline & $(0.085)$ & $(0.322)$ & $(0.215)$ & $(0.162)$ & $(0.171)$ & $(0.15)$ \\
\hline \multirow[t]{2}{*}{ high sch. } & $0.735^{* * *}$ & -0.439 & $0.688^{* *}$ & 0.686 & $0.490^{*}$ & $0.828^{* * *}$ \\
\hline & $(0.22)$ & $(0.85)$ & $(0.347)$ & $(0.492)$ & $(0.291)$ & $(0.304)$ \\
\hline \multirow[t]{2}{*}{ college } & $0.743^{* * *}$ & -0.707 & 0.5 & 0.712 & $0.535^{*}$ & $0.825^{* * *}$ \\
\hline & $(0.22)$ & $(0.84)$ & $(0.362)$ & $(0.499)$ & $(0.278)$ & $(0.292)$ \\
\hline \multirow[t]{2}{*}{ univ. } & $0.483^{* *}$ & -0.76 & 0.429 & 0.478 & 0.188 & $0.505^{*}$ \\
\hline & $(0.221)$ & $(0.837)$ & $(0.339)$ & $(0.502)$ & $(0.289)$ & $(0.303)$ \\
\hline \multirow[t]{2}{*}{ UR gap } & $0.134^{* * *}$ & 0.125 & -0.013 & 0.093 & $0.230^{* * *}$ & -0.008 \\
\hline & $(0.032)$ & $(0.109)$ & $(0.081)$ & $(0.06)$ & $(0.056)$ & $(0.13)$ \\
\hline \multirow[t]{2}{*}{ married } & -0.122 & $-1.886^{* * *}$ & -0.08 & 0.244 & -0.12 & $-0.382^{* *}$ \\
\hline & $(0.077)$ & $(0.456)$ & $(0.333)$ & $(0.171)$ & (0.119) & $(0.15)$ \\
\hline \multirow[t]{2}{*}{ work rel. } & $0.951^{* * *}$ & $2.112^{* * *}$ & $1.112^{* * *}$ & $0.820 * * *$ & $1.012^{* * *}$ & $0.982^{* * *}$ \\
\hline & $(0.076)$ & $(0.536)$ & $(0.245)$ & $(0.147)$ & $(0.13)$ & $(0.154)$ \\
\hline \multirow[t]{2}{*}{ parental } & $1.057^{* * *} *$ & $2.389 * * *$ & $0.986^{* * *}$ & $1.002^{* * *}$ & $0.958^{* * *}$ & $1.112^{* * *}$ \\
\hline & $(0.083)$ & & & & & \\
\hline \multirow[t]{2}{*}{ C 1930-39 } & 0.19 & & & & & \\
\hline & $(0.243)$ & & & & & \\
\hline \multirow[t]{2}{*}{ C $1940-49$} & -0.023 & & & & & \\
\hline & $(0.222)$ & & & & & \\
\hline \multirow[t]{2}{*}{ C 1950-59 } & -0.226 & & & & & \\
\hline & (0.197) & & & & & \\
\hline \multirow[t]{2}{*}{ C 1960-69 } & $-0.397^{* *}$ & & & & & \\
\hline & $(0.177)$ & & & & & \\
\hline \multirow[t]{2}{*}{ C $1970-79$} & $-0.321^{*}$ & & & & & \\
\hline & $(0.173)$ & & & & & \\
\hline \multirow[t]{2}{*}{ experience } & $-0.145^{* * *}$ & $-0.184^{* * *}$ & $-0.121^{* * *}$ & $-0.142^{* * *}$ & $-0.181^{* * *}$ & $-0.210^{* * *}$ \\
\hline & $(0.006)$ & $(0.026)$ & $(0.012)$ & $(0.01)$ & $(0.014)$ & $(0.025)$ \\
\hline \multirow[t]{2}{*}{ break 3} & $-0.138^{* * *}$ & $-0.125^{* *}$ & $-0.122^{* * *}$ & $-0.148^{* * *}$ & $-0.160 * * *$ & $-0.197^{*}$ \\
\hline & (0.019) & $(0.06)$ & $(0.036)$ & $(0.032)$ & $(0.033)$ & $(0.102)$ \\
\hline Obs & 2478 & 85 & 293 & 737 & 836 & 452 \\
\hline $\ln (\mathrm{L})$ & -8013 & -186 & -728 & -1962 & -2137 & -1104 \\
\hline
\end{tabular}

Notes: Standard errors are in parentheses. ${ }^{* *},{ }^{* *}$, and $*$ denote $1 \%, 5 \%$, and $10 \%$ level of significance, respectively. C 1930-39 refers to the 1930-1939 birth cohort, similarly, C 1940-49 to C 1970-79 refer to the 1940-1949 to 1970-1979 birth cohorts. 
Table 4.20: Cox Proportional Hazard Results: Fourth Spells for Men by Birth Cohort

\begin{tabular}{|c|c|c|c|c|c|}
\hline & Total & Coh $1930-49$ & Coh 1950-59 & Coh 1960-69 & Coh 1970-79 \\
\hline \multirow[t]{2}{*}{ age began } & $0.102^{* * *}$ & $0.110^{* * *}$ & $0.129^{* * *}$ & 0.055 & $0.206^{* * *}$ \\
\hline & $(0.014)$ & $(0.031)$ & $(0.022)$ & $(0.034)$ & $(0.056)$ \\
\hline \multirow[t]{2}{*}{ part-time } & 0.192 & & 0.504 & 0.357 & $-37.578^{* * *}$ \\
\hline & $(0.307)$ & & $(0.564)$ & $(0.743)$ & $(1.096)$ \\
\hline \multirow[t]{2}{*}{ immigrant } & 0.122 & $-0.820^{*}$ & 0.428 & 0.071 & 0.132 \\
\hline & $(0.184)$ & $(0.465)$ & $(0.383)$ & $(0.386)$ & $(0.242)$ \\
\hline \multirow[t]{2}{*}{ high sch. } & $0.957^{* *}$ & 0.588 & $1.011^{*}$ & $2.747^{* *}$ & $0.972^{* *}$ \\
\hline & $(0.434)$ & $(0.726)$ & $(0.597)$ & (1.311) & $(0.472)$ \\
\hline \multirow[t]{2}{*}{ college } & $0.939 * *$ & $1.217^{* *}$ & 0.799 & $2.944^{* *}$ & $0.916^{* *}$ \\
\hline & $(0.442)$ & $(0.487)$ & $(0.654)$ & $(1.298)$ & $(0.449)$ \\
\hline \multirow[t]{2}{*}{ univ. } & 0.429 & 0.914 & 0.041 & $2.865^{* *}$ & 0.432 \\
\hline & $(0.457)$ & $(0.574)$ & $(0.715)$ & (1.338) & $(0.475)$ \\
\hline \multirow[t]{2}{*}{ UR gap } & 0.043 & -0.302 & -0.076 & 0.092 & 0.262 \\
\hline & $(0.079)$ & $(0.196)$ & $(0.123)$ & $(0.133)$ & $(0.235)$ \\
\hline \multirow[t]{2}{*}{ married } & 0.144 & $1.311^{*}$ & $0.663^{* *}$ & 0.187 & $-0.932^{*}$ \\
\hline & $(0.152)$ & $(0.79)$ & $(0.332)$ & $(0.246)$ & $(0.491)$ \\
\hline \multirow[t]{2}{*}{ work rel. } & $0.696^{* * *}$ & $1.100^{*}$ & 0.461 & $0.596^{* *}$ & $0.505^{* *}$ \\
\hline & $(0.151)$ & $(0.572)$ & $(0.328)$ & $(0.287)$ & $(0.242)$ \\
\hline \multirow[t]{2}{*}{ parental } & 0.03 & & & -0.021 & \\
\hline & $(0.216)$ & & & $(0.364)$ & \\
\hline \multirow[t]{2}{*}{ C 1930-39 } & -0.676 & & & & \\
\hline & $(0.681)$ & & & & \\
\hline \multirow[t]{2}{*}{ C $1940-49$} & 0.126 & & & & \\
\hline & $(0.465)$ & & & & \\
\hline \multirow[t]{2}{*}{ C 1950-59 } & -0.254 & & & & \\
\hline & $(0.33)$ & & & & \\
\hline \multirow[t]{2}{*}{ C 1960-69 } & $-0.590^{* *}$ & & & & \\
\hline & $(0.279)$ & & & & \\
\hline C $1970-79$ & $\begin{array}{r}-0.561^{* *} \\
(0.244)\end{array}$ & & & & \\
\hline \multirow{2}{*}{ experience } & $-0.153^{* * *}$ & $-0.194^{* * *}$ & $-0.146^{* * *}$ & $-0.182^{* * *}$ & $-0.229 * * *$ \\
\hline & $(0.014)$ & $(0.038)$ & $(0.019)$ & $(0.033)$ & $(0.05)$ \\
\hline \multirow[t]{2}{*}{ break 3} & $-0.183^{* *}$ & -0.177 & $-0.406^{* * *}$ & -0.1 & 0.054 \\
\hline & $(0.073)$ & $(0.223)$ & $(0.15)$ & $(0.123)$ & $(0.167)$ \\
\hline Obs & 465 & 62 & 140 & 138 & 97 \\
\hline $\ln (\mathrm{L})$ & -1200 & -92 & -268 & -243 & -183 \\
\hline
\end{tabular}

Notes: Standard errors are in parentheses. $* * *, * *$, and $*$ denote $1 \%, 5 \%$, and $10 \%$ level of significance, respectively. C 1930-39 refers to the 1930-1939 birth cohort, similarly, C 1940-49 to C 1970-79 refer to the 1940-1949 to 1970-1979 birth cohorts. 
Table 4.21: Cox Proportional Hazard Results: Fourth Spells for Women by Birth Cohort

\begin{tabular}{|c|c|c|c|c|c|c|}
\hline & Total & C 1930-39 & C $1940-49$ & C 1950-59 & C 1960-69 & C $1970-79$ \\
\hline \multirow[t]{2}{*}{ age began } & $0.076^{* * *}$ & $0.148 * * *$ & $0.071^{* * *}$ & $0.077^{* * *}$ & $0.091^{* * *}$ & 0.02 \\
\hline & $(0.007)$ & $(0.029)$ & $(0.014)$ & $(0.011)$ & $(0.016)$ & $(0.028)$ \\
\hline \multirow[t]{2}{*}{ part-time } & $0.260^{* * *}$ & $0.827^{* *}$ & $0.535^{* *}$ & 0.095 & $0.322^{* *}$ & 0.318 \\
\hline & $(0.081)$ & $(0.347)$ & $(0.225)$ & $(0.144)$ & $(0.139)$ & $(0.225)$ \\
\hline \multirow[t]{2}{*}{ immigrant } & -0.123 & 0.181 & -0.251 & -0.033 & $-0.344^{*}$ & -0.141 \\
\hline & $(0.093)$ & $(0.327)$ & $(0.244)$ & $(0.176)$ & $(0.188)$ & $(0.193)$ \\
\hline \multirow[t]{2}{*}{ high sch. } & $0.544^{* *}$ & 0.452 & 0.749 & $1.102^{* *}$ & 0.223 & $0.654^{*}$ \\
\hline & $(0.232)$ & $(1.271)$ & $(0.557)$ & $(0.514)$ & $(0.245)$ & $(0.341)$ \\
\hline \multirow[t]{2}{*}{ college } & $0.557^{* *}$ & 0.209 & 0.554 & $1.103^{* *}$ & 0.25 & $0.633^{* *}$ \\
\hline & $(0.232)$ & $(1.215)$ & $(0.595)$ & $(0.515)$ & $(0.224)$ & $(0.319)$ \\
\hline \multirow[t]{2}{*}{ univ. } & 0.343 & 0.11 & 0.607 & $0.987^{*}$ & -0.142 & 0.398 \\
\hline & $(0.23)$ & $(1.228)$ & $(0.558)$ & $(0.516)$ & $(0.23)$ & $(0.302)$ \\
\hline \multirow[t]{2}{*}{ UR gap } & $0.163^{* * *}$ & 0.012 & 0.096 & $0.128^{*}$ & $0.246^{* * *}$ & -0.138 \\
\hline & $(0.034)$ & $(0.117)$ & $(0.092)$ & $(0.068)$ & $(0.061)$ & $(0.155)$ \\
\hline \multirow[t]{2}{*}{ married } & $-0.254^{* * *}$ & $-1.611^{* * *}$ & $-0.607^{* *}$ & 0.024 & -0.209 & -0.214 \\
\hline & $(0.084)$ & $(0.45)$ & $(0.306)$ & $(0.196)$ & $(0.129)$ & $(0.157)$ \\
\hline \multirow[t]{2}{*}{ work rel. } & $0.978^{* * *}$ & $1.857^{* * *}$ & $0.933^{* * *}$ & $0.840^{* * *}$ & $1.049^{* * *}$ & $1.178^{* * *}$ \\
\hline & $(0.087)$ & $(0.56)$ & $(0.325)$ & $(0.166)$ & $(0.136)$ & (0.203) \\
\hline parental & $\begin{array}{r}1.035^{* * *} \\
(0.09)\end{array}$ & $2.561^{* * *}$ & $1.016^{* * *}$ & $0.905^{* * *}$ & $1.001^{* * *}$ & $1.086^{* * *}$ \\
\hline \multirow[t]{2}{*}{ C 1930-39 } & $0.702^{* *}$ & & & & & \\
\hline & $(0.308)$ & & & & & \\
\hline \multirow[t]{2}{*}{ C $1940-49$} & 0.292 & & & & & \\
\hline & $(0.284)$ & & & & & \\
\hline \multirow[t]{2}{*}{ C 1950-59 } & 0.073 & & & & & \\
\hline & $(0.267)$ & & & & & \\
\hline \multirow[t]{2}{*}{ C 1960-69 } & -0.061 & & & & & \\
\hline & $(0.249)$ & & & & & \\
\hline \multirow[t]{2}{*}{ C $1970-79$} & 0.016 & & & & & \\
\hline & $(0.244)$ & & & & & \\
\hline \multirow[t]{2}{*}{ experience } & $-0.153^{* * *}$ & $-0.175^{* * *}$ & $-0.123^{* * *}$ & $-0.152^{* * *}$ & $-0.185^{* * *}$ & $-0.204^{* * *}$ \\
\hline & $(0.007)$ & $(0.027)$ & & & $(0.014)$ & $(0.027)$ \\
\hline \multirow[t]{2}{*}{ break 3} & $-0.133^{* * *}$ & $-0.127^{*}$ & $-0.123^{* * *}$ & $-0.123^{* * *}$ & $-0.168^{* * *}$ & $-0.261^{* *}$ \\
\hline & $(0.02)$ & $(0.07)$ & $(0.037)$ & $(0.03)$ & $(0.036)$ & $(0.111)$ \\
\hline Obs & 2013 & 75 & 241 & 597 & 698 & 355 \\
\hline $\ln (\mathrm{L})$ & -6203 & -175 & -567 & -1506 & -1729 & -797 \\
\hline
\end{tabular}

Notes: Standard errors are in parentheses. ${ }^{* * *},{ }^{* *}$, and $*$ denote $1 \%, 5 \%$, and $10 \%$ level of significance, respectively. C 1930-39 refers to the 1930-1939 birth cohort, similarly, C 1940-49 to C 1970-79 refer to the 1940-1949 to 1970-1979 birth cohorts. 
for women in the earliest cohort. However, these results - particularly for men - are suspect due to small sample sizes.

Figure 4.5: Baseline Hazards: Fourth Spells by Gender and Birth Cohort
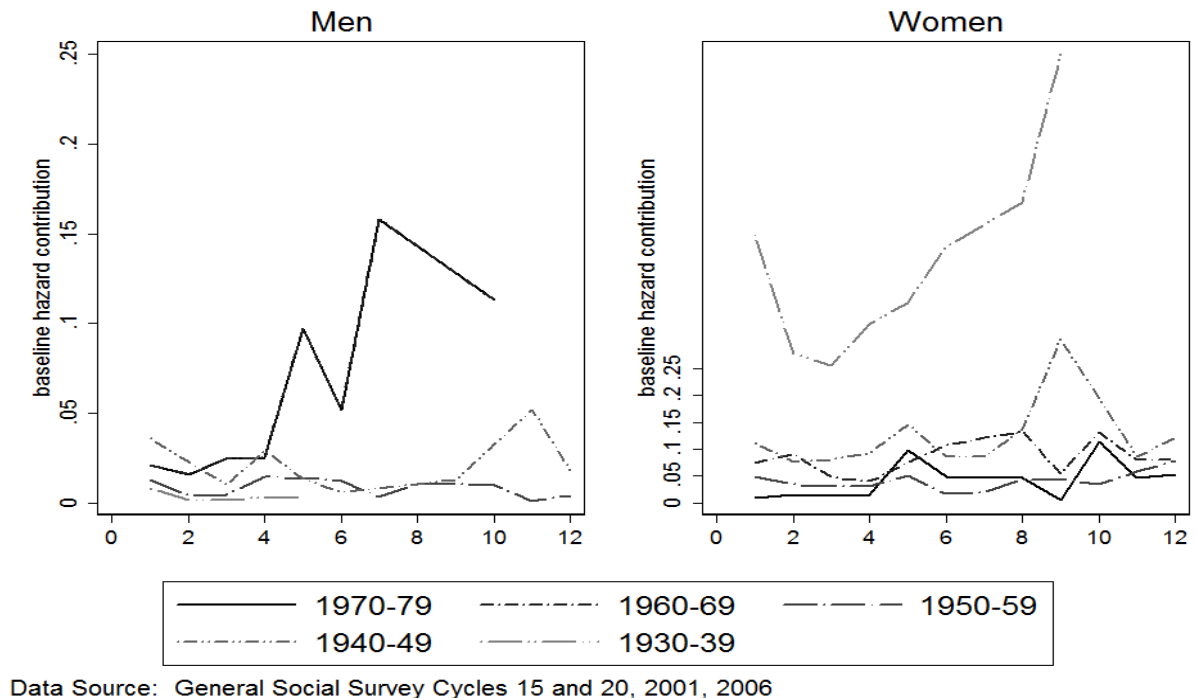

Fourth spells tend to repeat the pattern identified for third spells. However, for women, part-time status appears to have a weaker impact on latter cohorts of workers. On the whole, however fourth and third spells are remarkably similar across cohorts for women. For men, there are too few observations to reliably evaluate the results by cohort. Nevertheless, being born in a latter cohort (in the full sub-sample equation) tends to reduce the hazard of separation in the fourth spell.

\subsubsection{The Fifth Spell}

Fewer than half of those in the sample who experienced a fourth spell participate in a fifth. Fifth spells are, on average, only slightly longer than fourth spells and are begun about 1 year later in life than are fourth spells. The ratio of men 
to women in the sample is slightly higher in fifth spells than fourth spells (one man per four women rather than one per five). In most other aspects, the characteristics of those who are engaged in fifth spells are similar to those in fourth spells.

Table 4.22 shows the total sample results with the usual variables having the same signs and similar levels of significance. However, gender is no longer a significant contribution to the hazard (with the exception of the 1930s cohort which suffers from a small sample size). The age at which work began has a diminishing positive impact across successive cohorts. Likewise, lifetime experience has a diminishing negative impact across cohorts. The total sub-sample estimation yields increasingly small reductions in the hazard across successive cohorts as was the case with first employment spells in relation to those born in the 1980s who had not completed high school.

Table 4.23 shows the results for men, while all cohort-based estimations suffer from small sample sizes the total sub-sample of men in their fifth spell has a sufficient sample size for analysis. Only the age at which work began, high school education and work related separations contribute positively and significantly to the hazard. Lifetime experience and cohort effects negatively impact the hazard, with cohort effects causing milder declines in the hazard across successive birth cohorts.

Table 4.24 presents the regression results for women in their fifth spell. As before, age work began, the unemployment rate gap, work related separations and parental responsibilities contribute positively to the hazard. Cohort effects, lifetime experience and the duration of the previous break reduce the hazard of separation. The cohort effects also show a dampening of the reduction in the hazard across 
Table 4.22: Cox Proportional Hazard Results: Fifth Spells for Both Genders by Birth Cohort

\begin{tabular}{|c|c|c|c|c|c|c|}
\hline & Total & C 1930-39 & C 1940-49 & C 1950-59 & C 1960-69 & C 1970-79 \\
\hline \multirow[t]{2}{*}{ Male } & 0.055 & $5.125 * * *$ & 0.506 & 0.282 & -0.251 & -0.123 \\
\hline & $(0.127)$ & (1.793) & $(0.375)$ & $(0.223)$ & $(0.226)$ & $(0.231)$ \\
\hline \multirow[t]{2}{*}{ age began } & $0.136^{* * *}$ & $0.224^{* * *}$ & $0.208^{* * *}$ & $0.151^{* * *}$ & $0.154^{* * *}$ & $0.088^{* *}$ \\
\hline & $(0.012)$ & $(0.051)$ & $(0.027)$ & $(0.021)$ & $(0.034)$ & $(0.043)$ \\
\hline \multirow[t]{2}{*}{ part-time } & 0.108 & -0.281 & -0.177 & $0.377^{* *}$ & -0.228 & -0.107 \\
\hline & $(0.123)$ & $(0.634)$ & $(0.361)$ & $(0.178)$ & $(0.259)$ & $(0.326)$ \\
\hline \multirow[t]{2}{*}{ immigrant } & -0.185 & $-2.780^{* *}$ & -0.177 & -0.286 & -0.19 & $-0.507^{*}$ \\
\hline & $(0.132)$ & $(1.165)$ & $(0.359)$ & $(0.245)$ & $(0.276)$ & $(0.298)$ \\
\hline \multirow[t]{2}{*}{ high sch. } & 0.274 & 0.348 & -0.227 & 1.807 & -0.568 & $0.819^{*}$ \\
\hline & $(0.52)$ & $(1.286)$ & $(0.464)$ & (1.203) & $(0.625)$ & $(0.484)$ \\
\hline \multirow[t]{2}{*}{ college } & 0.188 & 1.159 & -0.188 & 1.85 & -0.92 & $0.733^{*}$ \\
\hline & $(0.52)$ & $(1.03)$ & $(0.445)$ & (1.207) & $(0.649)$ & $(0.377)$ \\
\hline \multirow[t]{2}{*}{ univ. } & -0.015 & -0.486 & $-0.859^{* *}$ & 1.511 & -0.812 & $0.748^{*}$ \\
\hline & $(0.521)$ & $(0.959)$ & $(0.43)$ & (1.203) & $(0.634)$ & $(0.383)$ \\
\hline \multirow[t]{2}{*}{ UR gap } & $0.182^{* *}$ & 0.205 & 0.166 & 0.238 & 0.241 & -0.258 \\
\hline & $(0.082)$ & $(0.253)$ & $(0.267)$ & $(0.161)$ & $(0.167)$ & $(0.279)$ \\
\hline \multirow[t]{2}{*}{ married } & -0.025 & 1.137 & -0.036 & 0.396 & -0.207 & -0.188 \\
\hline & $(0.13)$ & $(1.762)$ & $(0.474)$ & $(0.299)$ & $(0.2)$ & $(0.236)$ \\
\hline \multirow[t]{2}{*}{ work rel. } & $1.594^{* * *}$ & $1.540^{*}$ & $2.427^{* * *}$ & $1.500^{* * *}$ & $1.500^{* * *}$ & $2.439^{* * *}$ \\
\hline & $(0.144)$ & $(0.916)$ & $(0.527)$ & $(0.229)$ & $(0.24)$ & $(0.403)$ \\
\hline parental & $\begin{array}{r}1.655^{* * *} * \\
(0.185)\end{array}$ & $3.432^{* *}$ & $5.585^{* * *}$ & $2.274^{* * *}$ & $1.755^{* * *}$ & $1.737^{* * *}$ \\
\hline \multirow[t]{2}{*}{ C 1930-39 } & $-2.456^{* * *}$ & & & & & \\
\hline & $(0.551)$ & & & & & \\
\hline \multirow[t]{2}{*}{ C $1940-49$} & $-2.465^{* * *}$ & & & & & \\
\hline & $(0.439)$ & & & & & \\
\hline \multirow[t]{2}{*}{ C 1950-59 } & $-2.143^{* * *}$ & & & & & \\
\hline & $(0.35)$ & & & & & \\
\hline \multirow[t]{2}{*}{ C 1960-69 } & $-1.804^{* * *}$ & & & & & \\
\hline & $(0.262)$ & & & & & \\
\hline \multirow[t]{2}{*}{ C $1970-79$} & $-0.937^{* * *}$ & & & & & \\
\hline & $(0.216)$ & & & & & \\
\hline \multirow[t]{2}{*}{ experience } & $-0.138^{* * *}$ & $-0.136^{* * *}$ & $-0.122^{* * *}$ & $-0.122^{* * *}$ & $-0.171^{* * *}$ & $-0.222^{* * *}$ \\
\hline & $(0.01)$ & $(0.05)$ & $(0.023)$ & $(0.016)$ & $(0.022)$ & $(0.036)$ \\
\hline \multirow[t]{2}{*}{ break 4} & $-0.098^{* * *}$ & -0.618 & $-0.111^{* * *}$ & $-0.111^{* * *}$ & 0.03 & -0.165 \\
\hline & $(0.022)$ & $(0.453)$ & $(0.026)$ & $(0.041)$ & $(0.046)$ & $(0.189)$ \\
\hline Obs & 1099 & 35 & 132 & 339 & 377 & 187 \\
\hline $\ln (\mathrm{L})$ & -3122 & -61 & -242 & -782 & -748 & -367 \\
\hline
\end{tabular}

Notes: Standard errors are in parentheses. ${ }^{* *},{ }^{* *}$, and $*$ denote $1 \%, 5 \%$, and $10 \%$ level of significance, respectively. C 1930-39 refers to the 1930-1939 birth cohort, similarly, C 1940-49 to C 1970-79 refer to the 1940-1949 to 1970-1979 birth cohorts. 
Table 4.23: Cox Proportional Hazard Results: Fifth Spells for Men by Birth Cohort

\begin{tabular}{|c|c|c|c|c|c|}
\hline & Total & Coh 1930-49 & Coh 1950-59 & Coh 1960-69 & Coh 1970-79 \\
\hline \multirow[t]{2}{*}{ age began } & $0.143^{* * *}$ & 0.137 & $0.117^{* * *}$ & $0.235^{* *}$ & 0.09 \\
\hline & $(0.026)$ & $(0.105)$ & $(0.039)$ & $(0.093)$ & $(0.09)$ \\
\hline \multirow[t]{2}{*}{ part-time } & 0.387 & & 0.187 & 0.751 & $2.160^{* *}$ \\
\hline & $(0.382)$ & & $(0.636)$ & $(1.309)$ & $(0.963)$ \\
\hline \multirow[t]{2}{*}{ immigrant } & -0.332 & 0.557 & -0.824 & $0.991^{*}$ & $-1.186^{*}$ \\
\hline & $(0.34)$ & $(1.396)$ & $(0.721)$ & $(0.537)$ & $(0.709)$ \\
\hline \multirow[t]{2}{*}{ high sch. } & $1.566^{* *}$ & -0.408 & 1.728 & 0.388 & 0.481 \\
\hline & $(0.68)$ & $(2.371)$ & $(1.305)$ & $(0.434)$ & $(1.252)$ \\
\hline \multirow[t]{2}{*}{ college } & $1.107^{*}$ & -1.504 & 1.535 & -0.66 & 0.523 \\
\hline & $(0.666)$ & $(1.938)$ & $(1.383)$ & $(0.578)$ & $(0.813)$ \\
\hline \multirow[t]{2}{*}{ univ. } & $1.222^{*}$ & -1.437 & 1.519 & 0.267 & 0.994 \\
\hline & $(0.65)$ & $(1.356)$ & (1.187) & $(0.514)$ & $(0.889)$ \\
\hline \multirow[t]{2}{*}{ UR gap } & -0.121 & -0.102 & -0.095 & -0.207 & 0.355 \\
\hline & $(0.138)$ & $(0.619)$ & $(0.282)$ & $(0.325)$ & $(0.38)$ \\
\hline \multirow[t]{2}{*}{ married } & 0.06 & -1.024 & 0.599 & $-0.788^{*}$ & 0.145 \\
\hline & $(0.247)$ & $(1.107)$ & $(0.615)$ & $(0.444)$ & $(0.527)$ \\
\hline \multirow[t]{2}{*}{ work rel. } & $2.646^{* * *}$ & $2.587^{* *}$ & $2.268^{* * *}$ & $3.340^{* * *}$ & $2.926^{* * *}$ \\
\hline & $(0.378)$ & $(1.043)$ & $(0.666)$ & $(0.922)$ & $(0.808)$ \\
\hline \multirow[t]{2}{*}{ parental } & 0.532 & & & 0.034 & \\
\hline & $(0.327)$ & & & $(0.935)$ & \\
\hline \multirow[t]{2}{*}{ C $1930-39$} & -0.04 & & & & \\
\hline & $(0.957)$ & & & & \\
\hline \multirow[t]{2}{*}{ C $1940-49$} & $-2.032^{* *}$ & & & & \\
\hline & $(0.997)$ & & & & \\
\hline \multirow[t]{2}{*}{ C $1950-59$} & $-2.404^{* * *}$ & & & & \\
\hline & $(0.774)$ & & & & \\
\hline \multirow[t]{2}{*}{ C 1960-69 } & $-2.014^{* * *}$ & & & & \\
\hline & $(0.478)$ & & & & \\
\hline \multirow[t]{2}{*}{ C $1970-79$} & $-1.039^{* * *}$ & & & & \\
\hline & $(0.368)$ & & & & \\
\hline \multirow[t]{2}{*}{ experience } & $-0.157^{* * *}$ & -0.142 & $-0.098^{* * *}$ & $-0.178^{* * *}$ & $-0.290 * * *$ \\
\hline & $(0.027)$ & $(0.117)$ & $(0.037)$ & $(0.046)$ & $(0.076)$ \\
\hline \multirow[t]{2}{*}{ break 4} & -0.1 & $-0.424^{*}$ & 0.097 & 0.133 & -0.499 \\
\hline & $(0.199)$ & $(0.23)$ & $(0.252)$ & $(0.406)$ & $(0.735)$ \\
\hline Obs & 226 & 23 & 68 & 70 & 50 \\
\hline $\ln (\mathrm{L})$ & -486 & -20 & -105 & -76 & -66 \\
\hline
\end{tabular}

Notes: Standard errors are in parentheses. $* * *, * *$, and $*$ denote $1 \%, 5 \%$, and $10 \%$ level of significance, respectively. C 1930-39 refers to the 1930-1939 birth cohort, similarly, C 1940-49 to C 1970-79 refer to the 1940-1949 to 1970-1979 birth cohorts. 
successive birth cohorts.

Figure 4.6 shows the baseline hazards for the equations, for both men and women of the 1930 s a volatile pattern can be observed. These volatile patterns can be attributed to small sample sizes (the 1970s cohort for men has an equally volatile pattern). The 1940s cohort for women shows increasing duration dependence, in other cases the baseline hazards are all essentially flat.

Figure 4.6: Baseline Hazards: Fifth Spells by Gender and Birth Cohort

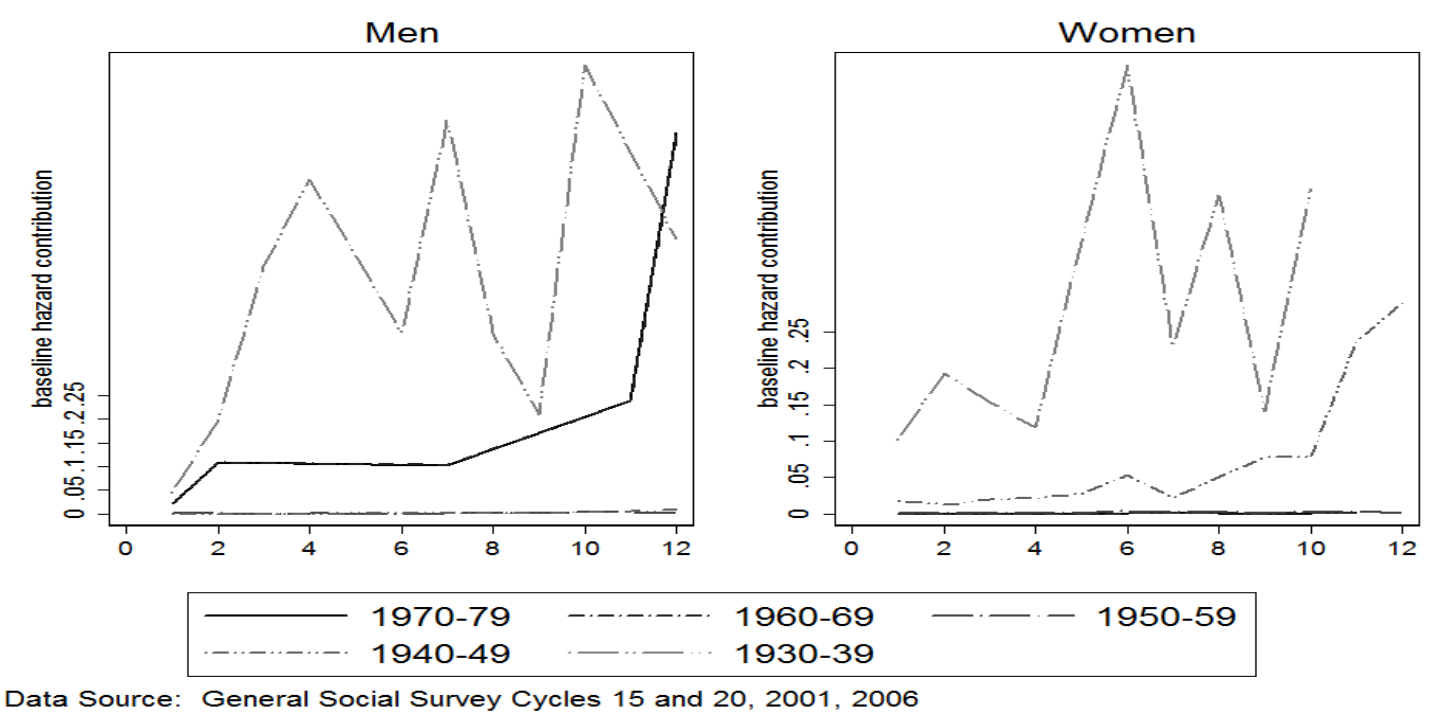

Fifth spells do not stand out significantly from fourth spells in terms of the variables which influence the hazard. One exception, for both men and women is that the cohort effects identified in first spells - namely, the decrease in the negative contribution of cohort effects to the hazard across successive birth cohorts - generally hold. This was a key characteristic of first spells that did not appear 
Table 4.24: Cox Proportional Hazard Results: Fifth Spells for Women by Birth Cohort

\begin{tabular}{|c|c|c|c|c|c|}
\hline & Total & Coh 1930-49 & Coh 1950-59 & Coh 1960-69 & Coh 1970-79 \\
\hline \multirow[t]{2}{*}{ age began } & $0.144^{* * *}$ & $0.193^{* * *}$ & $0.156^{* * *}$ & $0.152^{* * *}$ & $0.089 *$ \\
\hline & $(0.013)$ & $(0.024)$ & $(0.022)$ & $(0.038)$ & $(0.052)$ \\
\hline \multirow[t]{2}{*}{ part-time } & 0.039 & -0.116 & $0.344^{*}$ & -0.219 & -0.328 \\
\hline & $(0.131)$ & $(0.313)$ & $(0.191)$ & $(0.249)$ & $(0.356)$ \\
\hline \multirow[t]{2}{*}{ immigrant } & $-0.291^{*}$ & $-0.615^{* *}$ & -0.16 & -0.428 & -0.313 \\
\hline & $(0.149)$ & $(0.311)$ & $(0.267)$ & $(0.326)$ & $(0.343)$ \\
\hline \multirow[t]{2}{*}{ high sch. } & -0.284 & -0.55 & 0.355 & -0.764 & \\
\hline & $(0.489)$ & $(0.449)$ & $(0.458)$ & $(0.779)$ & \\
\hline \multirow[t]{2}{*}{ college } & -0.307 & -0.221 & 0.448 & -1.114 & -0.195 \\
\hline & $(0.493)$ & $(0.4)$ & $(0.469)$ & $(0.811)$ & $(0.312)$ \\
\hline \multirow[t]{2}{*}{ univ. } & -0.564 & $-0.831^{* *}$ & 0.067 & -1.068 & -0.432 \\
\hline & $(0.492)$ & $(0.418)$ & $(0.471)$ & $(0.794)$ & $(0.38)$ \\
\hline \multirow[t]{2}{*}{ UR gap } & $0.235^{* *}$ & $0.444^{* *}$ & 0.301 & 0.263 & -0.4 \\
\hline & $(0.105)$ & $(0.192)$ & $(0.2)$ & $(0.184)$ & $(0.36)$ \\
\hline \multirow[t]{2}{*}{ married } & -0.127 & 0.155 & 0.285 & -0.054 & -0.254 \\
\hline & $(0.15)$ & $(0.504)$ & $(0.353)$ & $(0.251)$ & $(0.283)$ \\
\hline \multirow[t]{2}{*}{ work rel. } & $1.357^{* * *}$ & $1.199^{* * *}$ & $1.217^{* * *}$ & $1.299 * * *$ & $2.352^{* * *}$ \\
\hline & $(0.16)$ & $(0.38)$ & $(0.244)$ & $(0.278)$ & $(0.441)$ \\
\hline parental & $\begin{array}{r}1.711^{* * *} \\
(0.208)\end{array}$ & $5.011^{* * *}$ & $2.120^{* * *}$ & $1.945^{* * *}$ & $1.683^{* * *}$ \\
\hline C 1930-39 & $\begin{array}{r}-2.635^{* * *} \\
(0.677)\end{array}$ & & & & \\
\hline \multirow[t]{2}{*}{ C $1940-49$} & $-2.617^{* * *}$ & & & & \\
\hline & $(0.57)$ & & & & \\
\hline \multirow[t]{2}{*}{ C $1950-59$} & $-2.099 * * *$ & & & & \\
\hline & $(0.488)$ & & & & \\
\hline \multirow[t]{2}{*}{ C $1960-69$} & $-1.670^{* * *}$ & & & & \\
\hline & $(0.417)$ & & & & \\
\hline \multirow[t]{2}{*}{ C $1970-79$} & $-0.811^{* *}$ & & & & \\
\hline & $(0.378)$ & & & & \\
\hline \multirow[t]{2}{*}{ experience } & $-0.137^{* * *}$ & $-0.115^{* * *}$ & $-0.131^{* * *}$ & $-0.165 * * *$ & $-0.215^{* * *}$ \\
\hline & $(0.011)$ & $(0.02)$ & $(0.018)$ & $(0.023)$ & $(0.036)$ \\
\hline \multirow[t]{2}{*}{ break 4} & $-0.085^{* * *}$ & $-0.103^{* * *}$ & $-0.102^{* *}$ & 0.031 & -0.157 \\
\hline & $(0.02)$ & $(0.024)$ & $(0.04)$ & $(0.045)$ & $(0.164)$ \\
\hline $\mathrm{N}$ & 873 & 144 & 271 & 307 & 137 \\
\hline $\ln (\mathrm{L})$ & -2313 & -314 & -588 & -587 & -247 \\
\hline Obs & 873 & 144 & 271 & 307 & 137 \\
\hline $\ln (\mathrm{L})$ & -2313 & -314 & -588 & -587 & -247 \\
\hline
\end{tabular}

Notes: Standard errors are in parentheses. ${ }^{* *},{ }^{* *}$, and $*$ denote $1 \%, 5 \%$, and $10 \%$ level of significance, respectively. C 1930-39 refers to the 1930-1939 birth cohort, similarly, C 1940-49 to C 1970-79 refer to the 1940-1949 to 1970-1979 birth cohorts. 
in spells two through four. It is uncertain why this would be the case but one explanation could be that the addition of lifetime experience and break durations explained many features that cohort effects otherwise would in the earlier spells while other unobserved characteristics become more prominent for the final spells.

\subsection{Conclusions}

Employment tenures beyond the first spell tend to be shorter and are begun later in life. In general, the prevalence of multiple spells increase across cohorts. Because each employment tenure may contain several jobs and can only be terminated by a prolonged absence from employment, the customary job shopping of youth is not evident in these tenures. In fact, the process is quite the reverse, with employment tenures shortening as the number of tenures rises, while for jobs the opposite seems to be the case. Furthermore, men are much more likely than women to not undergo bouts of separation from employment. Hence the proportion of men in each successive spell dwindles, from one in two to one in five by the fourth spell.

The key socio-economic factors that affect the hazard of separation are, as in the previous chapter, work-related separations and parental responsibilities as well as the age that work began. Part-time status also tends to be a major contributor to the hazard of separation. Conversely, cohort effects - which play a major role in first spells - as well as marital status tend to be insignificant contributors in the second through fourth spells. Finally, lifetime experience and the break between the last employment spell and the current contribute negatively to the hazard across 
all employment spells. This indicates that as work experience is accumulated individuals are more likely to settle in longer-term positions and as the length of the preceding separation becomes longer workers are less inclined to depart from their current spells. 


\section{Chapter 5: Conclusions}

Overall, this exploration of Canadian workers showed that much useful information regarding long-term employment behaviour can be inferred from the recollection of workers. The main question of the work was whether Canadian employment tenures had declined over time? And if so, what reasons - if any - were there for these declines? This chapter will summarize the evidenceand present the overall conclusions of the thesis. Finally, a proposal for ongoing work on the subject will be recommended.

\subsection{Summary}

First and foremost, it is important to emphasize the contribution this body of evidence makes to the study of employment stability. First, it brings to bear on the question an unused and novel dataset to evaluating the stability of employment over a long period. In fact, the General Social Survey is the only study in Canada which can consistently examine durations of employment begun over the course of the 1950s and 1960s. Because of the retrospective nature of the data a number of interesting technical issues arise when examining the results. While the dataset lacks the size and available covariates of the Labour Force Survey it allows for a 
longer-term perspective, which in turn allows the necessary results to be established. Secondly, a set of techniques for testing stability are developed which account for some of the characteristics of the data - these on their own are a contribution of the study. Finally, the key result of the study - that employment tenures shortened before the 1970s, when most studies of job stability begin - is also a contribution to the field.

In Chapter 2 it was shown that there was likely to be some significant difference between employment spells started before the 1970s and those which were started in that period and beyond. Namely, it was shown that over time the employment spells that were undertaken became shorter over the entire distribution of employment spells by decadal cohort. Importantly, it was shown that this process was generated mostly by the behavior of men with the changes for women being much less clear. This was done using a novel technique of decomposing employment distributions into heterogeneous worker types and then using the properties of these distributions to enhance the power and size of the parametric bootstrap procedure which produced the tests of stochastic dominance required to obtain the conclusions. While it was found that shifts in proportions between worker types did occur, the results, to a large extent, depended on the proportion of ongoing employment tenures. That is, over the distribution those whose spells did not end by the date of the survey, were more likely to be in lifetime employment if they came from an earlier cohort.

Data issues that were examined in Chapter 2 dealt primarily with the suitability of using retrospective data and the possible memory effects that could occur. The sample properties were examined and found to be consistent with the Cana- 
dian population. Annual heaping patterns - produced by forgetting the month of work and coded as the first or last month in a year - were addressed by rounding responses to the annual level. Furthermore, robustness checks were performed between the same survey collected at different intervals to determine whether the presence of recall errors could be detected by cohort - no consistent effects were found. The selection of decadal cohorts were also subject to testing by varying start dates and cohort length, this was found to not affect the results substantively. Overall, it was determined that the data provided useful information and the potential for bias entering the results from the data was manageable.

The following chapter, Chapter 3, focused exclusively on first employment spells and examined the covariates which could explain the changes and shifts identified in Chapter 2. Before the analysis began a series of benchmarking exercises comparing a GSS employment-based retention rate and the LFS job-based retention rate were conducted. It was found that the GSS-based retention rates were far less cyclically volatile and contained a negative time-trend in relation to the LFS-based measures. It was surmised that the time trend difference between the series was likely generated by structural factors which made it easier to continue in a job while taking a prolonged absence from employment such as the enhanced maternity leave provisions of Unemployment Insurance first introduced in the early 1970s.

Because of the distinct results for men and women identified in Chapter 2, estimates were performed by gender. While the focus was on employment spells conditioned on their respective birth cohorts, rather then the employment cohorts used in the preceding chapter, the overall results by year of birth for first spells 
were in-line with those performed on all employment spells by the year employment began (with a lag of about 20 years). Namely, those who began employment and had earlier birth years tended to have longer first spells than those who began their spells in subsequent decades. While this pattern was found for for both men and women, the decline in tenure was far more prominent for men. It was surmised that workers born after the 1950s were likely affected by the 1990s recession and associated jobless recovery, as a result a notable shift in the cohort patterns occurs in the post 1950s birth cohorts of both men and women. Parental leave was found to increase the hazard of separation strongly for women and the increasing hazard by cohort coincides with the increasing generosity of parental benefit provisions in the Unemployment Insurance system. It was surmised that this may have played a large role in explaining the divergence of employment tenures from job tenures as maternity provisions allowed women to break up employment without separating from their jobs in the post-1970 period. Layoffs, firm closures and other workrelated issues also increase the hazard of separation, even when accounting for the business cycle. This likely implies that firm shutdown and layoffs, particularly with regard to the post-1950s cohorts of workers, have significantly altered the stability of employment for both men and women.

Finally, in Chapter 4 the incidence of employment spells beyond the first was examined. These tenures tend to be shorter in average duration and are begun later in life. Furthermore, it was observed that the prevalence of multiple spells increases across cohorts. In all cohorts however, it was found that women were significantly more prone to undergo bouts of separation from employment than were men. The 
key factors which impacted the hazard of separation were, as was the case in Chapter 3, work-related separations and parental responsibilities as well as the age that work began. Part-time work was also identified as a positive contributor to the hazard of separation. Cohort effects - which played a significant role in first spells - and marital status did not significantly contribute to the hazard of separation in the second through fourth employment spell. Finally, lifetime experience and the break between the last employment spell and the current spell negatively impacted the hazard for all employment spells indicating that individuals are more likely to settle in longer-term positions as work experience compounds. And, as the length of the preceding separation becomes longer, workers are less inclined to depart from their current spells.

\subsection{Conclusion}

The overall evidence presented in this work lends support to the argument that employment tenures have declined in length over the latter half of the twentieth century. The largest changes to employment tenure were shown to have occurred prior to the 1980s, around the same time as the majority of studies examining job stability begin. However, the views are not incompatible as it was highlighted that declining employment tenure is not inconsistent with stable job tenure as the institutional structure of the economy changed so that continuous employment became less common than the stability of particular jobs. In so far as legislation permitting extended parental benefits, these declines in employment stability were likely 
welfare-enhancing. On the other hand, recessions with prolonged and jobless recoveries, were decidedly not welfare enhancing and also contributed to the deterioration of employment stability, with most of the effects falling on men.

\subsection{Future Work}

While the central question of the study can adequately be answered by the evidence presented there is much room left for further work. In particular, the GSS data used in the study can be used to further explore the usefulness of retrospective studies. While here the focus remained on constructed employment spells and their characteristics, it would be interesting to explore all retrospective variables across the survey and compare these across successive surveys (which are conducted every 5 years) in order to estimate how responses may change for various standardized groupings of respondents. This could shed light on the nature and patterns, if there are any, of memory effects that may be present beyond what was done in Chapter 2 for employment spells.

Moreover, there is a correspondent GSS survey that is administered in the United States, hence a number of interesting comparative studies can be done to determine whether similar patterns in employment stability are present. In particular, it would be interesting to verify whether the corresponding reductions in mean tenure occur in the U.S. when changes to parental leave provisions were instituted in Canada (to identify changes in institutional structures). While analysis of the United States is beyond the scope of this work, this would make an excellent 
complementary study. 


\section{Chapter A: Annex A: Technical Annex}

\section{A.1 Heterogeneity Testing}

The adaptive kernel density estimator utilizes a variable bandwidth. Varying the bandwidth along the support of the sample data reduces the variance of the estimates in areas with few observations, and reduces the bias of the estimates in areas with many observations.

The estimation procedure follows two steps: the first step computes an initial (fixed bandwidth) density estimate to get an idea of the density at each of the data points, and in the second step, this pilot estimate is used to adapt the size of the bandwidth over the data points when computing a new kernel density estimate.

Kernel density estimates are not unbiased, they are asymptotically biased, with a bias varying with the bandwidth and the shape of the true density function. For a given bandwidth, the bias does not tend to 0 as the sample size increases, therefore we should be careful about any inference that we make using this approach.

To estimate the densities using an adaptive kernel we use Abramson [46]. Let $Y_{1}, Y_{2}, \ldots Y_{n}$ be iid random variables with continuous distribution function $F(y)=$ $\operatorname{Pr}\left(Y_{i} \leq y\right)$ 
The estimator constructs the local bandwidth $h_{i}$ as a product of an estimated local bandwidth factor $\lambda_{i}$ and a fixed bandwidth $h$ at each sample point $\left(h_{i}=\lambda_{i} h\right)$. The local bandwidth factor stretches or shrinks the bandwidths to adapt to the density of the data, while the fixed bandwidth controls for the overall degree of smoothing.

$$
\widehat{f_{h_{i}}}(y)=\frac{1}{\sum_{i=1}^{n} w_{i}} \sum_{i=1}^{n} \frac{w_{i}}{h_{i}} K\left(\frac{y-Y_{i}}{h_{i}}\right)
$$

where $Y_{i}$ are data points associated to the weights $w_{i}$ and $K(u)$ is the kernel (window) function.

The kernel function is a weight function that puts different weights on different points. Typically, it puts more weight on points near $y$ and the weights decline as $Y_{i}$ gets farther away from $y$. "Near" and "far" from $y$ is determined by the bandwidth parameter $h_{i}$. The local bandwidth factors are proportional to the square root of the underlying density functions at the sample points:

$$
\lambda_{i}=\lambda\left(Y_{i}\right)=\left(\frac{G}{\widetilde{f}\left(Y_{i}\right)}\right)^{0.5}
$$

where $G$ is the geometric mean over all $i$ of the pilot density $\widetilde{f}(Y)$. The pilot density estimate is the kernel density estimate with fixed bandwidth $h$.

One can construct bands around the estimated density functions using the fact that the variance of the adaptive Kernel density estimator can be expressed as

$$
V\left(\widehat{f_{h_{i}}}(y)\right)=\left(\sum_{i=1}^{n} \frac{w_{i}^{2}}{n^{2}}\right) \frac{f(y)}{h_{i}} \int(K(s))^{2} d s .
$$




\section{A.2 Stochastic Dominance Testing}

The next subsections are extensions to stochastic dominance tests as developed by Linton, Maasoumi and Whang [20] to allow for censored distributions as in Huynh Ignaczak and Voia [21].

\section{A.2.1 Testing $H_{0}^{(1)}$ vs $H_{1}^{(1)}$.}

Considering the parameter

$$
\kappa=\sup _{y \leq y_{c}}\left|F^{\left(C_{t_{i}}\right)}(y)-F^{\left(C_{t_{j}}\right)}(y)\right|
$$

we rewrite the null and the alternative hypotheses under consideration as follows:

$$
H_{0}^{(1)}: \kappa=0 \quad \text { vs } \quad H_{1}^{(1)}: \quad \kappa>0 \text {. }
$$

An estimator of $\kappa$ can be defined by

$$
\widehat{\kappa}=\sup _{y \leq y_{c}}\left|\widehat{F^{\left(C_{t_{i}}\right)}}(y)-\widehat{F^{\left(C_{t_{j}}\right)}}(y)\right|,
$$

where $\widehat{F^{\left(C_{t_{i}}\right)}}(y)=\frac{1}{n} \sum_{i=1}^{n} 1\left\{Y^{\left(C_{t_{i}}\right)} \leq y\right\}$ and $\widehat{F^{\left(C_{t_{j}}\right)}}(y)=\frac{1}{m} \sum_{j=1}^{m} 1\left\{Y^{\left(C_{t_{j}}\right)} \leq y\right\}$ are the corresponding empirical distribution functions. The estimator $\widehat{\kappa}$ is consistent. Based on its asymptotic distribution we obtain that

$$
\widehat{K}=\sqrt{\frac{n m}{n+m}} \widehat{\kappa}
$$

is an appropriate statistic for testing the null hypothesis of equality of distributions (EoD) $H_{0}^{(1)}$ against the alternative $H_{1}^{(1)}$ of first order stochastic dominance (FOSD). Here $\mathrm{n}$ and $\mathrm{m}$ and sample sizes for the two distributions. The corresponding rejection 
(i.e., critical) region is $R: \widehat{K}>k_{\alpha}$ and the acceptance region is $A: \widehat{K} \leq k_{\alpha}$, where $k_{\alpha}$ is the critical value. Under the presence of censoring and nuisance parameters, the $k_{\alpha}$-critical value is not distribution free, and is estimated using a parametric bootstrap (See section A.1.3 below).

\section{A.2.2 Testing $H_{0}^{(2)}$ vs $H_{1}^{(2)}$.}

Now, considering the parameter

$$
\delta=\sup _{y \leq y_{c}}\left(F^{\left(C_{t_{i}}\right)}(y)-F^{\left(C_{t_{j}}\right)}(y)\right)
$$

we rewrite the hypotheses $H_{0}^{(2)}$ and $H_{1}^{(2)}$ as follows:

$$
H_{0}^{(2)}: \delta=0 \quad \text { vs } \quad H_{1}^{(2)}: \quad \delta>0 .
$$

The empirical estimator of $\delta$ is given by

$$
\widehat{\delta}=\sup _{y \leq y_{c}}\left(\widehat{F^{\left(C_{t_{i}}\right)}}(y)-\widehat{F^{\left(C_{t_{j}}\right)}}(y)\right) .
$$

The estimator $\widehat{\delta}$ is consistent. Therefore,

$$
\widehat{D}=\sqrt{\frac{n m}{n+m}} \widehat{\delta}
$$

is an appropriate statistic for testing the null hypothesis $H_{0}^{(1)}$ against the alternative $H_{1}^{(1)}$. The corresponding rejection region is $R: \widehat{D}>d_{\alpha}$ and the acceptance region is $A: \widehat{D} \leq d_{\alpha}$. Since the distributions are not, in general, identical, the critical value $d_{\alpha}$ is not distribution free and has to be estimated. Again, a parametric bootstrap is used. 


\section{A.2.3 Testing $H_{0}^{(3)}$ vs $H_{1}^{(3)}$.}

In this case, the parameter

$$
\tau=\sup _{y \leq y_{c}}\left(G_{2}^{\left(C_{t_{i}}\right)}(y)-G_{2}^{\left(C_{t_{j}}\right)}(y)\right)
$$

is strictly positive under the null. Therefore, to test the SOSD hypothesis we have under the null we have

$$
H_{0}^{(3)}: \tau=0 \quad \text { vs } \quad H_{1}^{(3)}: \quad \tau>0 .
$$

that one of the distributions SOSD the other under the alternative.

Define an estimator of $\tau$ by

$$
\widehat{\tau}=\sup _{y \leq y_{c}}\left(G_{2}^{\left(\widehat{\left.C_{t_{i}}\right)}\right.}(y)-G_{2}^{\left(\widehat{\left.C_{t_{j}}\right)}\right.}(y)\right)
$$

The estimator $\widehat{\tau}$ is consistent and we have that

$$
\widehat{T}=\sqrt{\frac{n m}{n+m}} \widehat{\tau} .
$$

The corresponding rejection region is $R: \widehat{T}>\theta_{\alpha}$ and the acceptance region is $A: \widehat{T} \leq \theta_{\alpha}$, where $\theta_{\alpha}$ is the $\alpha$-critical value of a distribution that depends on a transformation of $F^{\left(C_{t_{i}}\right)}$ and $F^{\left(C_{t_{j}}\right)}(x)$. Hence, $\theta_{\alpha}$ is not distribution free and has to be estimated as in the previous cases.

\section{A.3 Parametric Bootstrap}

By transforming a the parametric bootstrap to account for censored distributions we simulate the critical values in the following way: 
1. Sample $n_{\text {uncensored }}$ values from $Y_{1}^{\left(C_{t_{i}}\right)}, \ldots, Y_{n}^{\left(C_{t_{i}}\right)}$ from the estimated distributions obtained using the data:

$$
\int_{0}^{y_{c}} \widehat{f}_{\text {Duration }}(s) d s=\int_{0}^{y_{c}} \frac{\sum_{k=1}^{K} \widehat{p}_{k} \frac{1}{y \widehat{\sigma}_{k} \sqrt{2 \pi}} \exp \left(\frac{-\left(\log y-\widehat{\mu}_{k}\right)^{2}}{2 \widehat{\sigma}_{k}^{2}}\right)}{\int_{0}^{y_{c}} \sum_{k=1}^{K} \widehat{p}_{k} \frac{1}{y \widehat{\sigma}_{k} \sqrt{2 \pi}} \exp \left(\frac{-\left(\log y-\widehat{\mu}_{k}\right)^{2}}{2 \widehat{\sigma}_{k}^{2}}\right) d y} d s .
$$

Note that this DGP will generate bounded log-normal mixtures up to the censoring point $y_{c}$.

2. Then sample $n_{\text {censored }}$ observations using the proportion of censored data at the value of the censoring point. Define $n=n_{\text {uncensored }}+n_{\text {censored }}$.

3. Sample from cohort $j$ the estimated distributions $m=m_{\text {uncensored }}+m_{\text {censored }}$ values from $Y_{1}^{\left(C_{t_{j}}\right)}, \ldots, Y_{m}^{\left(C_{t_{j}}\right)}$.

4. Adjust the distributions to be stochastically equal under the null hypothesis. This is done in one side by pooling the estimated mixtures obtained for the two distributions of interest and estimating the resulting mixture distribution, and in the other side by estimating the mixture distribution obtained from pooling the data of the two distributions.

5. With the use of the resulting empirical distribution functions, $\widehat{F}^{\left(C_{t_{j}}\right)^{*}}(y)$ and $\widehat{F}^{\left(C_{t_{j}}\right)^{*}}(y)$, we define

$$
\widehat{K}^{*}=\sup _{y \leq y_{c}} \sqrt{\frac{n m}{n+m}}\left|\widehat{F}^{\left(C_{t_{i}}\right)^{*}}(y)-\widehat{F}^{\left(C_{t_{j}}\right)^{*}}(y)\right| .
$$

6. Repeat steps 1-5 $B$ times and define the critical value $k_{\alpha}^{*}$ as the smallest value of $y$ subject to at least $100(1-\alpha) \%$ of the obtained $B$ values of $\widehat{D}^{*}$ are at or below $y$. 
7. The rejection region is $\widehat{K}^{*}>k_{\alpha}^{*}$.

To estimate the critical values for the FOSD test the same steps are followed as in the EoD case, but by constructing the estimator

$$
\widehat{D}^{*}=\sup _{y \leq y_{c}} \sqrt{\frac{n m}{n+m}}\left(\widehat{F}^{\left(C_{t_{i}}\right)^{*}}(y)-\widehat{F}^{\left(C_{t_{j}}\right)^{*}}(y)\right) .
$$

The critical value $d_{\alpha}^{*}$ is defined as the smallest value of $y$ subject to at least 100(1$\alpha) \%$ of the obtained $B$ values of $\widehat{D}^{*}$ are at or below $y$. The rejection region is $\widehat{D}^{*}>d_{\alpha}^{*}$. The critical values of the SOSD test are calculated similarly to the EoD and FOSD cases. First, define $\widehat{G}_{2}^{\left(C_{t_{i}}\right)^{*}}(y)$ and $\widehat{G}_{2}^{\left(C_{t_{j}}\right)^{*}}(y)$ to construct

$$
\widehat{T}^{*}=\sup _{y \leq y_{c}} \sqrt{\frac{n m}{n+m}}\left({\widehat{G_{2}}}^{\left(C_{t_{i}}\right)^{*}}(y)-{\widehat{G_{2}}}^{\left(C_{t_{j}}\right)^{*}}(y)\right) .
$$

The critical value $\theta_{\alpha}^{*}$ is the smallest value of $y$ s.t. at least $100(1-\alpha) \%$ of the obtained $B$ values of $\widehat{T}^{*}$ are at or below $y$. In this case, the rejection region is $\widehat{T}^{*}>\theta_{\alpha}^{*}$. 


\section{Chapter B: Annex B: Variable Description}

\begin{tabular}{|c|c|}
\hline Variable & Description \\
\hline age & The age of the respondent at the time of the survey. \\
\hline year born & The year in which the respondent was born. \\
\hline male & Indicator for whether the respondent is male. \\
\hline age studies end & Age at which the respondent left their final year of schooling. \\
\hline immigrant & Indicator if the respondent immigrated to Canada. \\
\hline age work began & The age at which the relevant spell of employment began. \\
\hline part-time emp. & Indicator signifying fewer than 30 hours of work per week. \\
\hline edu university & Indicator if the highest level of schooling completed was university. \\
\hline edu comm college & Indicator if the highest level of schooling completed was comm. college. \\
\hline edu high school & Indicator if the highest level of schooling completed was high school. \\
\hline edu less than hs & Indicator if high school was not completed. \\
\hline married & Indicator for marriage (or common law relationship). \\
\hline parental & Indicator for separation caused by childcare responsibilities. \\
\hline work related & Indicator for separation caused by firm shutdown, plant closure or lack of work. \\
\hline emp duration & The duration, in years, of an employment spell. \\
\hline ur gap & The gap between a trend and the actual unemployment rates. \\
\hline lifetime Exp. & The cumulative sum of all spell lengths up to the current spell. \\
\hline break 1 dur & The duration of time away from work following the first spell. \\
\hline break 2 dur & The duration of time away from work following the second spell. \\
\hline break 3 dur & The duration of time away from work following the third spell. \\
\hline break 4 dur & The duration of time away from work following the fourth spell. \\
\hline cohort 1930-39 & Those born between 1930-39. \\
\hline cohort 1940-49 & Those born between 1940-49. \\
\hline cohort 1950-59 & Those born between 1950-59. \\
\hline cohort 1960-69 & Those born between 1960-69. \\
\hline cohort $1970-79$ & Those born between 1970-79. \\
\hline cohort $1980-89$ & Those born between 1980-89. \\
\hline gss 2001 & Indicator that data is from GSS 2001 (not GSS 2006). \\
\hline
\end{tabular}




\section{Bibliography}

[1] R.E. Hall, The Importance of Lifetime Jobs in the U.S. Economy, American Economic Review Vol. 72, pp. 716-724, 1982.

[2] F.X. Diebold, D. Neumark, D. Polsky, Job Stability in the United States, Journal of Labor Economics Vol. 15(2), pp. 206-233, 1994.

[3] H.S. Farber, Are Lifetime Jobs Disappearing? Job Duration in the United States: 1973-1993, NBER Working Paper No. W5014, 1995.

[4] A. Heisz, The Evolution of Job Stability in Canada: Trends and Comparisons with U.S. Results, Canadian Journal of Economics Vol. 38(1), pp. 105-127, 2005.

[5] D.A. Jaeger, A.H. Stevens, Is Job Stability in the United States Falling? Reconciling Trends in the Current Population Survey and Panel Study of Income Dynamics, Journal of Labor Economics Vol. 17, pp. S1-S28, 1999.

[6] K.A. Swinnerton, H. Wial, Is Job Stability declining in the U.S. economy?, Industrial and Labor Relations Review Vol. 48, pp. 293-304, 1995.

[7] S.J. Rose, Declining Job Security and the Professionalization of Opportunity, National Commission for Employment Policy Research Report No. 95-04, 1995.

[8] B.C. Fallick, A Review of the Recent Empirical Literature on Displaced Workers, Industrial and Labor Relations Review, Vol. 50 pp. 5-16, 1998.

[9] D. Hamermesh, What do we Know About Worker Displacement in the U.S.?, Industrial Relations, Vol. 28, pp. 51-59, 1989.

[10] H.S. Farber, Is the Company Man an Anachronism? Trends in Long Term Employment in the U.S., 1973-2006, Princeton University Industrial Relations Section Working Paper \#518, 2007. 
[11] D.A. Green, W.C. Riddell, Job Durations in Canada: is Long Term Employment Declining?, in Transition and Structural Change in the North American Labour Market, ed. Michael G. Abbott, Charles M. Beach, and Richard P. Chaykowski, Kingston, ON: IRC press, 1997.

[12] A. Nakamura, A. Heisz, G. Picot, Job Tenure, Worker Mobility and the Youth Labour Market During the 1990s, Analytical Studies Branch Research Paper Series No. 155, Statistics Canada, 2001.

[13] D. Neumark, D. Polsky, D. Hansen, Has job stability declined yet: New evidence for the 1990s?, in On the Job, Is Long Term Employment a Thing of the Past?, ed. D. Neumark, New York: Russell Sage Foundation, 2000.

[14] P. Brochu, The Source of the New Canadian Job Stability Patterns, Canadian Journal of Economics Vol. 46(2), pp. 412-440., 2013.

[15] H.S. Farber, Mobility and Stability: The Dynamics of Job Change in Labour Markets, in Handbook of Labour Economics, Vol. 3B, eds. Orley C. Ashenfelter and David Card, Elsevier Science B.V. 1999.

[16] P. Brochu, Estimating labour market transitions and continuations using repeated cross sectional data, Economics Letters Vol. 111(1), pp. 84-87, 2011.

[17] I. Blumen, M. Kogen and P. McCarthy, The Industrial Mobility of Workers as a Probability Process, Ithaca, NY: Cornell University Press, 1955.

[18] B.W. Silverman, Density Estimation for Statistics and Data Analysis, Monographs on Statistics and Applied Probability, London: Chapman and Hall, 1986.

[19] G. McLachlan and D. Peel, Finite Mixture Models, New York: Wiley, 2000.

[20] O. Linton, E. Maasoumi and Y-J Whang, Consistent Testing for Stochastic Dominance under General Sampling Schemes, Review of Economic Studies, Vol. 72(3), pp. 735-765, 2005.

[21] K.P. Huynh, L. Ignaczak and M.C. Voia, Stochastic Dominance Tests for Censored Distributions with Nuisance Parameters, Carleton University Department of Economics Working Paper, CEP 10-02, 2009.

[22] A.W. Bowman and A. Azzalini, Applied Smoothing Techniques for Data Analysis: The Kernel Approach with S-Plus Illustrations, Oxford, UK: Oxford University Press, 1997. 
[23] A. Pagan and A. Ullah, Nonparametric Econometrics, Themes in Modern Econometrics, New York: Cambridge University Press, 1999.

[24] I. H. Salgado-Ugarte, M. Shimuzu and T. Taniuchi, snp6: Exploring the Shape of Univariate Data Using Kernel Density Estimators, Stata Technical Bulletin 16, pp. 8-19, 1993.

[25] I. H. Salgado-Ugarte, M. Shimuzu and T. Taniuchi, snp6.2: Practical Rules for Bandwidth Selection in Univariate Density Estimation, Stata Technical Bulletin 27, pp. 5-19, 1995.

[26] I. H. Salgado-Ugarte and M. A. Perez-Hernandez, Exploring the Use of Variable Bandwidth Kernel Density Estimators, Stata Journal Vol. 3(2), pp. 133-147, 2003.

[27] M. Ureta, The Importance of Lifetime Jobs in the U.S. Economy, Revisited, American Economic Review Vol. 82, pp. 322-334, 1992.

[28] N. Torelli, U. Trivellato, Modeling Inaccuracies in Job Search Duration Data, Journal of Econometrics Vol. 59(1-2), pp. 187-211, 1993.

[29] Green, David A. and James Townsend, Understanding the Wage Patterns of Canadian Less Skilled Workers: the Role of Implicit Contracts, Canadian Journal of Economics, Vol. 43(1), pp. 373-403, 2010.

[30] L. Ignaczak, M. Voia, A Retrospective Analysis of Employment Duration: Evidence from the Second Half of the Twentieth Century, Labour Vol. 25(1), pp. 97-125, 2011.

[31] L.N. Christofides, C.J. McKenna, Employment Flows and Job Tenure in Canada, Canadian Public Policy Vol. 19(2), pp. 145-161, 1993.

[32] J. Fine, R. Gray, A Proportional Hazards Model for the Subdistribution of a Competing Risk, Journal of the American Statistical Association Vol. 94(446), pp. 496-509, 1999.

[33] C. Zorn, Modeling Duration Dependence, Political Analysis Vol. 8(4), pp. 367$380,2000$.

[34] L.D. Fisher, D.Y. Lin, Time-Dependent Covariates in The Cox ProportionalHazards Regression Model, Public Health Vol. 20: pp. 145-157, 1999. 
[35] Y. Ostrovsky, Long-Run Earnings Inequality and Earnings Instability among Canadian Men Revisited, The B.E. Journal of Economic Analysis \& Policy Vol. 10(1) (Contributions), Article 20, 2010.

[36] R. Jackman and R. Layard, Does long-term unemployment reduce a person's chance of a job? A time-series test, Economica, Vol. 58, pp. 93-106, 1991.

[37] C.A. Pissarides, Loss of skill during unemployment and the persistence of employment shocks, Quarterly Journal of Economics, Vol. 107, pp. 1371-1391, 1992.

[38] B. Lockwood, Information externalities in the labour market and the duration of unemployment, Review of Economic Studies, Vol. 58, pp. 733-753, 1991.

[39] R. Gibbons and L.F. Katz, Layoffs and lemons, Journal of Labor Economics, Vol. 9, pp. 351-380, 1991.

[40] R.H. Topel and M.P. Ward, Job mobility and the careers of young men, Quarterly Journal of Economics, Vol. 107, pp. 439-479, 1992.

[41] R.M. Gritz, The impact of training on the frequency and duration of employment, Journal of Econometrics, Vol. 57(1-3), pp. 21-51, 1993.

[42] B. Jovanovic, Matching, Turnover, and Unemployment, Journal of Political Economy, Vol. XCII, pp. 108-122, 1984.

[43] J.J. Heckman, R.J. Lalonde and J.A. Smith, The economics and econometrics of active labor market policy, in O. Ashenfelter, D. Card (Eds.), Handbook of Labor Economics, vol. 3, Elsevier: Amsterdam, 1999.

[44] D. Doiron and T. Gorgens, State dependence in youth labor market experiences, and the evaluation of policy interventions, Journal of Econometrics, Vol. 145, pp. 81-97, 2008.

[45] B. Cockx and M. Picchio, Are short-lived jobs stepping stones to long-lasting jobs?, Oxford Bulletin of Economics and Statistics, Vol. 74(5), pp. 646-675, 2012.

[46] I. Abramson, On Bandwidth Variation in Kernel EstimatesA Square Root Law, Annals of Statistics, Vol. 10(4), pp. 1217-1223, 2012. 